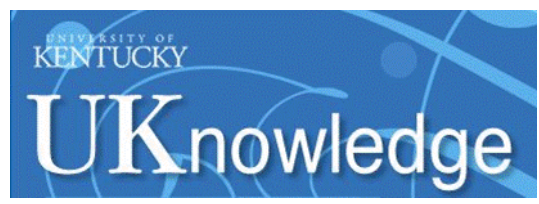

University of Kentucky

UKnowledge

Theses and Dissertations--Electrical and Computer Engineering

2016

\title{
A MODULAR ELECTRICAL POWER SYSTEM ARCHITECTURE FOR SMALL SPACECRAFT
}

Timothy M. Lim

University of Kentucky, timothymlim@gmail.com

Digital Object Identifier: http://dx.doi.org/10.13023/ETD.2016.331

Right click to open a feedback form in a new tab to let us know how this document benefits you.

\section{Recommended Citation}

Lim, Timothy M., "A MODULAR ELECTRICAL POWER SYSTEM ARCHITECTURE FOR SMALL SPACECRAFT" (2016). Theses and Dissertations--Electrical and Computer Engineering. 90.

https://uknowledge.uky.edu/ece_etds/90

This Master's Thesis is brought to you for free and open access by the Electrical and Computer Engineering at UKnowledge. It has been accepted for inclusion in Theses and Dissertations--Electrical and Computer Engineering by an authorized administrator of UKnowledge. For more information, please contact UKnowledge@lsv.uky.edu. 


\section{STUDENT AGREEMENT:}

I represent that my thesis or dissertation and abstract are my original work. Proper attribution has been given to all outside sources. I understand that I am solely responsible for obtaining any needed copyright permissions. I have obtained needed written permission statement(s) from the owner(s) of each third-party copyrighted matter to be included in my work, allowing electronic distribution (if such use is not permitted by the fair use doctrine) which will be submitted to UKnowledge as Additional File.

I hereby grant to The University of Kentucky and its agents the irrevocable, non-exclusive, and royalty-free license to archive and make accessible my work in whole or in part in all forms of media, now or hereafter known. I agree that the document mentioned above may be made available immediately for worldwide access unless an embargo applies.

I retain all other ownership rights to the copyright of my work. I also retain the right to use in future works (such as articles or books) all or part of my work. I understand that I am free to register the copyright to my work.

\section{REVIEW, APPROVAL AND ACCEPTANCE}

The document mentioned above has been reviewed and accepted by the student's advisor, on behalf of the advisory committee, and by the Director of Graduate Studies (DGS), on behalf of the program; we verify that this is the final, approved version of the student's thesis including all changes required by the advisory committee. The undersigned agree to abide by the statements above.

Timothy M. Lim, Student

$$
\text { Dr. James Lumpp, Major Professor }
$$

Dr. Cai-Cheng Lu, Director of Graduate Studies 


\section{A MODULAR ELECTRICAL POWER SYSTEM ARCHITECTURE FOR SMALL SPACECRAFT}

THESIS

A thesis submitted in partial fulfillment of the requirements for the degree of Master of Science in Electrical Engineering in the College of Engineering at the University of Kentucky

By

Timothy Meng Lim

Lexington, Kentucky

Director: Dr. James Lumpp Jr, Professor of Electrical and Computer Engineering Lexington, Kentucky 2016

Copyright (C) Timothy Meng Lim 2016 
ABSTRACT OF THESIS

\section{A MODULAR ELECTRICAL POWER SYSTEM ARCHITECTURE FOR SMALL SPACECRAFT}

Small satellites and CubeSats have established themselves within the aerospace community because of their low cost and high return on investment. Many CubeSats are developed in a short time frame and often leverage commercial off the shelf components for quick turnaround missions. With regard to the Electrical Power System, commercially available products typically use a centralized architecture. However, a centralized architecture is not reusable, since missions that require additional solar arrays or batteries would necessitate a redesign of the power system. With the range of CubeSat sizes and mission goals, it is obvious that a one-size-fits-all solution is not appropriate. This thesis details a reusable and scalable power system architecture applicable to a variety of missions. Reusability is achieved by using common building blocks or "modules," where the same modules can be used between missions. Scalability is achieved by not limiting the number of modules that can be connected together-more modules can be added as needed. In this system, solar arrays and battery units connect directly to a common bus, supplying an unregulated voltage to each subsystem. These subsystems then regulate the bus voltage to their individual needs. The power system also features direct energy transfer and solar-only operation.

KEYWORDS: Small Satellites, CubeSats, Electrical Power System, Direct Energy Transfer, Distributed Power System 


\section{A MODULAR ELECTRICAL POWER SYSTEM ARCHITECTURE FOR SMALL SPACECRAFT}

By

Timothy Meng Lim

Dr. James E. Lumpp Director of Thesis

Dr. Cai-Cheng Lu Director of Graduate Studies

July 14, 2016 


\section{ACKNOWLEDGEMENTS}

I would like to acknowledge the support of Kentucky EPSCoR and the Kentucky Space Grant Consortium for allowing me to perform research in an area of interest and allowing me to achieve my educational goals.

I would like to thank Dr. James Lumpp for his support and advice during my graduate studies. Without his invitation to join his research laboratory I would not have been able to enjoy many opportunities and experiences throughout my college career. I would also

like to thank Dr. Aaron Cramer and Dr. Samir Rawashdeh for their patience, insight, and support through all of the grant proposals and hardware development.

I would like to thank my colleagues from the Space Systems Laboratory who have directly influenced my growth as an engineer. From soldering to populating circuit boards, they have taught me everything I know as an engineer. Our group outings were great experiences as well. I will never forget our times hanging out at conferences or being able to witness the launch of our satellite.

Finally, I would like to thank my family for allowing me the opportunity to achieve my goals. I want to thank my parents for supporting me during my pursuit of a college degree. I want to thank my sister for always being there when I needed her. I really appreciate the support you all have given me. 


\section{TABLE OF CONTENTS}

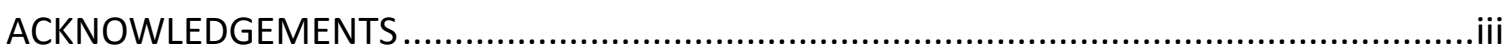

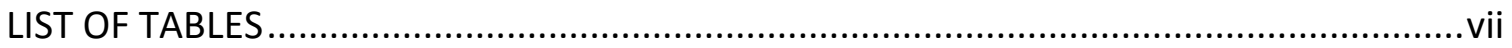

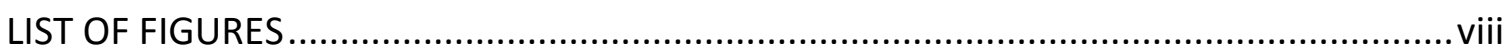

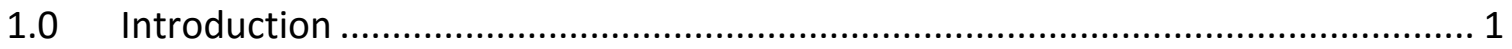

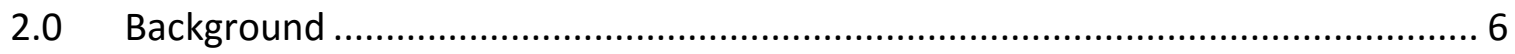

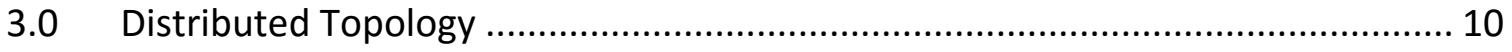

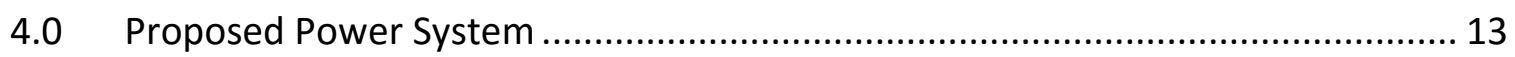

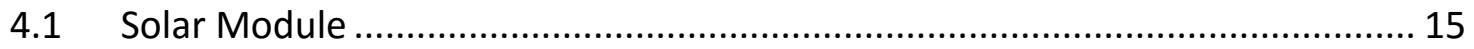

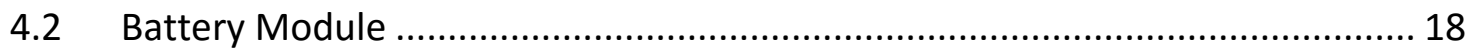

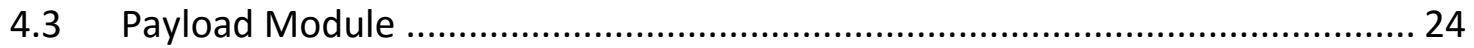

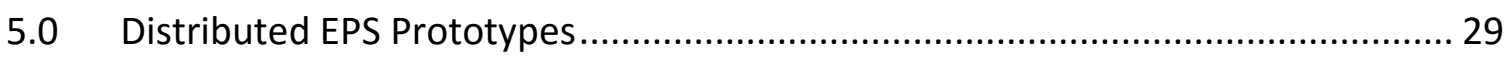

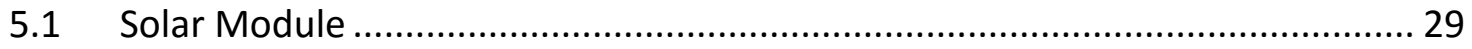

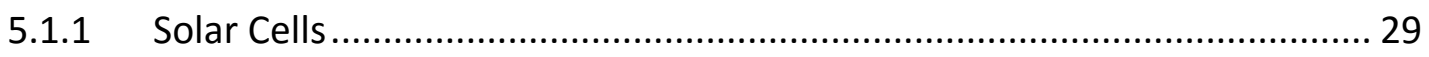

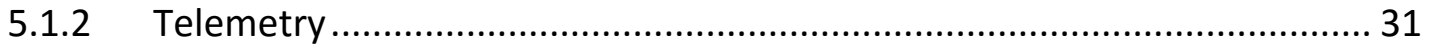

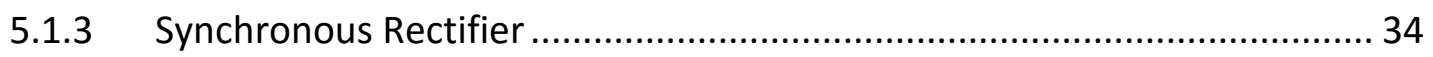

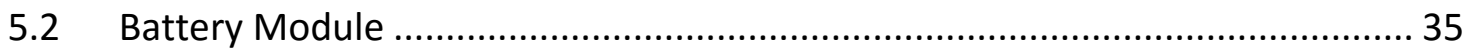

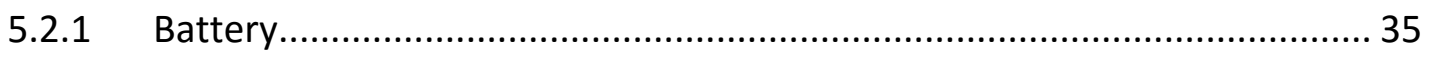

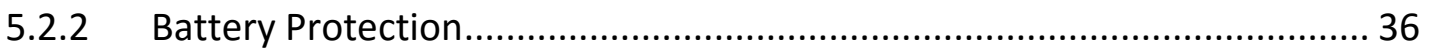




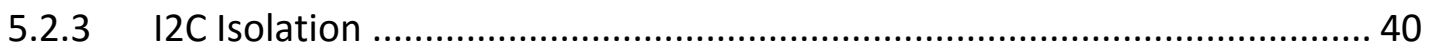

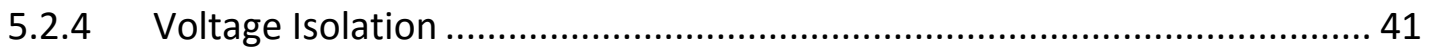

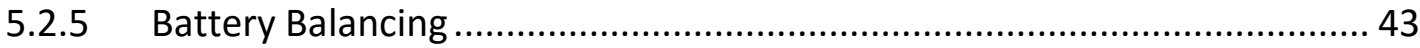

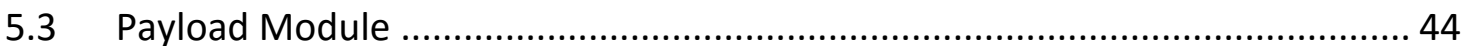

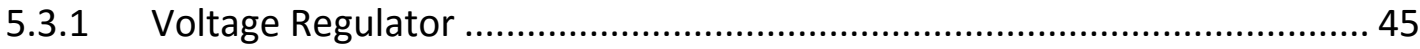

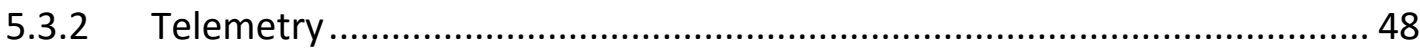

5.3.3 Load Protection and Control............................................................... 50

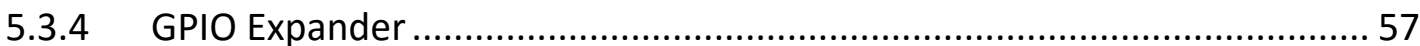

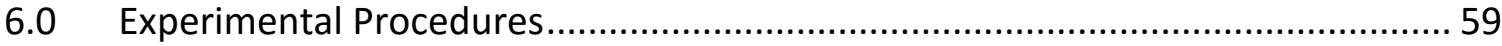

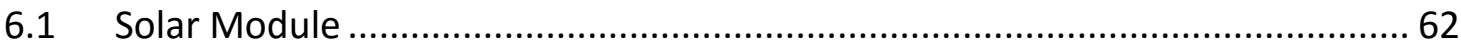

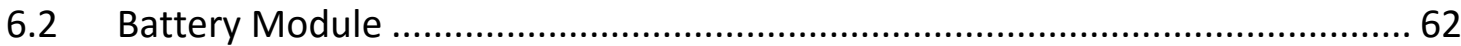

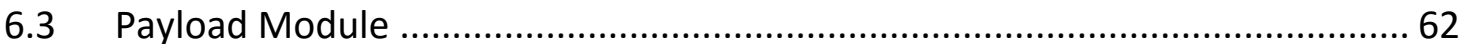

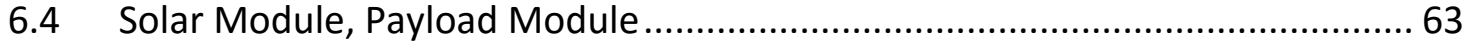

6.5 Battery Module + Battery Module, Payload Module...................................... 63

6.6 Solar Module, Battery Module + Battery Module ............................................ 63

6.7 Solar Module, Battery Module + Battery Module, Payload Module ................. 63

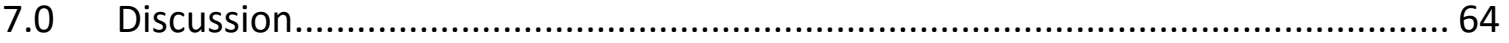

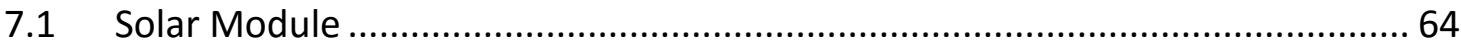

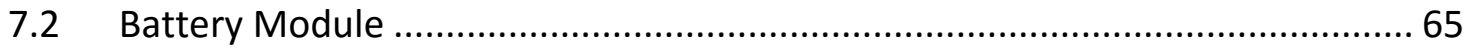




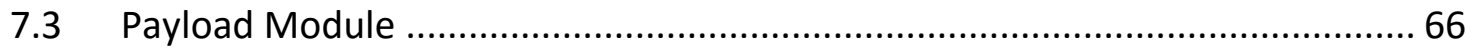

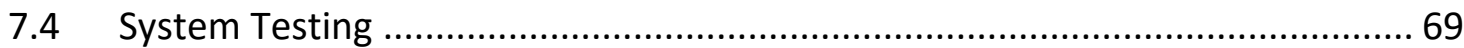

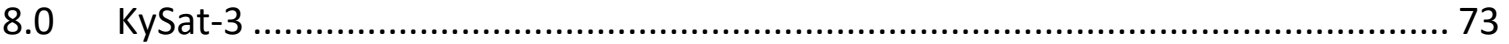

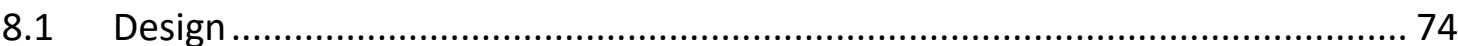

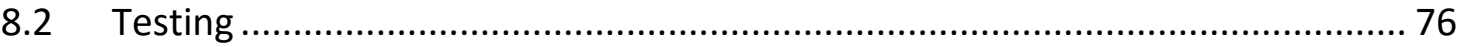

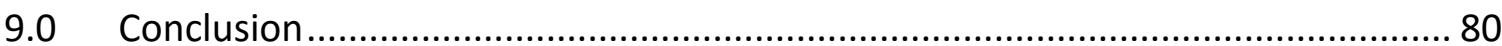

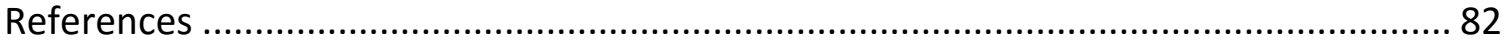

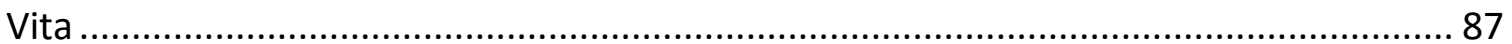




\section{LIST OF TABLES}

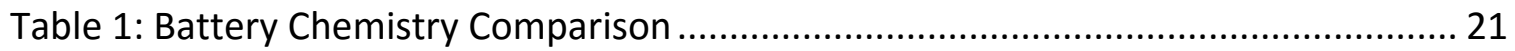

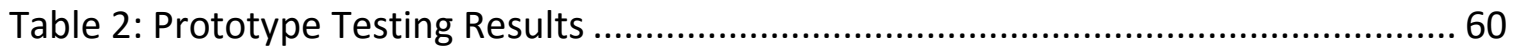




\section{LIST OF FIGURES}

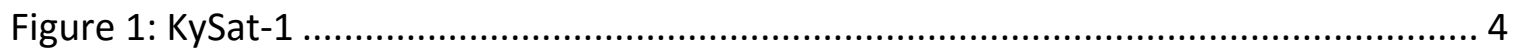

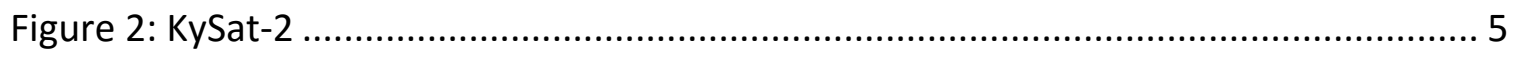

Figure 3: Diagram of a Centralized Architecture ..................................................... 8

Figure 4: Diagram of a Distributed Architecture .................................................... 13

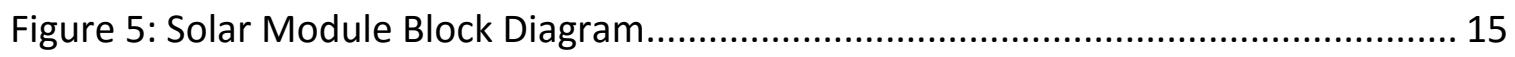

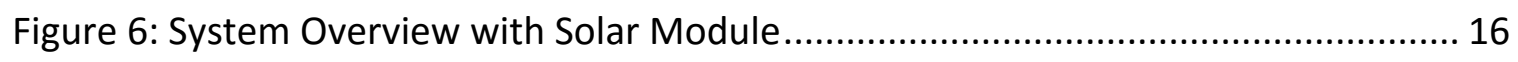

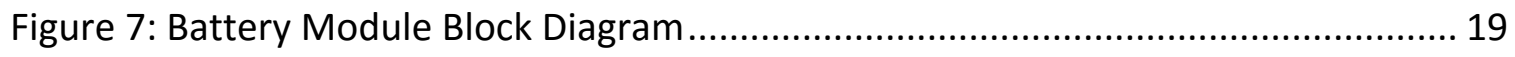

Figure 8: System Overview with Solar and Battery Modules ..................................... 20

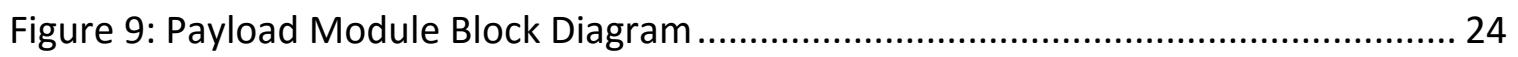

Figure 10: System Overview with Solar, Battery, and Payload Modules ........................ 25

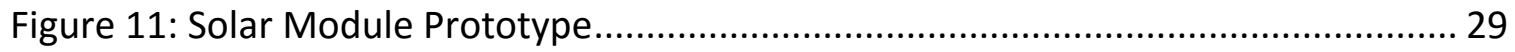

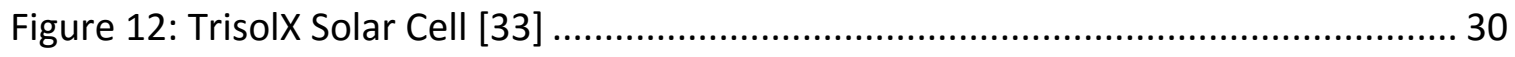

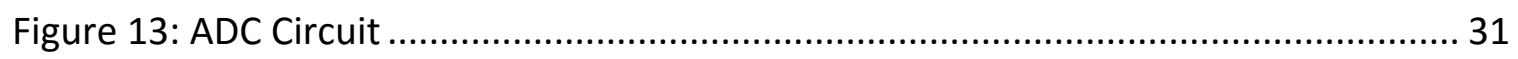

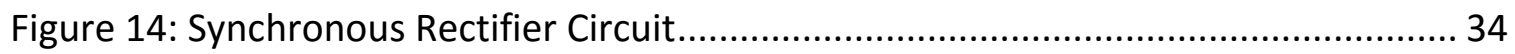

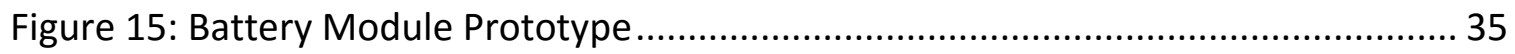

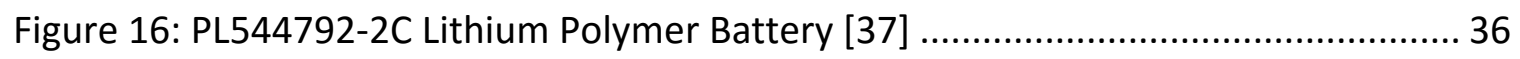

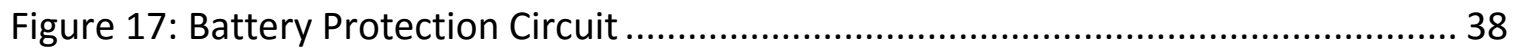

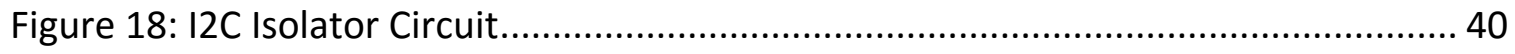

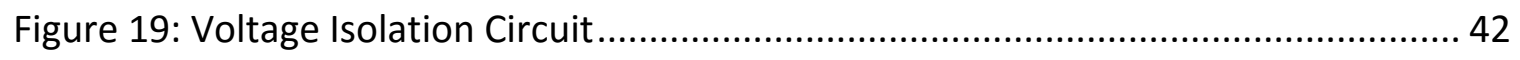

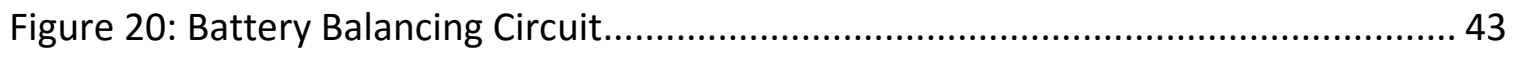

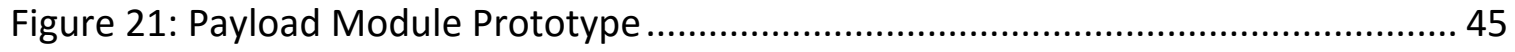




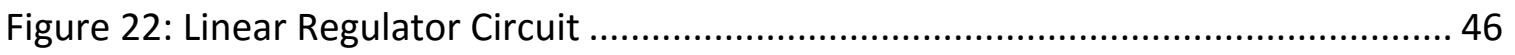

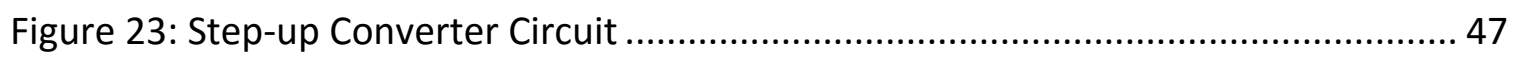

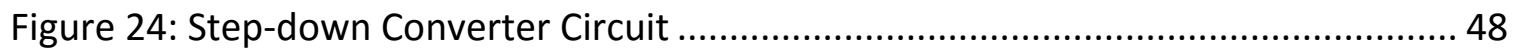

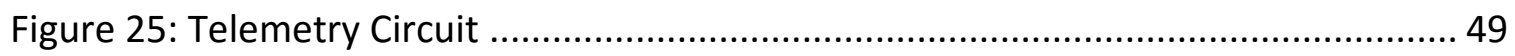

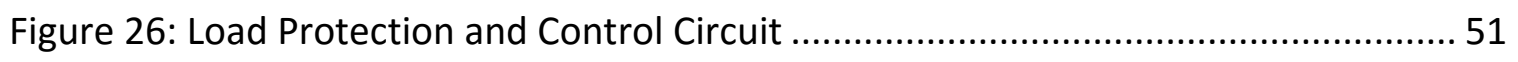

Figure 27: Alternative Payload Protection and Control Circuit ................................... 54

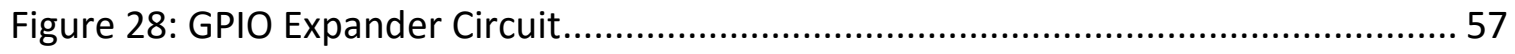

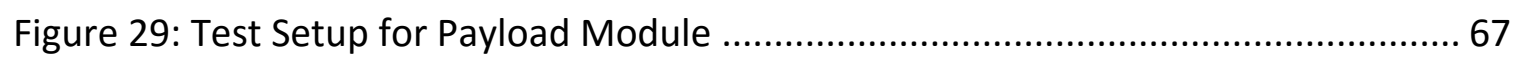

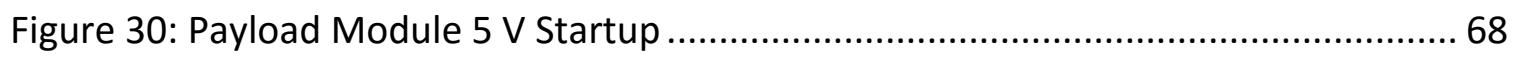

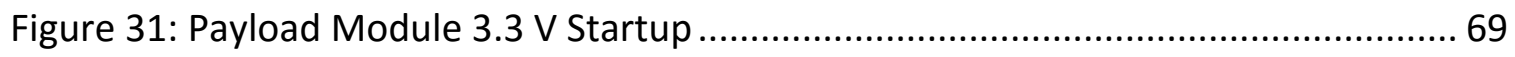

Figure 32: Common Bus Voltage and Payload Module Outputs for System Testing ....... 70

Figure 33: KySat-3 Electrical Power System...................................................... 75

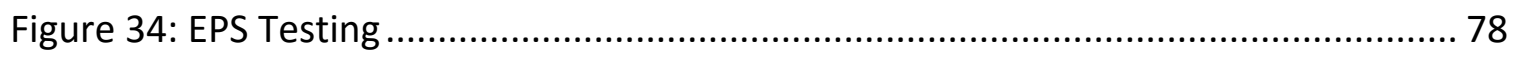




\subsection{Introduction}

Before the CubeSat standard was developed, research groups had some difficulty in performing microgravity experiments. It was a rigorous and time consuming procedure for any group to put hardware into a space environment due to the process of designing systems, assembling the components, then getting equipment verified for launch. In the year 1999, the CubeSat standard was developed to enable space research by groups without strong aerospace experience. Dr. Jordi Puig-Suari of California Polytechic State University and Dr. Robert Twiggs of Stanford University introduced the standard to allow more groups around the world to perform experiments in a space environment [1], to develop skills necessary for satellite development [2], and to keep development and launch costs low [3] [4]. The mechanical standards meant that a universal launcher could be used to jettison satellites into space even though all of the satellites in the launcher may be designed by different groups around the world.

Because the cost to develop [5] and launch a CubeSat is much lower than a large satellite [6], experiments performed by a CubeSat are typically higher-risk [4]. These experiments tend to be unfeasible or unjustifiable on a larger satellite, but are an acceptable risk for the low cost CubeSat, such as a solar sail or experimental thrusters. CubeSats have been developed by academia and commercial groups. Even Kickstarter campaigns have been created for a CubeSat project [7]. 
The CubeSat was designed to minimize risk to the rest of the launch vehicle and other payloads. The standardized form factor eliminates the amount of work previously needed to mate a satellite with its launcher [3]. This enables rapid replacements of satellites in the launcher and allows for a group to take advantage of a launch opportunity quickly without worrying about physical compatibility issues [8]. CubeSats are typically the secondary payload on a launch vehicle [9], riding along for missions such as International Space Station resupply runs and launching of telecommunications satellites [4].

The basic form factor of the CubeSat is a single cube with dimensions of $10 \mathrm{~cm} \mathrm{x} 10 \mathrm{~cm} \mathrm{x}$ $10 \mathrm{~cm}$ with a maximum mass of 1.33 kilograms [10]. This is considered a $1 \mathrm{U}$ (one unit). Other CubeSat sizes are derived from the base unit, such as $0.5 \mathrm{U}, 1.5 \mathrm{U}, 2 \mathrm{U}, 3 \mathrm{U}, 6 \mathrm{U}$, and 12U. The form factor is relatively small so that multiple CubeSats can be launched at once using a single launcher [3].

The typical launcher for a CubeSat is called a Poly-PicoSatellite Orbital Deployer (P-POD). The P-POD consists of a spring loaded plate and a controllable door [8]. As the launch vehicle approaches the correct altitude, a command is given to the P-POD to open the door and jettison the payload. CubeSats can also be launched by hand in the case of Chasqui-I [11].

Radiation mitigation is usually minimal in CubeSats because in Low Earth Orbit (LEO), the satellite is only in space for 24 months. In this timeframe, consumer electronics are stable 
enough for normal operation. For a CubeSat to tolerate radiation for more time radiation hardened components are needed, which are typically too costly for a CubeSat mission [4].

The rate at which CubeSats have been launched has been increasing and expected to keep increasing in the future. From the years 2003 to 2012, 100 total CubeSats were launched into space. Just in the year 2013, 100 CubeSats were launched, roughly ten times the yearly average of the ten previous years. Extrapolations put the estimated number of CubeSat launches to increase to 200 to 700 per year for the next 30 years [12]. The short development timeframe combined with the architecture's low cost to design and launch means that the CubeSat platform will probably remain popular for the near future.

At the University of Kentucky Space Systems Laboratory, two CubeSats have been developed and launched, KySat-1 and KySat-2. KySat-1 was launched in 2011, but failed to enter orbit when the payload fairing of the Taurus rocket failed to separate. A picture of KySat-1 is shown in Figure 1. KySat-1 was a $1 \mathrm{U}$ CubeSat that was designed for educational outreach by allowing mobile ground stations to contact and converse with the satellite [13]. These mobile ground stations would be taken to various schools around the state of Kentucky so that students could interact with the satellite. 


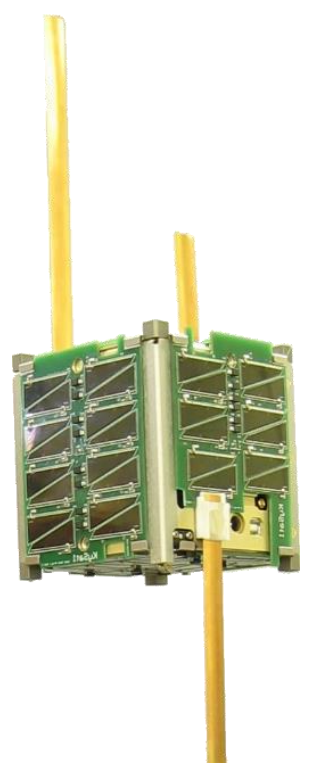

Figure 1: KySat-1

KySat-2 was launched in 2013, but unlike KySat-1, the launch was successful. A picture of KySat-2 is shown in Figure 2. KySat-2 was a $1 \mathrm{U}$ CubeSat that was fairly similar to KySat-1, with the main physical difference being the deployable solar panels on four of its faces. KySat-2 continued the goal of educational outreach to students across Kentucky, with another goal of testing a novel system called a stellar gyroscope that utilized an onboard camera and a sequence of star pictures to determine the satellite's attitude [14]. KySat2 was heard across the world from countries such as Russia, Japan, Argentina, and Australia but unfortunately the satellite would not accept any commands sent to it from the ground. The satellite remained in space for two years before finally deorbiting and reentering the atmosphere. 


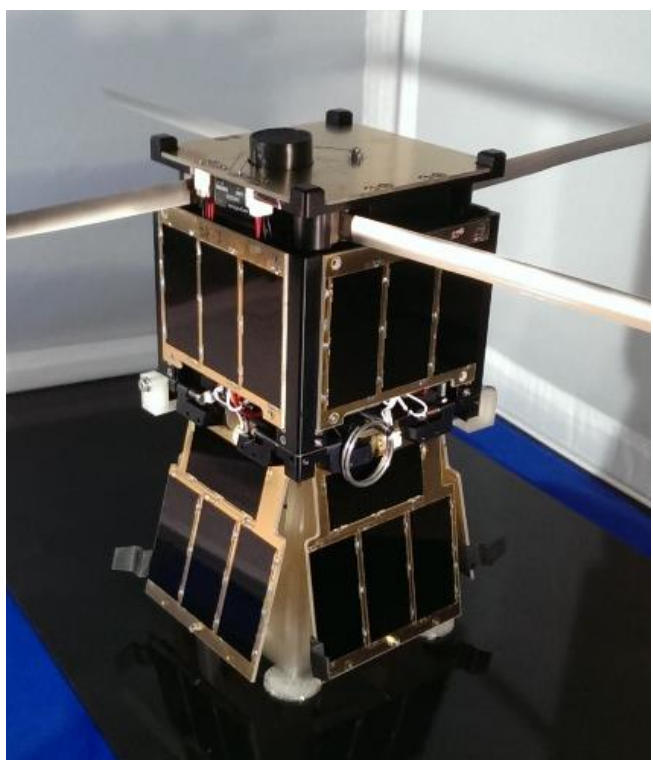

Figure 2: KySat-2 


\subsection{Background}

The hardware in a CubeSat is very similar to the systems found in larger satellites. Typical CubeSat subsystems include: the Command and Data Handling (C\&DH) system, the Electrical Power System (EPS), communication hardware, the Attitude Determination and Control System (ADCS), the propulsion system, and a camera. These subsystems can either be designed in-house by the CubeSat developers or purchased from a third party vendor specializing in CubeSat system design [4].

This work focuses on the EPS. The EPS is responsible for generating, storing, and supplying energy to the rest of the satellite [15]. Due to space constraints, certain components such as batteries and solar arrays are scaled down to fit, but they still serve the same purpose as they would in a larger satellite.

There are various companies that offer EPS solutions for developers that are not willing to develop an EPS on their own [4]. Examples of these companies include Clyde Space, Pumpkin, and CubeSatKit. Their EPS units are fairly standardized, with components such as voltage regulators already chosen for the customer. When using these commercialoff-the-shelf (COTS) systems, the developers must take into account the compatibility between the EPS and the other subsystems the developer plans to use. The COTS EPS may not be able to handle a payload that requires a unique voltage rail or a large power draw without some modification. 
KySat-1 used a COTS EPS from Clyde Space [16]. The EPS provided connections for six solar panels, a battery, a $3.3 \mathrm{~V}$ voltage rail, and a $5 \mathrm{~V}$ voltage rail. The rails could be monitored and turned on or off as needed. Telemetry from the unit includes electrical data such as rail voltage, rail current, temperature, and battery charge status. The solar arrays were made from SpectroLab triple junction GaAs TASC cells.

KySat-2 contained a custom EPS unit developed by Morehead State University. The EPS used three 18650 Lithium-ion batteries for energy storage and used Direct Energy Transfer as the solar array interface [17]. Two voltage rails were provided, one at $3.3 \mathrm{~V}$ and the other at $5 \mathrm{~V}$. Telemetry data from KySat-2's EPS was similar to KySat-1's EPS. The solar arrays were also designed and assembled by Morehead State University.

Whether a CubeSat EPS is a custom design or a commercial-off-the-shelf design, the typical EPS architecture is centralized [18], as shown in Figure 3, where solar panels, batteries, and satellite payloads all tie into a single circuit board. Specific voltage rails are supplied to each subsystem that requires a given voltage. 


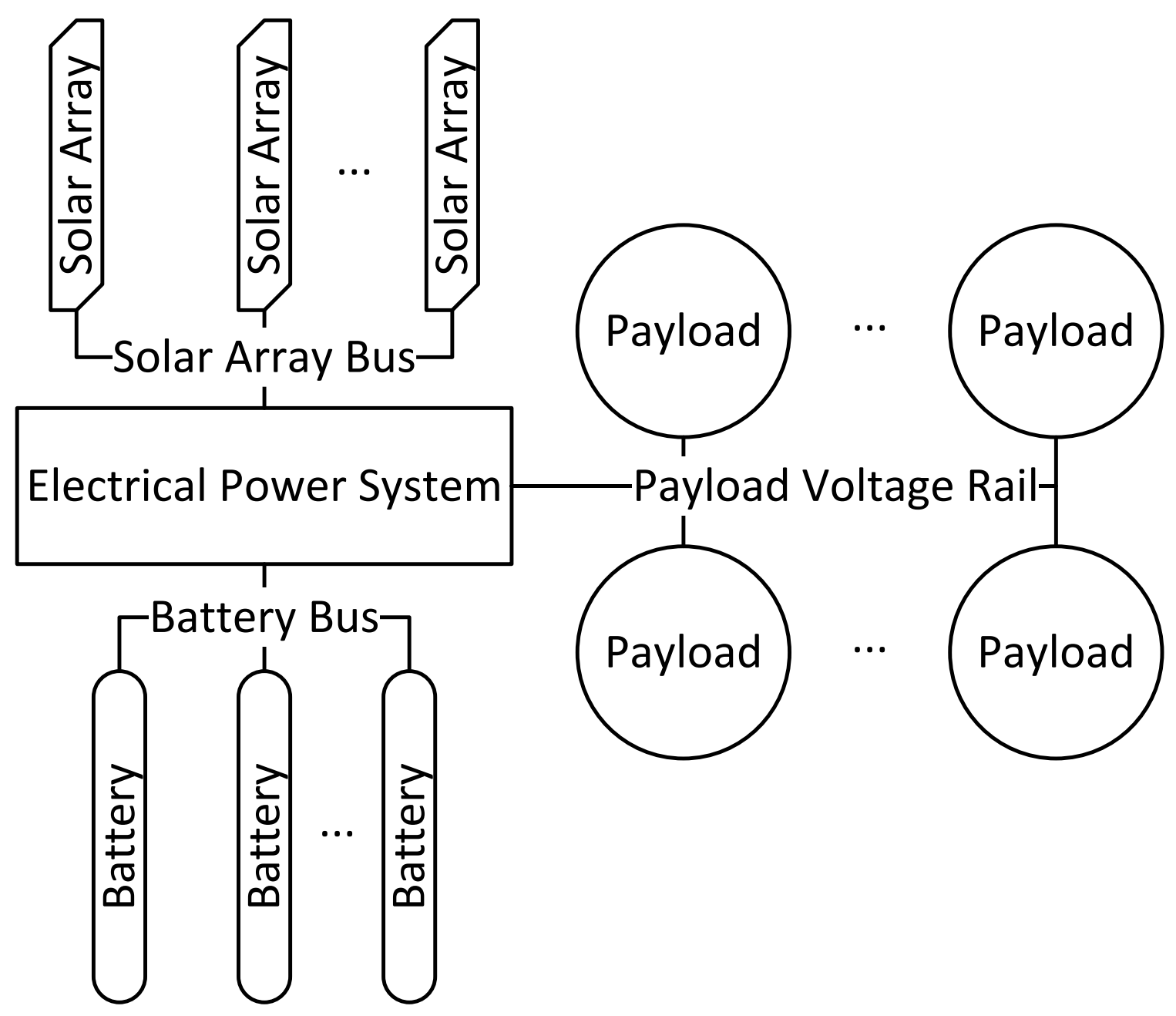

Figure 3: Diagram of a Centralized Architecture

This type of EPS architecture is prevalent in small satellites due to the simplicity of its design [18], its physical space efficiency [18], and the availability of COTS designs [19] [20] [21]. However, there are disadvantages to the centralized architecture. One drawback is that a centralized EPS's regulators are designed for the worst case current draws of all the payloads attached to the regulator, which means the regulator is not operating at the optimal point on its efficiency curve during normal operation [18]. Another drawback is in the centralized architecture's lack of reusability; major design changes may need to be 
made before a previous EPS design can be used again for another mission [19]. As the required subsystems for a mission change, the original EPS is either less efficient for the new requirements or is rendered completely unusable for the new mission [18]. For groups developing a simple small satellite, a centralized power system architecture is acceptable. However, in more complex small satellite designs the centralized architecture is not always practical due to the architecture's lack of customization.

This work first describes the distributed power system topology, which is efficient, reusable, fault tolerant, and can be customized as needed. Then, a reference power system implementation is presented that is based on the distributed power system principles. After that, testing on the reference implementation is described with the experimental results explained to show the effectiveness of the distributed architecture. Finally, the distributed EPS used in the CubeSat KySat-3 is detailed as a real-world use of the distributed topology principles. 


\subsection{Distributed Topology}

The distributed power system topology is commonly used on more complicated electronic systems, such as medium/large satellites and aircraft [22] [23]. The typical characteristic of a distributed power system is a high voltage bus supplied throughout the system [24], where subsystems that require power connect to the bus and then condition and regulate energy for themselves [22].

In aircraft, typical distributed bus voltages have progressed from $28 \mathrm{~V} D C$ to $115 \mathrm{~V} A C$ to $270 \mathrm{~V} \mathrm{DC} \mathrm{[23].} \mathrm{In} \mathrm{the} \mathrm{case} \mathrm{of} \mathrm{the} \mathrm{International} \mathrm{Space} \mathrm{Station,} \mathrm{a} 120 \mathrm{~V}$ bus is used [22]. Supplying a higher voltage and a lower current throughout the system minimizes the energy loss due to the distribution of the energy itself, as a higher current at a lower voltage would incur more loss through the resistance of the connections.

The benefits of the distributed topology include scalability, reusability, efficiency, and fault tolerance [23]. Scalability is enabled by the distributed bus. A subsystem needing energy from the bus simply needs an interface engineered between the subsystem and the bus. The only limitation on the number of subsystems is the total power available from the bus rather than the total power available from a regulator in the case of a centralized EPS. A single distributed topology is suitable for a wide variety of missions.

Reusability is related to scalability. If the subsystem interface is properly engineered, the subsystem and its interface can be used in any system that matches the distributed bus 
for which it was designed. The interface only needs to be redesigned if the distributed bus has changed; otherwise, no modifications are necessary. Subsystems used in previous missions can be used in any combination as needed for future missions.

The distributed power system is efficient as well. Because the subsystem interface is designed solely for the subsystem, the power conditioning and regulation circuits can be designed for maximum efficiency when the subsystem is operating normally. In a centralized power system, the common regulator will not be operating at its optimal point if some of the subsystems attached to the regulator are inactive.

Because each subsystem is responsible for its own power conditioning and regulation, a subsystem anomaly is less likely to have an effect on neighboring subsystems. In a distributed topology, if a subsystem overloads its voltage regulator by drawing too much current, it is unlikely that other subsystems on the bus will be affected. Contrasting that behavior with the same situation on a centralized bus, the same overloaded regulator would interrupt the power supply to all other subsystems connected to that regulator, potentially jeopardizing the satellite's mission.

One disadvantage to the distributed power topology is that the topology needs extra circuitry to interface subsystems to the distributed bus. The additional circuitry is required to perform the individual subsystem power conditioning and regulation. More components typically introduce more points of failure in an electronic system. In a small 
satellite, the extra circuitry takes up more physical volume, which can result in a shortage of space for other satellite subsystems. Another disadvantage is due to the nature of switching regulators. These regulators look like negative impedances to the distributed bus because they are a constant power load. This may cause instability in the bus [25] [26]. Finally, a distributed power system requires more customization, since each subsystem interface is unique. The time required to properly design a distributed power system may not be available to all small satellite developers.

The distributed power system topology offers many benefits when compared to a centralized architecture, but designing a fully distributed electrical power system may not be possible for a typical group interested in developing a small satellite. A solution is presented in this work that combines the benefits of centralized and decentralized architectures, enabling the proposed small satellite power system to have scalability, efficiency, and fault tolerance while also being simple to prepare for all types of missions. 


\subsection{Proposed Power System}

In the EPS design described herein, distributed topology concepts are applied to the design of a small satellite power system. This is realized by supplying an unregulated voltage bus throughout the power system. The various subsystems of the satellite are connected to the unregulated bus. Solar cells and secondary batteries are attached to the bus as well. The distributed architecture used for the proposed EPS is shown in Figure 4.

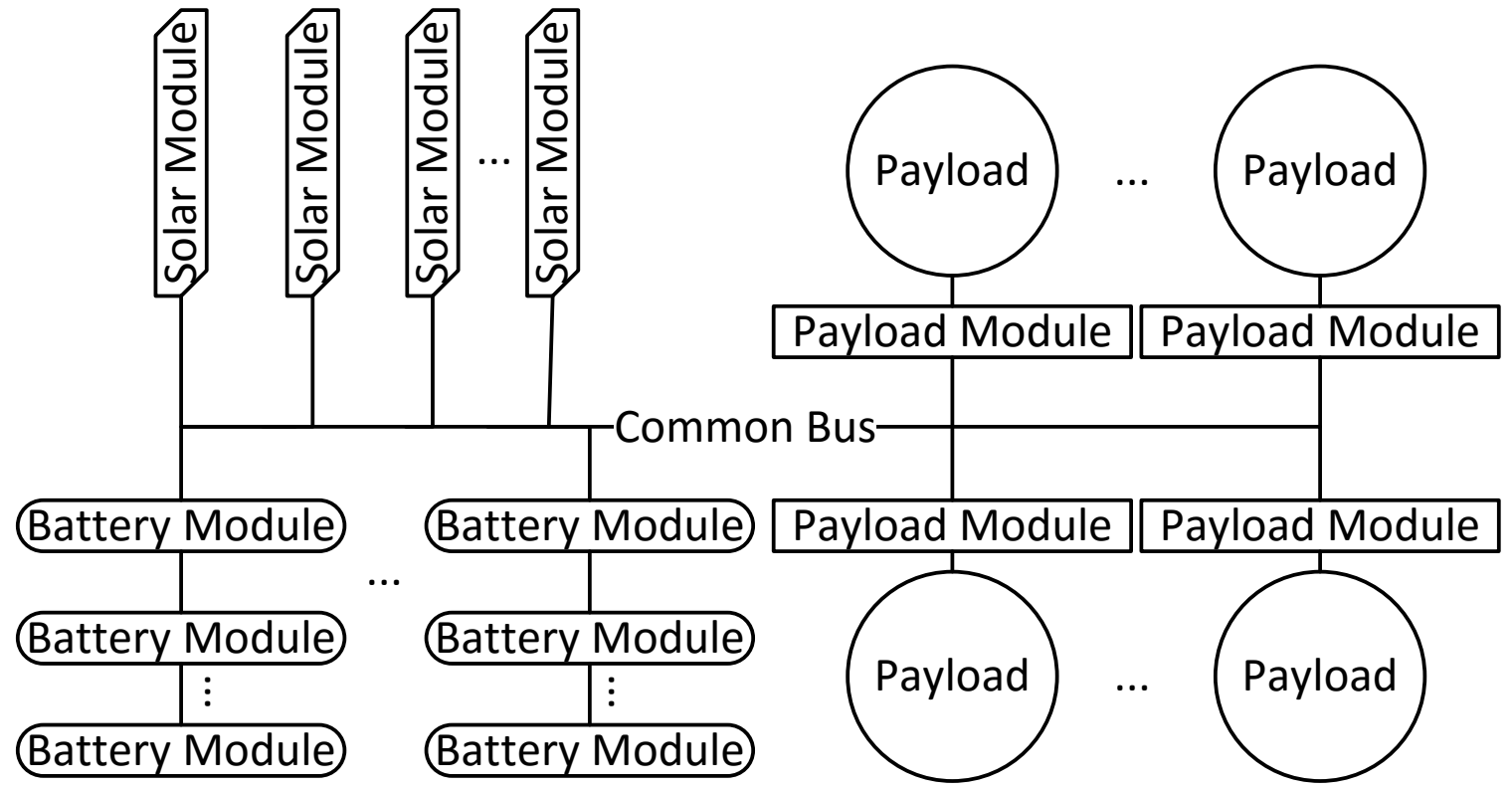

Figure 4: Diagram of a Distributed Architecture

The proposed EPS is separated into three types of modules: the solar module, the battery module, and the payload module. The solar module is responsible for energy generation and transfer to the common bus. The battery module is responsible for energy storage and supply. The payload module is responsible for energy regulation and usage. 
Modularizing the subsystems allows for scalability if the modules are correctly designed. The three module types can be attached to the common bus in any quantity as dictated by the mission requirements. The battery modules can even be placed in series with one another to increase the common bus voltage without losing any functionality.

The standard modules allow for reusability because the design of each module remains nearly the same across missions. The solar module and battery module are always the same from mission to mission. The payload module is the only unit that would require modifications, but only if the common bus voltage changes. Standardization also reduces the chance that the modules are incompatible with each other when connected to the common bus.

The three modules are engineered for maximum efficiency as well. For instance, components used for the solar module are selected so that minimal energy is lost when energy is transferred from the solar cell to the common bus. Also, the voltage regulator on the payload module is chosen to be optimal for each individual payload. More energy can be dedicated towards powering subsystems which is critical for a small satellite's power budget.

Distributed electrical power systems for small satellites have been the subject of previous research. Other researchers have considered the distributed topology to be the best approach because of its efficiency and ability to be used in multiple classes of satellites 
[18]. One distributed power system implementation has switching regulators as the interface between the batteries and the common bus so that the bus voltage can be held constant [27]. While this solution is very flexible, allowing for bus voltages both above and below the battery voltage, it is too complicated to justify its use over an unregulated bus. The proposed EPS is easier to implement with similar functionality.

The following three sections describe the three module types in more detail.

\subsection{Solar Module}

The solar module is responsible for energy generation and transfer in the distributed EPS. The block diagram in Figure 5 details the major components in the module.

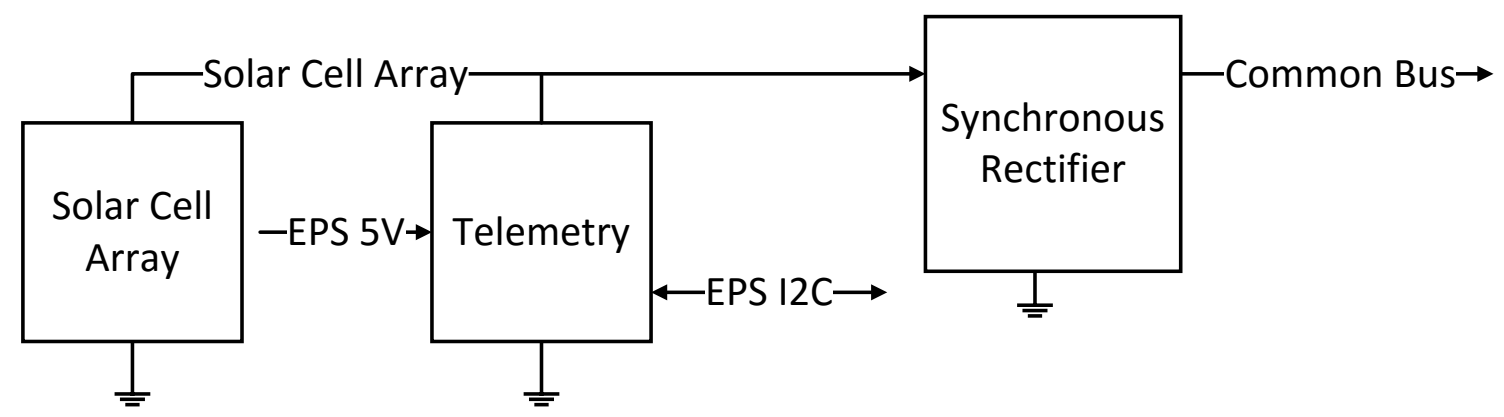

Figure 5: Solar Module Block Diagram

Figure 6 shows the system overview with the simplified solar module added. 


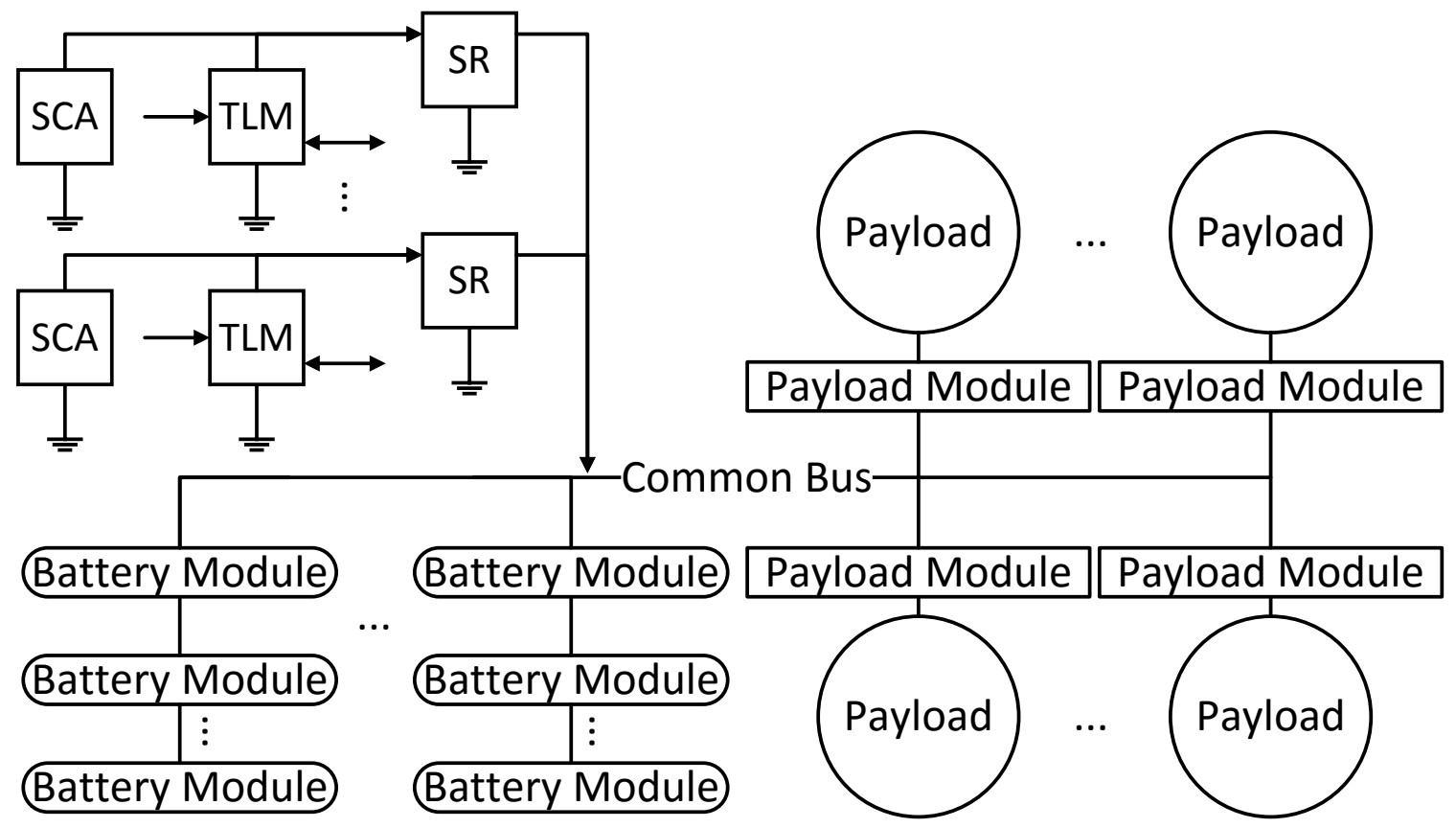

Figure 6: System Overview with Solar Module

Solar cells attached to the solar module generate energy to be used by the rest of the EPS.

The generated energy from the solar cells then needs to be transferred to the rest of the EPS through the unregulated bus. This should be done efficiently because energy is sparse in a satellite environment. In addition, the interface should prevent voltage backfeed from the unregulated bus onto a solar string in the shade.

There are two methods generally used for the energy transfer from the solar cell array, maximum power point tracking (MPPT) and direct energy transfer (DET). MPPT uses a switching converter to manipulate the operating point of the solar array so that the solar array always sees an ideal load, making the energy transfer very efficient. The isolation 
between solar arrays provided by the MPPT interface allows multiple solar arrays to be connected to a single bus. MPPT is used in some COTS EPS units and also in custom EPS units for various CubeSats as well [28]. In contrast, DET uses a diode as the interface between the solar array and its load. The load then directly determines the operating point of the solar array, which may or may not be at the optimal point for maximum power transfer. The interface diode allows multiple solar arrays to be connected to a single bus similarly to MPPT. The diode prevents voltage backfeed onto any solar string in the shade.

In previous work at the University of Kentucky Space Systems Laboratory it was found that a DET solar array interface with a synchronous rectifier is more efficient, more reliable in a radiation environment and is not affected by the rotation dynamics of the spacecraft, which greatly hinder MPPT [29]. The advantages of DET in typical operating conditions make it the ideal choice for the proposed EPS.

In the reference implementation of the distributed EPS, telemetry can be gathered through a quad input analog to digital converter (ADC) integrated circuit (IC). One differential input is dedicated to measuring the voltage of the solar array and another differential input is dedicated to measuring the voltage across a current sense resistor in series with the solar array. The remaining two inputs are unused, allowing a sun sensor or a temperature sensor to be attached to the ADC. This extra data could be useful to the 
operators of the satellite. For example, the solar panels themselves could also be used as a sun sensor.

The ADC communicates through Inter-Integrated Circuit (I2C), a communication protocol popular for embedded systems. I2C is a bi-directional open-drain protocol that is advantageous for modular system design.

The telemetry circuits do require an external voltage rail to operate, because the telemetry circuits need a reference voltage to determine the amplitude of the signal they are sampling. This allows the solar module to have the ability to report telemetry even when sunlight does not shine on the solar array.

\subsection{Battery Module}

The battery module is responsible for energy storage and energy supply when the solar arrays are not in sunlight (an eclipse situation). The block diagram in Figure 7 details the major components in the battery module. 


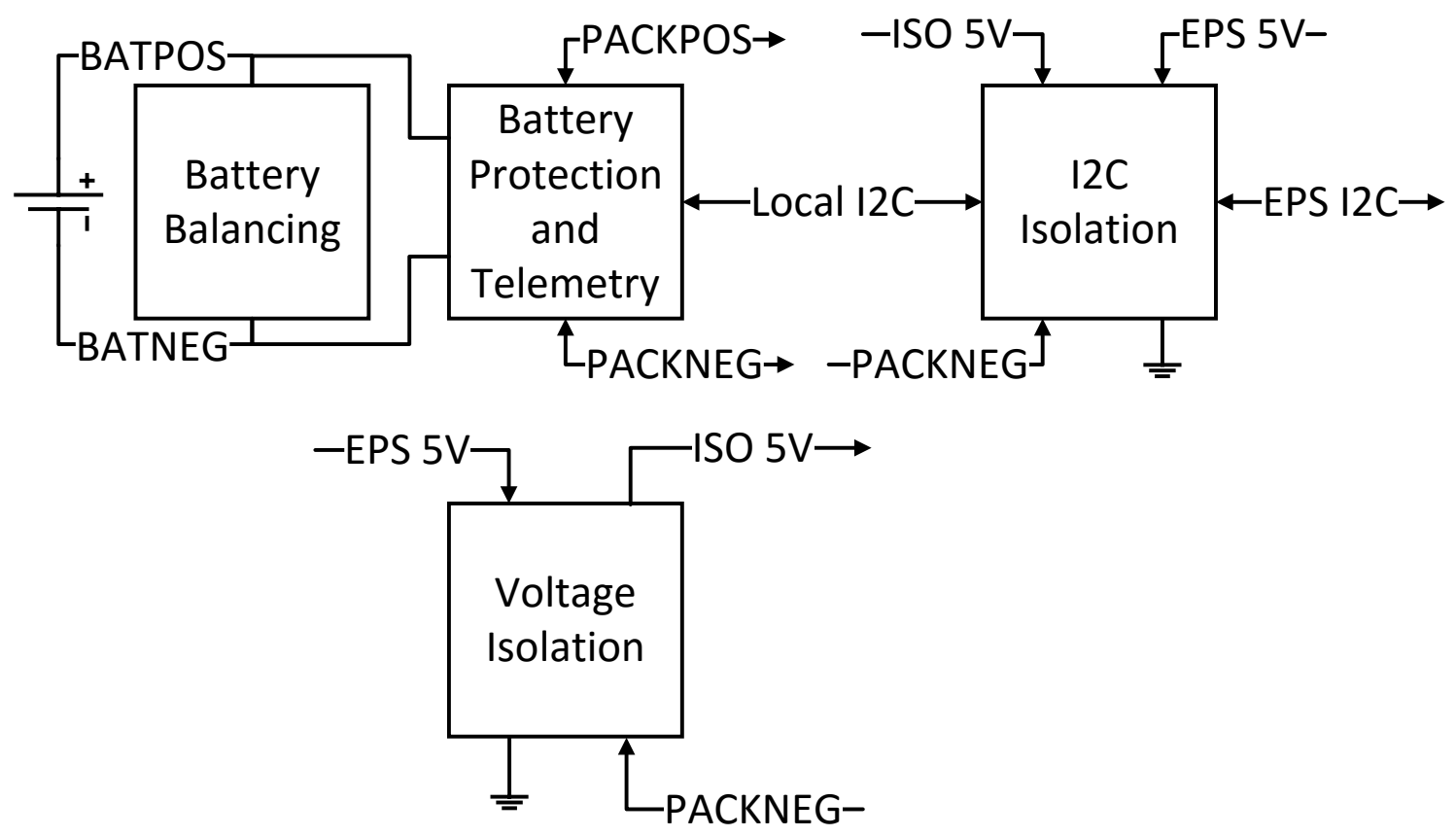

Figure 7: Battery Module Block Diagram

Figure 8 shows the system overview with the simplified solar module and battery module added. 


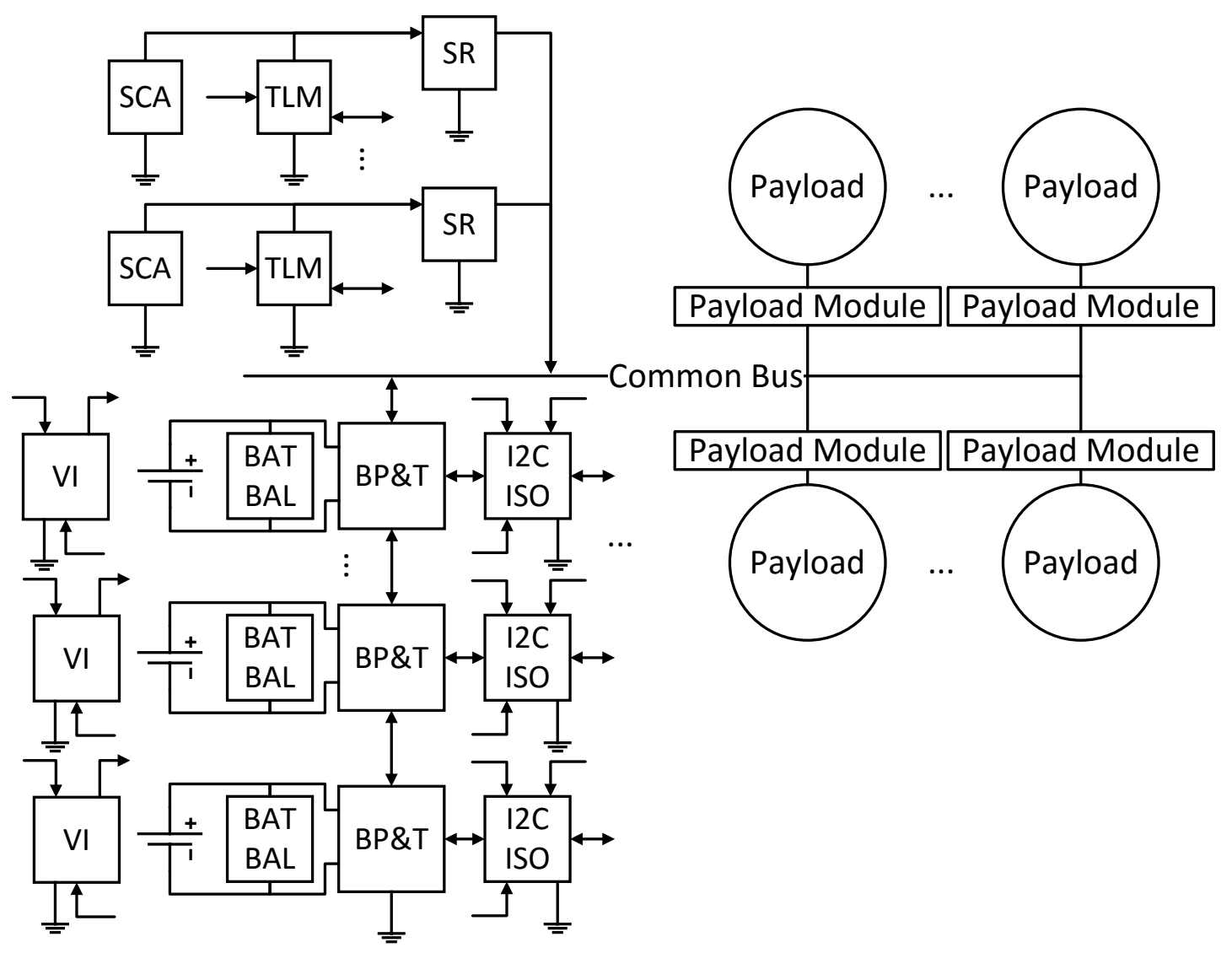

Figure 8: System Overview with Solar and Battery Modules

Four battery chemistries were considered for the EPS: nickel cadmium, nickel metal hydride, lithium ion, and lithium polymer. Table 1 summarizes the characteristics of all four battery chemistries [30]. The lithium polymer chemistry was selected for the battery module. This is because of the chemistry's high energy density [31], resistance to the memory effect, high nominal voltage, and prismatic form factor [32]. Some drawbacks are the chemistry's low cycle life and volatility if overcharged or overdischarged. 
Table 1: Battery Chemistry Comparison

\begin{tabular}{|c|c|c|c|c|c|}
\hline $\begin{array}{c}\text { Battery } \\
\text { Chemistry }\end{array}$ & $\begin{array}{c}\text { Energy } \\
\text { Density } \\
\text { (Wh/kg) }\end{array}$ & $\begin{array}{c}\text { Cycle } \\
\text { Life }\end{array}$ & $\begin{array}{c}\text { Nominal Cell } \\
\text { Voltage (V) }\end{array}$ & $\begin{array}{c}\text { Memory } \\
\text { Effect? }\end{array}$ & $\begin{array}{c}\text { Form } \\
\text { Factor }\end{array}$ \\
\hline $\begin{array}{c}\text { Nickel- } \\
\text { Cadmium }\end{array}$ & $45-80$ & 1500 & 1.25 & Yes & Cylindrical \\
\hline $\begin{array}{c}\text { Nickel Metal } \\
\text { Hydride }\end{array}$ & $60-120$ & 400 & 1.25 & Yes & Cylindrical \\
\hline $\begin{array}{c}\text { Lithium lon } \\
\text { Lithium } \\
\text { Polymer }\end{array}$ & $110-160$ & $\begin{array}{c}400- \\
750\end{array}$ & 3.6 & No & Cylindrical \\
\hline
\end{tabular}

Lithium polymer batteries require strict protection because they are very volatile when stressed outside its limits. The protection circuit used in the battery module handles overvoltage protection, undervoltage protection, and overcurrent protection (charge and discharge). When the battery is in an overvoltage condition, the charge current path is blocked, only allowing a discharge current from the battery. When the battery is in an undervoltage condition, the discharge current path is blocked, only allowing a charge current into the battery. When the battery is in a charge overcurrent condition, both the charge and the discharge current paths are blocked. The protection circuit then delays for a specific amount of time before checking if the battery's voltage is greater than the voltage supplied to the battery. If so, both of the current paths are reestablished. When the battery is in a discharge overcurrent condition, the discharge current path is blocked. The protection circuit then delays for an amount of time before checking if the battery's voltage is less than the voltage supplied to the battery. If so, the current path is reestablished. 
To achieve scalability, the battery modules must be able to be placed in any series or parallel combination. This presents two challenges that must be overcome: cell balancing and telemetry gathering.

When batteries are placed in a series string, variances in manufacturing and inherent battery characteristics mean that the batteries could be charging and discharging at different rates, even though their specifications are the same. This could result in eventual battery protection lockouts because one battery in a string could be in an overvoltage condition and another battery in an undervoltage condition. In this situation, a charge current to the string is not possible because of the overvoltage battery. Conversely, a discharge current from the string is not possible because of the undervoltage battery. The string would be locked out from use by the EPS until the overvoltage battery slowly selfdischarges.

To avoid this situation, a cell balancing circuit was placed on the battery module. The circuit consists of a zener diode and a resistor placed parallel to the battery. The zener diode is chosen so that its zener voltage is above normal battery voltages and below the overvoltage limit. When the battery voltage is above the zener voltage, the zener diode is in reverse breakdown, allowing current to flow through the diode. This balancing current is limited by the balancing resistor. 
As a battery module reaches an overvoltage condition, more current gets shunted through the balancing circuit. The balancing circuit attempts to regulate all battery modules to the zener voltage. If one battery charges much faster than the others in its string, more current is drawn from it as it reaches full capacity. This allows the other batteries in the string to catch up to its state of charge.

The overall efficiency of the battery modules is then reduced, as some energy is diverted to balance the batteries. However, additional losses are only realized when the battery is approaching an overcharge condition and not during normal operation.

Telemetry is useful for operators of the satellite to determine the state of charge of the battery bank and to decide what actions to take based on that information. The protection circuit in the reference design provides telemetry through an $12 \mathrm{C}$ interface; however, if battery modules are placed in series, the $12 \mathrm{C}$ voltage levels are not referenced to ground potential. Instead, the levels are referenced to the negative leg of its local battery. The $12 \mathrm{C}$ signals need to be level shifted (both logic high and logic low) so that communication can be established no matter where the battery module is positioned in a string. A galvanic isolation IC was connected to each battery module to perform the required $\mathrm{I} 2 \mathrm{C}$ level shifting. 


\subsection{Payload Module}

The payload module is responsible for regulating the energy to the other subsystems in the satellite. The block diagram in Figure 9 details the major components of the payload module.

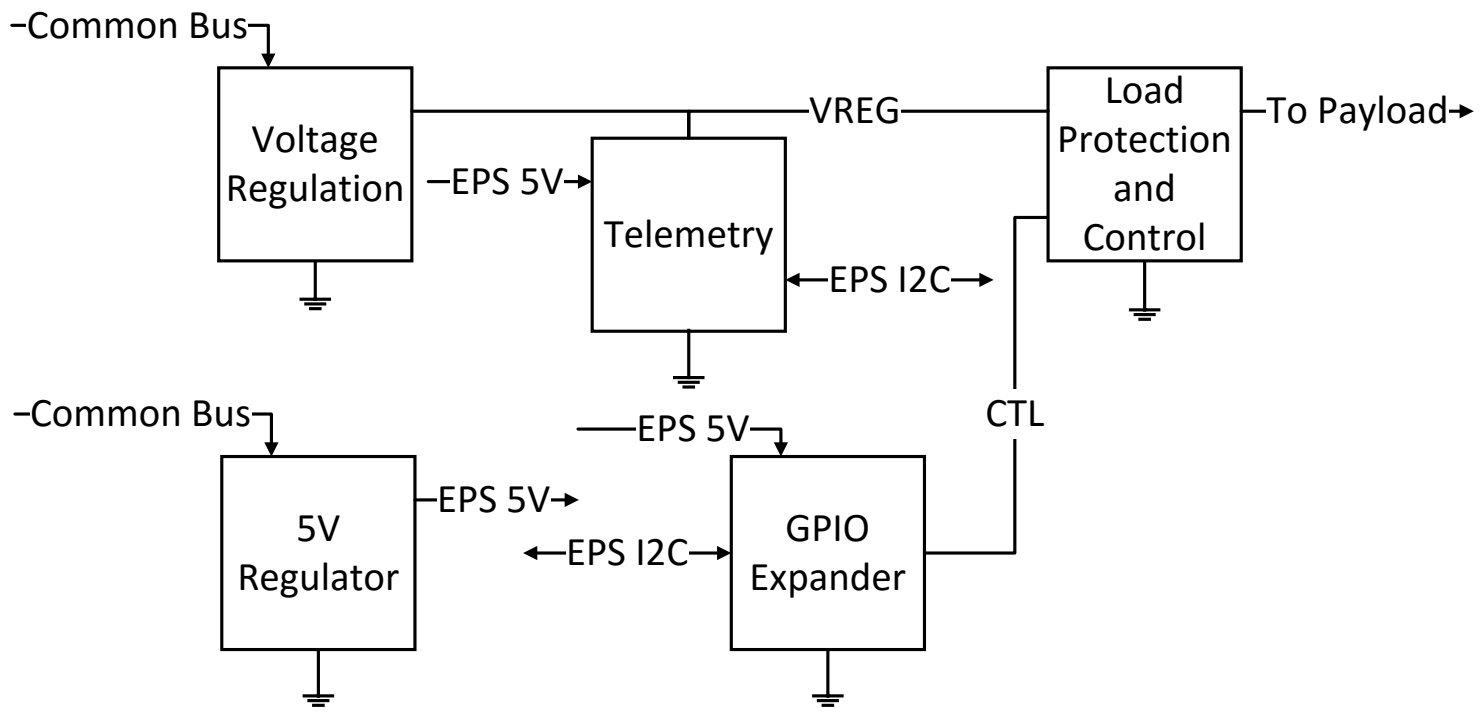

Figure 9: Payload Module Block Diagram

Figure 10 shows the system overview with the simplified solar module, battery module, and payload module added. 


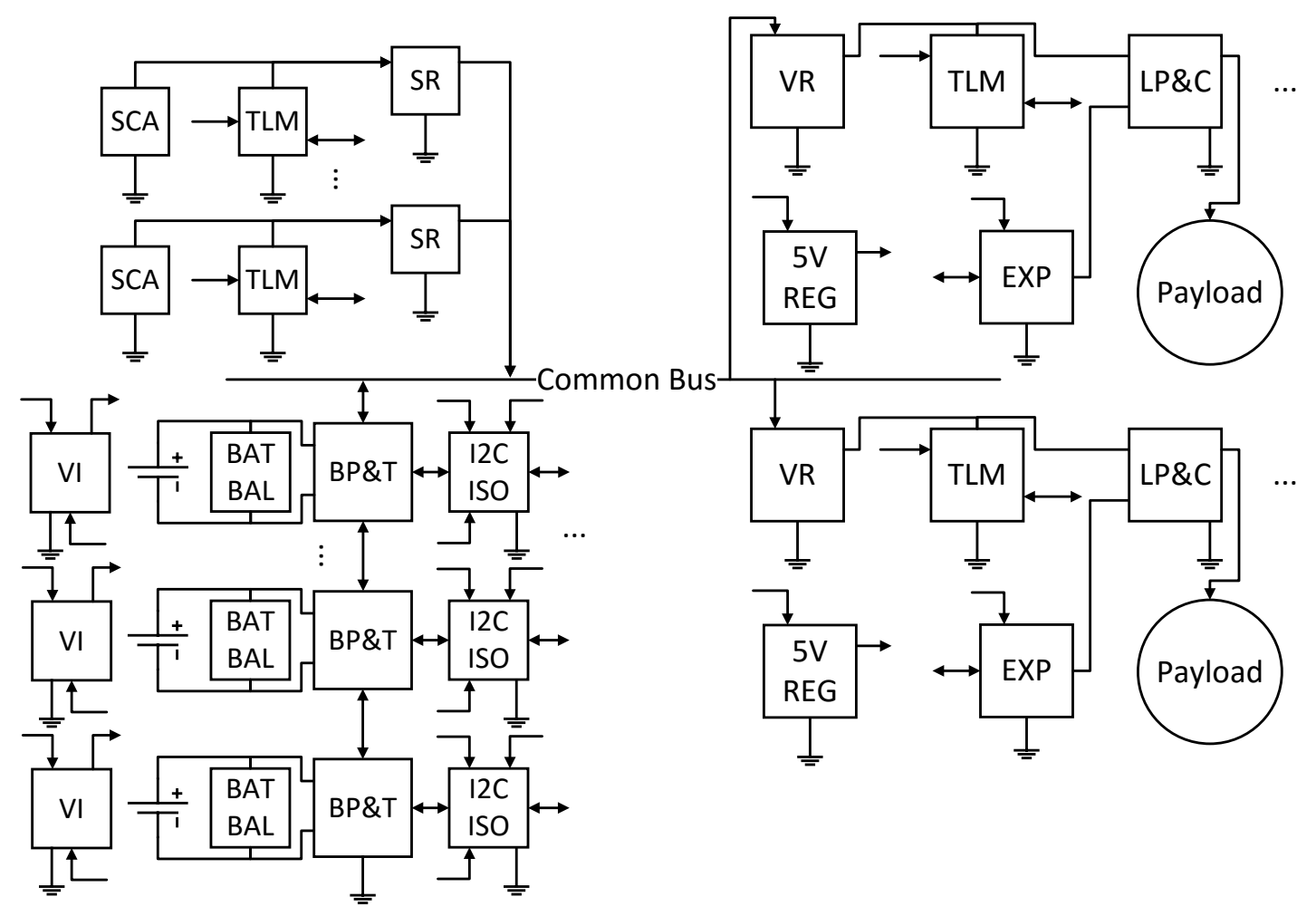

Figure 10: System Overview with Solar, Battery, and Payload Modules

The main component in the payload module is the voltage regulator. The voltage regulator converts energy from the unregulated bus to the attached payload and directly affects the efficiency of the payload module itself. Without the regulator, the payload will not operate.

There are two methods commonly used for voltage regulation. The first is linear regulation, where a higher voltage is regulated to a lower voltage. This is done by dissipating the difference in voltage across the regulator itself. Linear regulators are very stable and typically have a noise free output voltage. The main disadvantage to linear regulators is that they are very inefficient due to the excess energy being dissipated by 
the regulator. Typical efficiency values for linear regulators range between $50 \%$ and $70 \%$. Linear regulators are commonly used for subsystems that do not require much energy because the low efficiency of the regulator connected to a less demanding load would have a small impact on the overall power budget.

The second method used for voltage regulation is called a switched mode power supply, or a switching regulator. Switching regulators can be used to regulate a higher voltage to a lower voltage (step-down regulator) or regulate a lower voltage to a higher voltage (step-up regulator). This is done by rapidly switching the voltage across an inductor, with the components in different configurations depending on the desired result. Not much energy is wasted to perform the conversion, so switching regulators are very efficient. Typical efficiency values for switching regulators range from $80 \%$ to $95 \%$. However, due to the presence of a high frequency switch signal, the output voltage from switching regulators tends to be electrically noisy. The switching regulator circuit is also typically more complex than linear regulators. Switching regulators are commonly used for subsystems that demand more power because a low efficiency regulator would waste too much energy on voltage regulation, which could be detrimental to the overall power budget.

The payload module also handles payload protection in the form of overvoltage protection, undervoltage protection, and overcurrent protection. If the regulator provides a higher or lower voltage than specified by the payload, the protection circuit 
will cut off the power supply to the payload to avoid accidental damage to the payload. If the payload starts to draw more current than expected, then the protection will cut off the power supply to the payload and allow the payload to reset. The protection circuit also allows for an external source to control the power supply to the payload, so satellite subsystems can be individually powered on and off. This is useful for energy management of the satellite or performing hard resets of subsystems.

The payload module also provides telemetry to determine the status of the payload. The voltage provided to the payload and the current draw of the payload can be obtained through the telemetry circuits. Like the other two modules, the telemetry circuits in the payload module use $12 \mathrm{C}$ for communication in the reference designs.

In the reference implementation, a general purpose input/output expander is used for payload control. The expander also uses $12 \mathrm{C}$ for communication.

The telemetry circuits and the expander require an external voltage rail to operate. This means telemetry can be gathered and the payload can be commanded as long as the payload module can draw energy from the common bus.

The payload modules can be placed in parallel to attach more satellite subsystems to the EPS. If a subsystem is used again in a future mission, the payload module designed for it 
can be reused without modification if the unregulated bus is within the payload module's specification. 


\subsection{Distributed EPS Prototypes}

Prototypes were created for the three types of modules by designing and assembling printed circuit boards for each module. The overall design was loosely based on the EPS for the CubeSat KySat-2 so that the prototypes could be tested with the spare hardware. The following three sections detail the three module prototypes and their circuitry.

\subsection{Solar Module}

The reference implementation of the solar module prototype consists of the solar cells, the synchronous rectifier circuit, and the telemetry circuit. Figure 11 shows the solar module prototype.

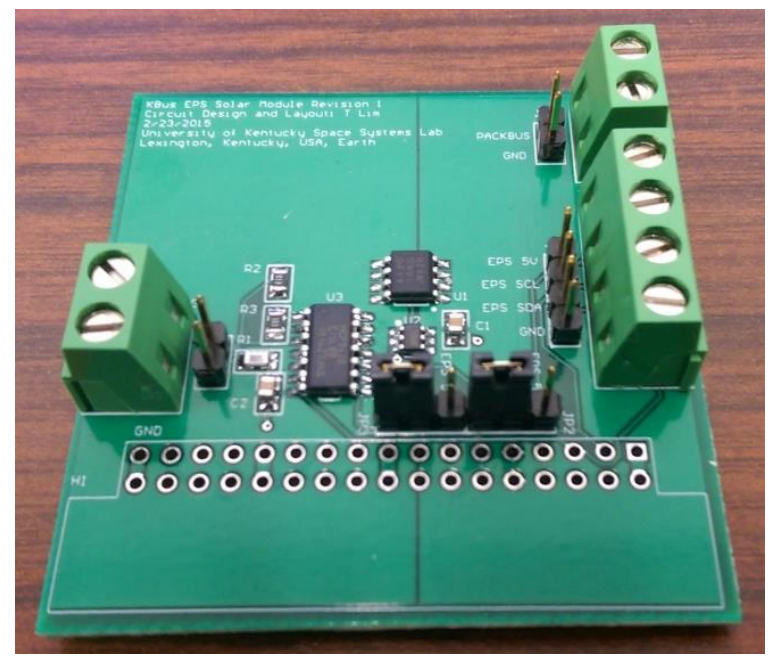

Figure 11: Solar Module Prototype

\subsubsection{Solar Cells}

Solar cells convert solar energy into energy usable by the satellite. The solar cells used in the reference implementation are supplied from TrisolX. The solar cell chemistry is GaAs 
with an open circuit voltage of $2.62 \mathrm{~V}$, maximum power voltage of $2.33 \mathrm{~V}$, maximum power current of $14.6 \mathrm{~mA}$, and an efficiency of $28 \%$ [33]. These cells are made from the cutoffs of larger space rated solar cells, so many of them are needed in parallel to produce enough current to supply a satellite. Figure 12 shows a single TrisolX solar cell.

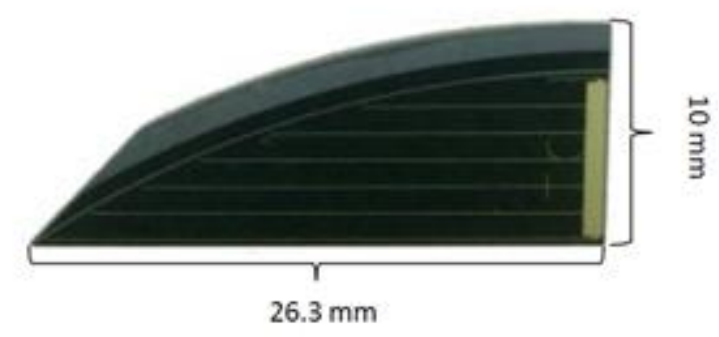

Figure 12: TrisolX Solar Cell [33]

The maximum solar string length is set to seven cells, which results in a maximum open circuit voltage of $18.34 \mathrm{~V}$ and a maximum power voltage of $16.31 \mathrm{~V}$. This limit was set because the reference implementation was designed to be similar to the EPS used on KySat-2. A larger solar string is possible, but may require some other components further down the circuit to be changed.

The TrisolX cells cannot produce the same current as the cells used on KySat-2 on their own, but five sets of TrisolX solar cells in parallel are a good approximation. This results in a maximum power current of $73 \mathrm{~mA}$. Each solar array produces $1.19 \mathrm{~W}$ of power, so a CubeSat with four solar arrays produces $4.76 \mathrm{~W}$ in ideal conditions. More than likely, only two arrays will be in sunlight at a given time, so the expected production is $2.38 \mathrm{~W}$. Relative to KySat-2, this is very good because KySat-2 used $2 \mathrm{~W}$ of energy. The TrisolX 
solar arrays would still result in a positive power budget if they replaced the original solar arrays.

\subsubsection{Telemetry}

Telemetry is used on the solar module to provide the status of the solar arrays to the EPS. The telemetry circuit is based on an analog-to-digital converter (ADC). The MCP3428 from Microchip Technology Inc. was chosen as the solar module's ADC. The ADC circuit is shown in Figure 13.

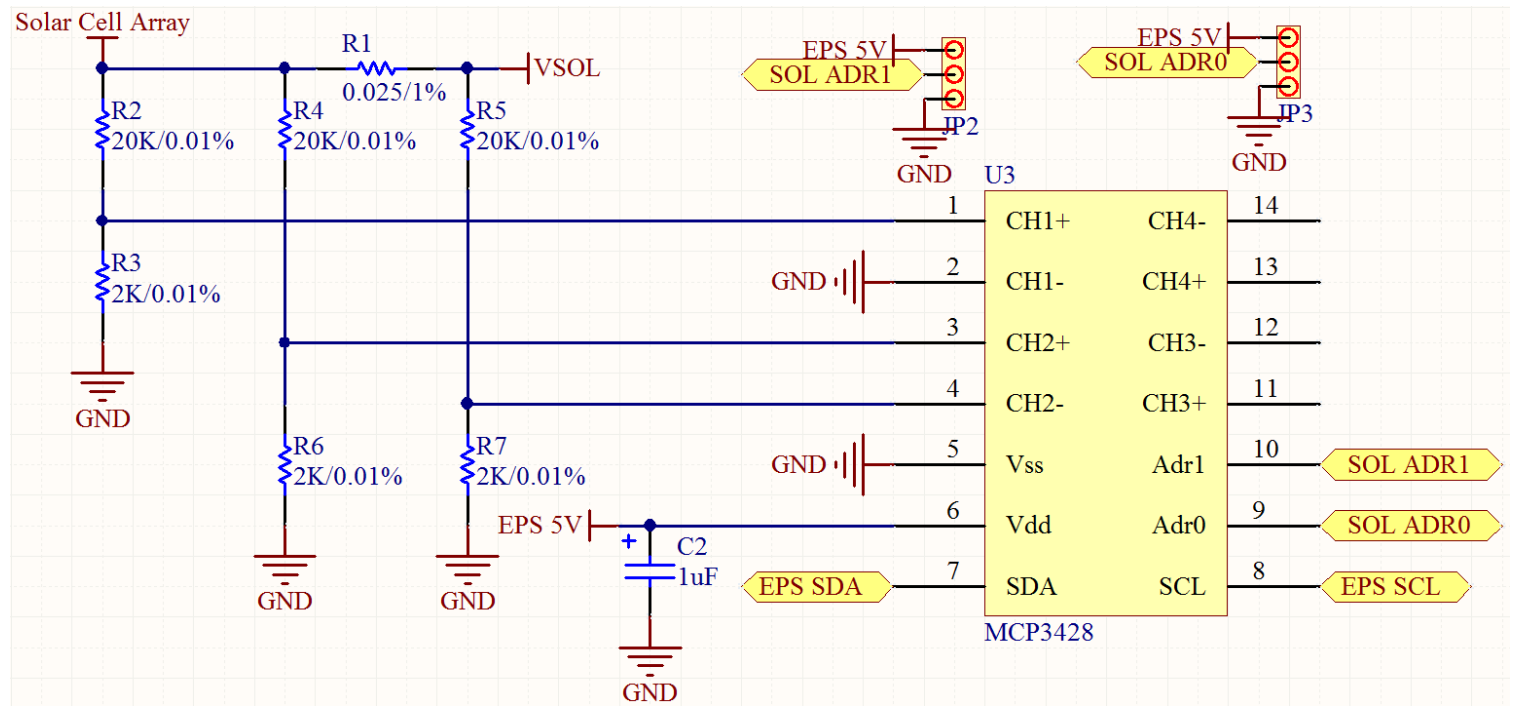

Figure 13: ADC Circuit

The first criteria when selecting an ADC to use was its communication method. The distributed EPS uses an $12 \mathrm{C}$ bus, so the ADC must be compatible with the $12 \mathrm{C}$ standard. The next criteria is the number of $12 \mathrm{C}$ addresses the ADC can support and the address range of the ADC. Because the total number of solar modules connected to the bus is 
unknown, it is best to choose the ADC that can handle the maximum number of modules without address interference.

The MCP3428 contains four differential input pairs. The inputs can be sampled with a resolution up to sixteen bits with a minimum of fifteen samples per second. The MCP3428 can also be placed in one-shot conversion mode where the ADC sleeps after taking a measurement. This reduces the energy draw of the IC. The MCP3428 has an onboard voltage reference of $2.048 \mathrm{~V}$. The input voltage range of the IC is $2.7 \mathrm{~V}$ to $5.5 \mathrm{~V}$. The MCP3428 has nine different usable I2C addresses [34].

In the reference implementation, the MCP3428 is powered from an external $5 \mathrm{~V}$ rail because the telemetry should be active as long as the EPS is active. The other option is to have the ADC powered from the solar array itself, but that would mean when the solar cells are shaded, the telemetry IC would not receive any power. In this case, the IC would not respond to an EPS request for telemetry, so the solar string status would be unknown. In the current implementation, the solar string voltage is always known to the EPS whether the cells are in sunlight or in shade.

The voltage measurement is connected to Channel 1 of the ADC. It is a single ended measurement with the negative pin of the differential input connected to GND. The voltage range of the solar string varies from $0 \mathrm{~V}$ to $20 \mathrm{~V}$, which is greater than the voltage reference and the maximum input voltage of the MCP3428. A voltage divider is used to 
bring the solar voltage down to a measurable level. The divider made from a $20 \mathrm{k} \Omega$ resistor and a $2 \mathrm{k} \Omega$ resistor divides the solar voltage by eleven. The voltage range seen by Channel 1 is now $0 \mathrm{~V}$ to $1.818 \mathrm{~V}$, well within the ADC input voltage limits. The voltage divider resistors are extremely accurate at $0.01 \%$ tolerance so that variance in resistance minimally affects the accuracy of the measurement. The ADC can sample a measurement with sixteen bits of accuracy, making the ADC accurate to $0.687 \mathrm{mV}$ after accounting for the voltage divider. For the voltage measurement, the gain remains at the default setting of one.

The current measurement is connected to Channel 2 of the ADC. It is a differential measurement, with the positive pin of the differential input on the solar voltage side and the negative pin of the differential input on the bus voltage side. Voltage dividers used for the voltage measurement are used again for the current measurement to bring the voltage range down to a measurable level. The estimated accuracy of the current measurement is $3.43 \mathrm{~mA}$ at a resolution of sixteen bits and a gain of eight.

The voltage supplied to the Adr pins on the IC determines the I2C address of the MCP3428. The Adr pins can be connected to Vdd, Vss, or left floating. This results in nine possible I2C addresses for the MCP3428. 


\subsubsection{Synchronous Rectifier}

The synchronous rectifier is used to efficiently transfer energy from the solar cells to the unregulated bus. The synchronous rectifier used in the reference implementation is based on the LTC4412HV integrated circuit from Linear Technology. The synchronous rectifier circuit is shown in Figure 14.

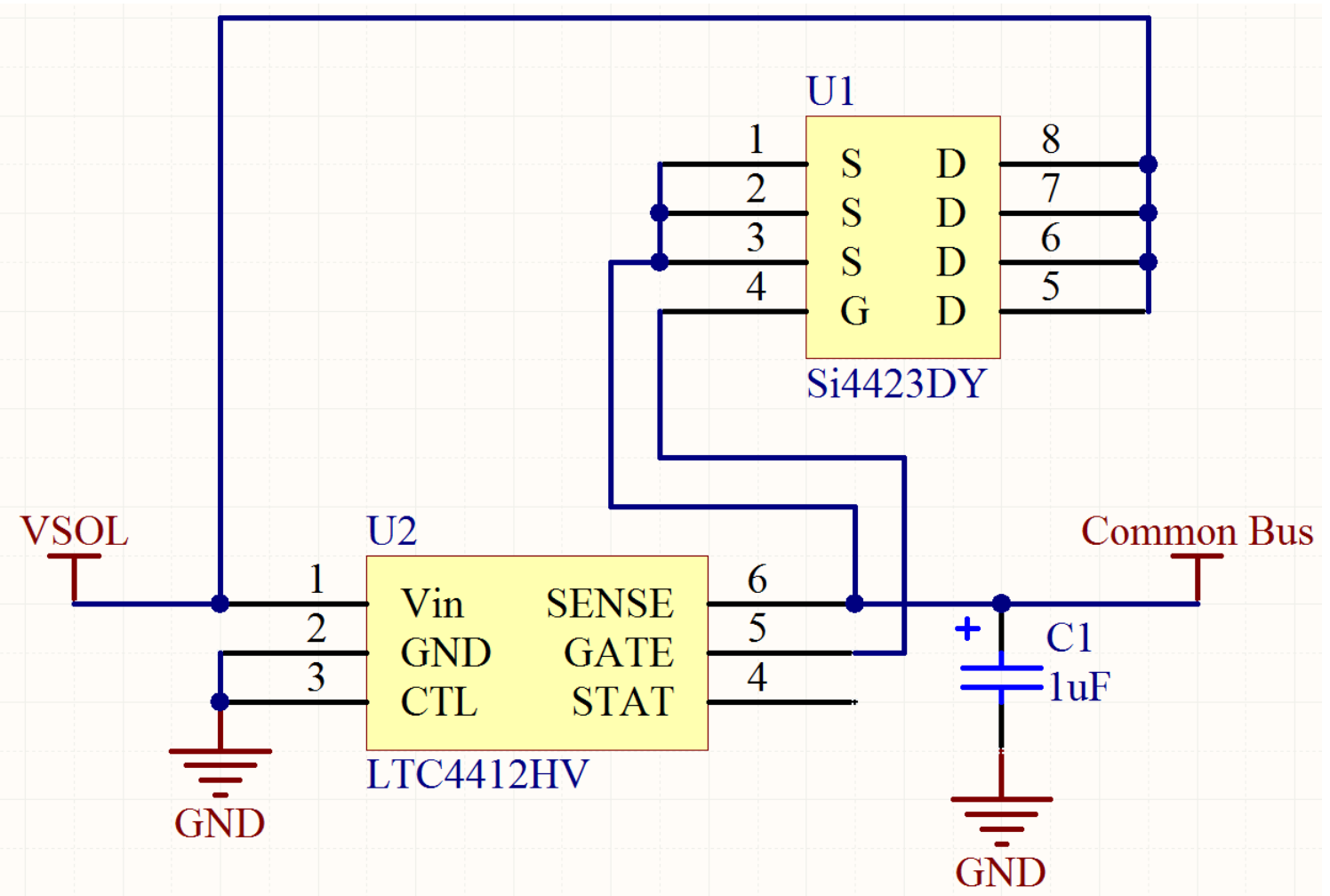

Figure 14: Synchronous Rectifier Circuit

The main criteria when selecting the synchronous rectifier was the input voltage range.

The solar string can range from $0 \mathrm{~V}$ to $20 \mathrm{~V}$, so the synchronous rectifier circuit must be able to accept all voltages within that range. 
The LTC4412 HV has an absolute voltage rating of $-14 \mathrm{~V}$ to $40 \mathrm{~V}$, which covers the voltage range of the solar string [35]. The MOSFET used for the energy transfer is the Si4423DY from Vishay Siliconix. The MOSFET is P-type with a maximum $\mathrm{V}_{\mathrm{ds}}$ of $-20 \mathrm{~V}$ and a maximum drain current of -10 A [36], which covers the expected voltage and current ranges of the solar cells. The turn on voltage is at most $-0.9 \mathrm{~V}$ and the expected on-state resistance is no greater than $0.0115 \Omega$ at a $V_{g s}$ of $-1.8 \mathrm{~V}$.

\subsection{Battery Module}

The reference implementation of the battery module prototype consists of the battery, battery protection circuit, $12 \mathrm{C}$ isolator, the voltage isolator, and the battery balancing circuit. Figure 15 shows the battery module prototype.

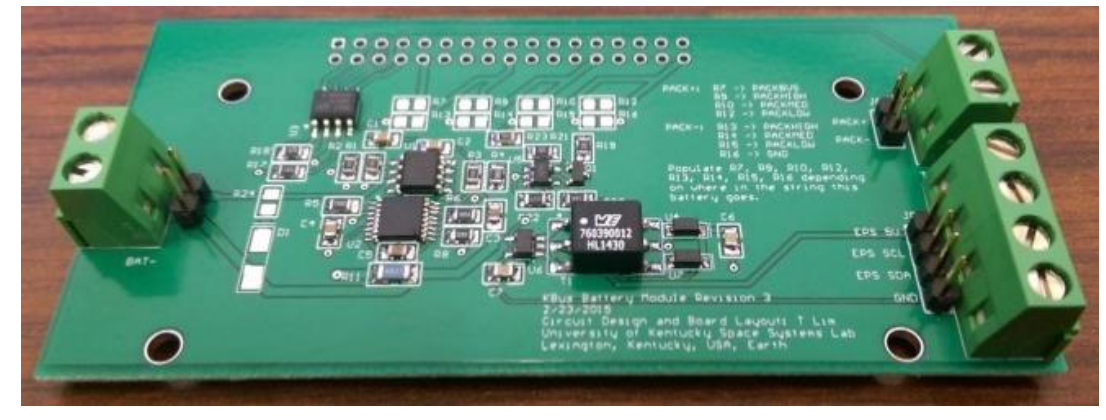

Figure 15: Battery Module Prototype

\subsubsection{Battery}

The battery stores excess solar energy from the solar cells and supplies energy to the satellite when the solar arrays are shaded. The main criteria when selecting the battery is the battery capacity and the physical dimensions of the cell. One of the design goals is to have the ability to place two batteries side by side inside the satellite, so a single cell 
must be smaller than $100 \mathrm{~mm} \times 50 \mathrm{~mm}$ in length and width. The battery selected for the reference implementation is the Lithium polymer PL544792-2C from BatterySpace, shown in Figure 16.

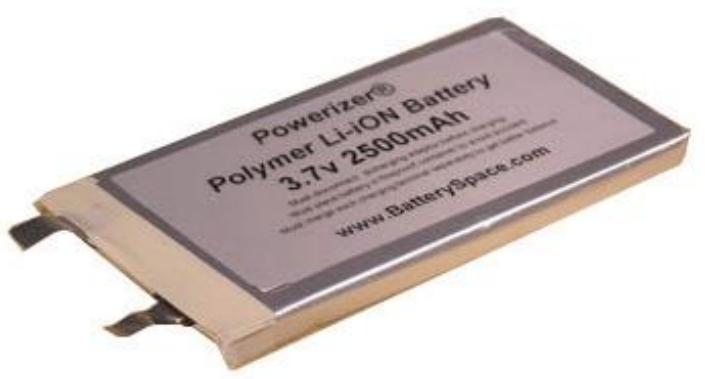

Figure 16: PL544792-2C Lithium Polymer Battery [37]

The PL544792-2C has a nominal voltage of $3.7 \mathrm{~V}$, capacity of $2500 \mathrm{mAh}$, and dimensions of $92.5 \mathrm{~mm} \times 47 \mathrm{~mm} \times 5.4 \mathrm{~mm}$ [37]. Its cycle life is greater than 500 , with charge rate of $0.5 \mathrm{C}$ and discharge rate of $2.0 \mathrm{C}$. The mass of the battery is $51 \mathrm{~g}$. The Lithium-polymer's prismatic form factor helps reduce the amount of physical space the batteries fill in the satellite, so more room can be made for other hardware.

\subsubsection{Battery Protection}

The Lithium polymer battery chemistry chosen for the reference implementation is very volatile when the cell is overcharged or overdischarged. A dedicated battery protection circuit is needed for each cell to make sure the batteries remain within the bounds of normal operation. Therefore, the battery protection circuit must disable the battery when overcharged, disable the battery when overdischarged, and only monitor one cell per circuit. The single cell per circuit criteria is driven by the scalability of the distributed 
EPS; if more voltage is needed on the unregulated bus then battery modules need to be easily added in series with each other without modification to the circuit. Finally, the battery protection circuit needs to provide telemetry for data such as the battery voltage and battery current. An all-in-one IC means there are fewer parts to assemble on the circuit board and fewer components that could fail in the space environment. The telemetry would need to be accessed through $12 \mathrm{C}$, so the option of multiple $12 \mathrm{C}$ addresses is necessary as well.

The battery protection circuit chosen for the reference implementation is based on the DS2764 from Maxim Semiconductor. The battery protection circuit is shown in Figure 17. 


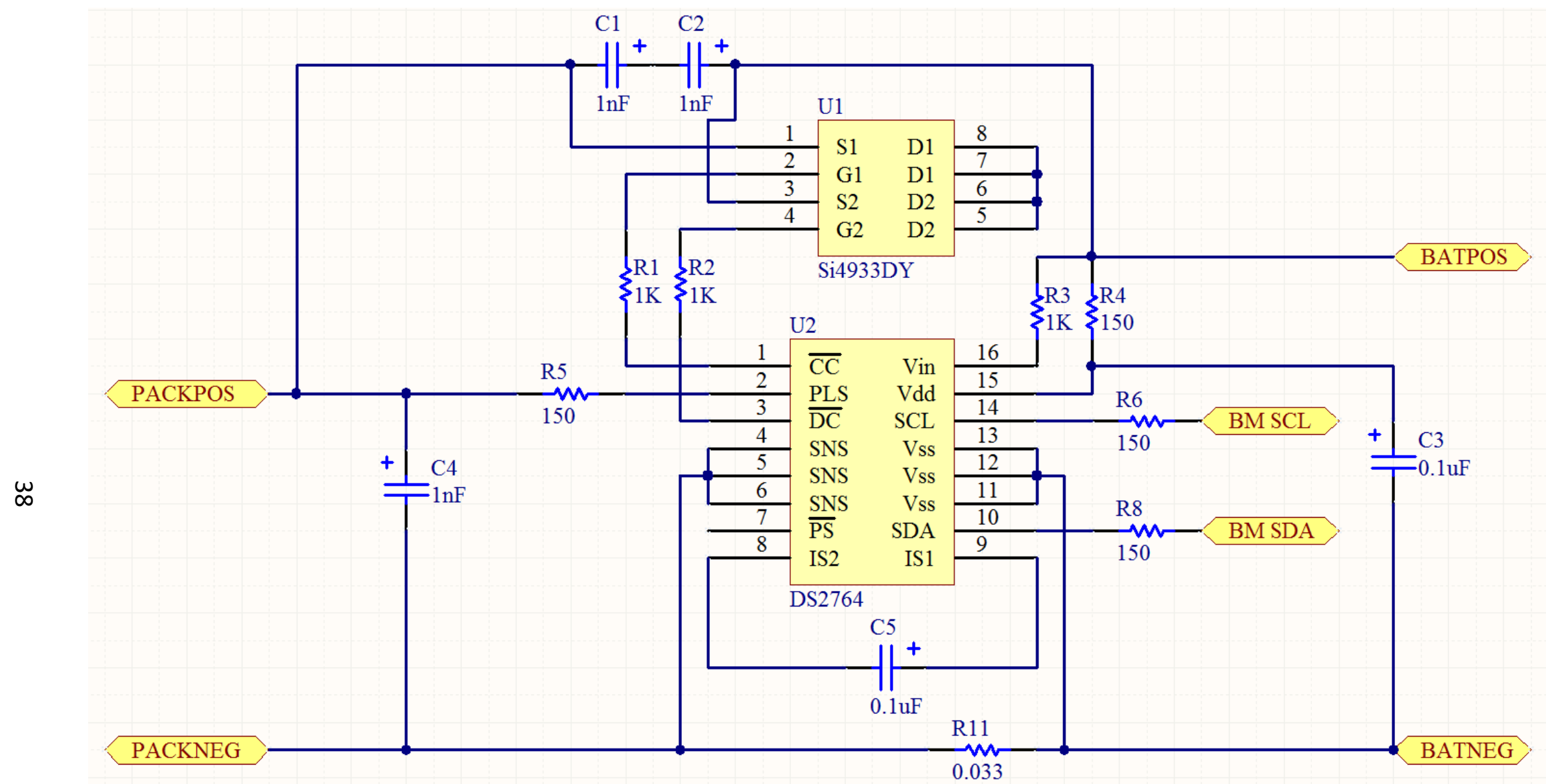

Figure 17: Battery Protection Circuit 
The DS2764 protects the battery from overvoltage, undervoltage, and overcurrent/short circuits [38]. The IC provides telemetry in the form of battery voltage, battery current, and temperature through an I2C interface. The DS2764 only monitors a single battery cell, so multiple ICs can be placed in series as needed.

The battery is disabled in the event of a fault through the Si4933DY dual MOSFET IC. The Si4933DY has two P-channel MOSFETs on the IC, with a maximum $V_{d s}$ of $-12 \mathrm{~V}$ and a continuous current rating of $-5.9 \mathrm{~A}$ [39]. Its gate threshold voltage is at most $-1 \mathrm{~V}$ with maximum on-state resistance of $0.022 \Omega$ at a $\mathrm{V}_{\mathrm{gs}}$ of $-1.8 \mathrm{~V}$. The DS2764 turns the MOSFETs on or off depending on the fault condition detected.

The overvoltage limit is always set to $4.35 \mathrm{~V}$, and the undervoltage limit is always set to 2.6 V. The DS2764 uses an external current sense resistor for the overcurrent/short circuit protection. When the IC sees a voltage difference of $47.5 \mathrm{mV}$ across the sense resistor, the overcurrent protection kicks in. At the sense resistor value of $0.038 \Omega$, the overcurrent limit is $1.25 \mathrm{~A}$, corresponding to a $0.5 \mathrm{C}$ charge rate of the battery chosen for the reference implementation. Overcurrent can be triggered during both charging and discharging, making the $0.5 \mathrm{C}$ charge rate the limiting factor.

The I2C address of the DS2764 is user controlled through the I2C bus. There are no address limitations, so the DS2764 has 127 possible addresses. 


\subsubsection{I2C Isolation}

The I2C telemetry from the battery protection circuit has its voltage levels based on the battery voltage of the battery the DS2764 protects. When battery modules are placed in series with one another to increase the unregulated bus voltage, the telemetry from each DS2764 is on its own set of logic levels. This necessitates the use of an $12 \mathrm{C}$ isolator to shift the various logic levels back down to a single level so that the EPS can correctly receive telemetry from each battery protection circuit.

The $12 \mathrm{C}$ isolator circuit chosen for the reference implementation is based on the Si8600 from Silicon Laboratories. The I2C isolator circuit is shown in Figure 18.

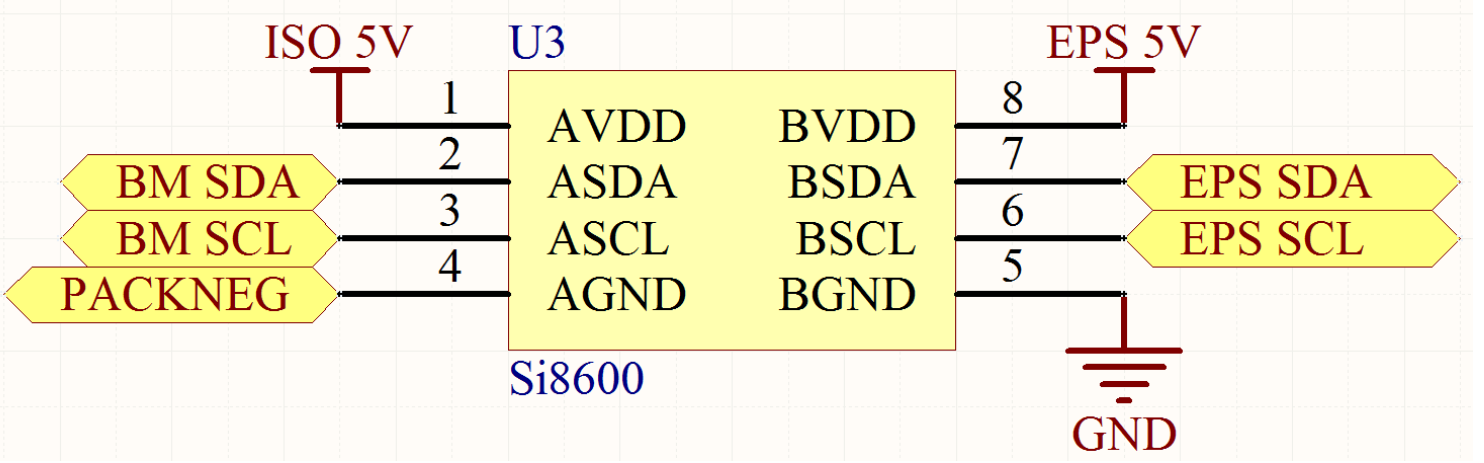

Figure 18: I2C Isolator Circuit

The Si8600 has independent, bidirectional SDA and SCL isolation channels [40]. The isolation is tolerant of up to $5000 \mathrm{Vrms}$. Its operating supply voltage is $3 \mathrm{~V}$ to $5.5 \mathrm{~V}$. The Si8600 uses galvanic isolators to isolate the $12 \mathrm{C}$ communication signals from each other. Side A connects to the DS2764 I2C lines, while side B connects to the EPS I2C lines. Side $B$ is powered by an external voltage supply provided by the EPS. Side A is powered from 
a voltage isolator using that same external supply. The voltage isolator is detailed in the next section.

\subsubsection{Voltage Isolation}

A voltage isolator is not necessary to operate the $12 \mathrm{C}$ isolator, but makes telemetry gathering more available during EPS operation. The alternative power source for the $12 \mathrm{C}$ isolator is directly from the battery connected to the module's DS2764. However, because the Si8600's minimum operating supply voltage is $3 \mathrm{~V}$ and the battery undervoltage limit is $2.6 \mathrm{~V}$, the battery voltage could dip below $3 \mathrm{~V}$ but still be above 2.6 V. In this case, the EPS would still continue to operate, but the battery telemetry would be inaccessible due to the $\mathrm{I} 2 \mathrm{C}$ isolator browning out. An external voltage supply is already being provided to the Si8600 on the EPS side, so a voltage isolator is a simple method to allow that voltage supply to be used on the DS2764 side of the I2C isolator.

The voltage isolator chosen for the reference implementation is based on the SN6501 from Texas Instruments. The voltage isolation circuit is shown in Figure 19. 


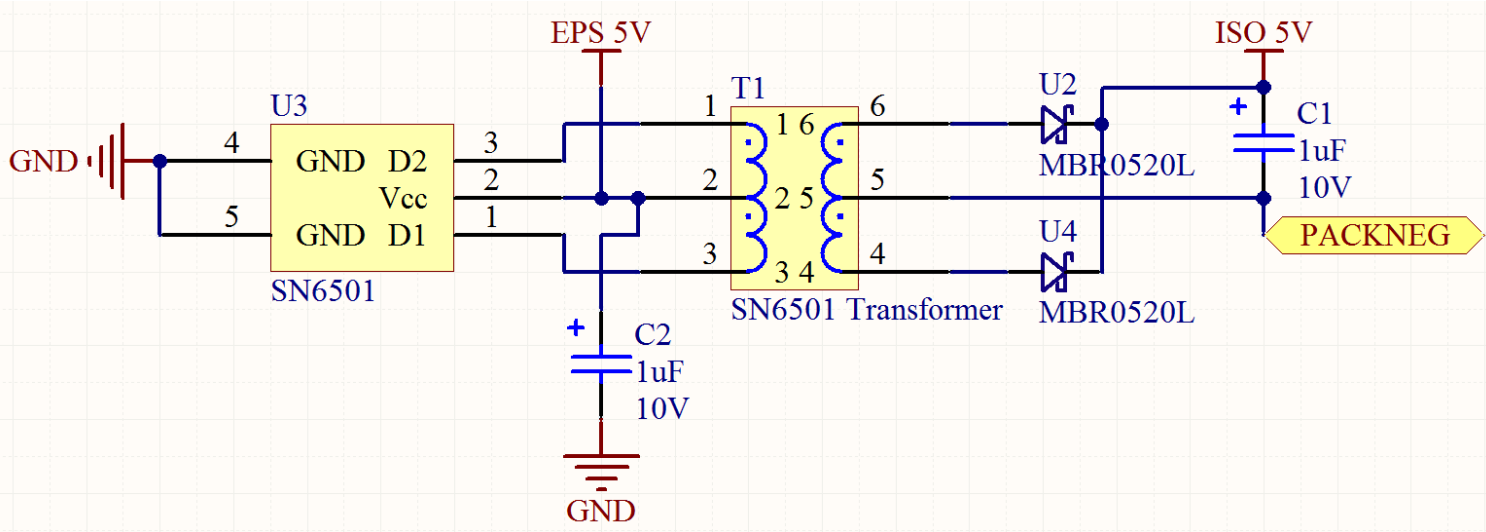

Figure 19: Voltage Isolation Circuit

The SN6501 uses an external transformer and a rectifying circuit to isolate a given voltage [41]. The overall circuit converts a DC voltage to $A C$ voltage, applies the $A C$ voltage to a transformer, and then rectifies the transformed $A C$ voltage back to DC voltage at a new reference potential. Even if a battery is discharged below $3 \mathrm{~V}$, the $12 \mathrm{C}$ isolators will still operate, providing telemetry throughout the full battery voltage range.

The MBR0520L Schottky diode was used as the rectifying diode. The MBR0520L has a forward voltage of less than $0.385 \mathrm{~V}$ [42]. This is beneficial because less energy is lost during the rectifying process as compared to a typical diode's forward voltage of $0.7 \mathrm{~V}$. The EPS should draw only enough energy as needed to operate so that more energy can be given to the rest of the systems on the satellite. The transformer's coil ratio is tuned so that the rectified output can be immediately used to power the $12 \mathrm{C}$ isolator. 


\subsubsection{Battery Balancing}

Due to variances in the battery production process, each battery charges and discharges at a different rate. Over time, this may result in a battery deadlock, where one battery in a pack is in overvoltage and another battery is in undervoltage. In this case, the pack cannot charge due to the battery in overvoltage disabling the charge path and the pack cannot discharge due to the battery in undervoltage disabling the discharge path. The battery pack is rendered useless until self-discharge brings the battery in overvoltage down to a normal voltage. A battery balancing circuit was added to the battery module to minimize the chance of a battery deadlock.

The battery balancing circuit chosen for the reference implementation consists of a Zener diode and a resistor. The battery balancing circuit is shown in Figure 20.

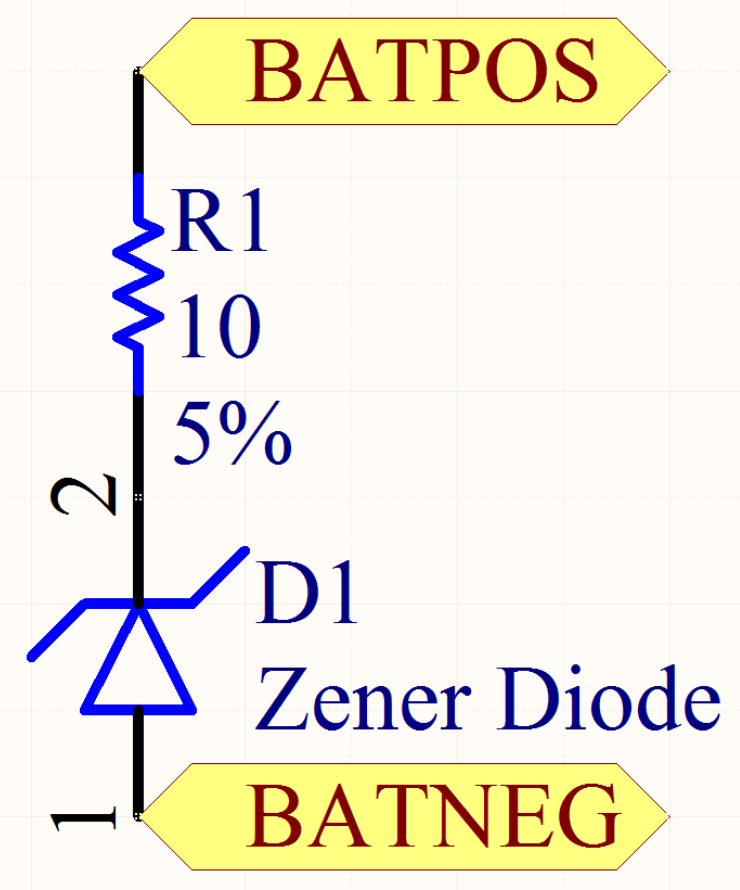

Figure 20: Battery Balancing Circuit 
The Zener diode is chosen so that the diode is in breakdown mode before the overvoltage limit is reached, at $4.35 \mathrm{~V}$. In the reference implementation, the Zener diode chosen is the KDZTR3.9B, with a minimum Zener voltage of $3.9 \mathrm{~V}$ and a maximum Zener voltage of 4.4 V. If the Zener voltage is too low, then the balancing circuit activates early and reduces the overall battery module efficiency, but if the Zener voltage is too high, the balancing circuit activates too late and could result in the batteries deviating from the balanced state much faster. The KDZTR3.9B typically has a Zener voltage of about $4.15 \mathrm{~V}$, which is perfect for the reference implementation.

The series resistor is used as a current limit, so the maximum balancing current is 17.5 $\mathrm{mA}$. This is much larger compared to a lithium polymer self-discharge rate of $5 \%$ a month, or about $0.173 \mathrm{~mA}$ with a battery capacity of $2500 \mathrm{mAh}$. The battery balancing circuit may not prevent battery deadlock situations, but if they do occur, the balancing circuit should bring the pack out of deadlock much faster than it would be if the EPS had to wait for the batteries to self-discharge.

\subsection{Payload Module}

The reference implementation of the payload module prototype consists of the voltage regulator, telemetry circuit, load protection and control circuit, and the GPIO expander. Figure 21 shows the payload module prototype. 


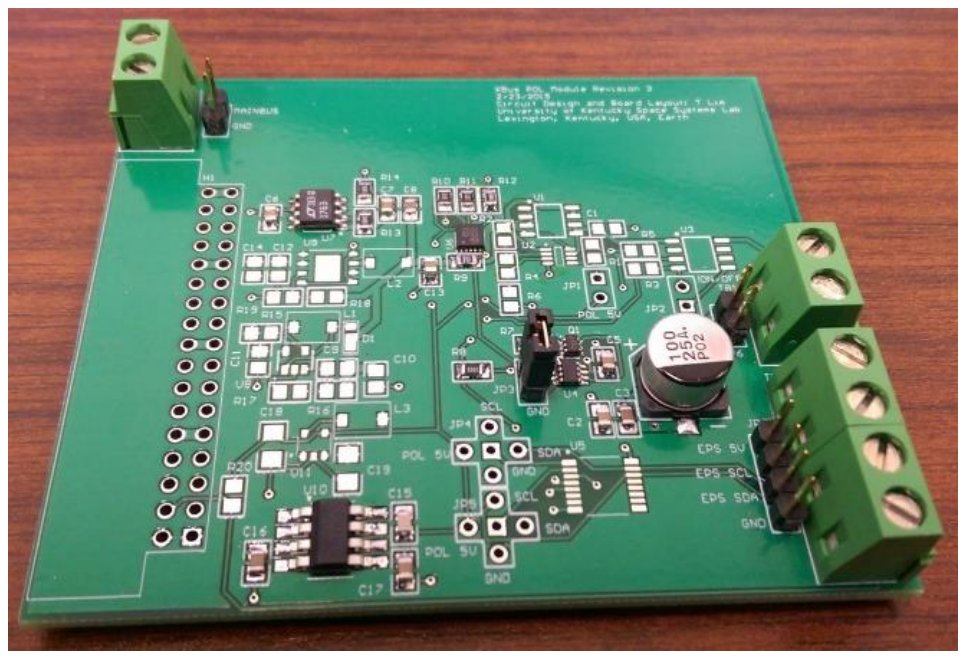

Figure 21: Payload Module Prototype

\subsubsection{Voltage Regulator}

The voltage regulator is used to supply usable energy to the payload connected to the module. For the reference implementation, three voltage regulators were chosen: one linear regulator, one step-up converter, and one step-down converter. The regulators must be adjustable and able to handle an output current of $0.5 \mathrm{~A}$ for the linear regulator and $1 \mathrm{~A}$ for the switching regulators. The output current requirements were based on the EPS used in KySat-2.

The linear regulator chosen for the reference implementation is the LT1763 from Linear Technology. The LT1763 circuit is shown in Figure 22. 


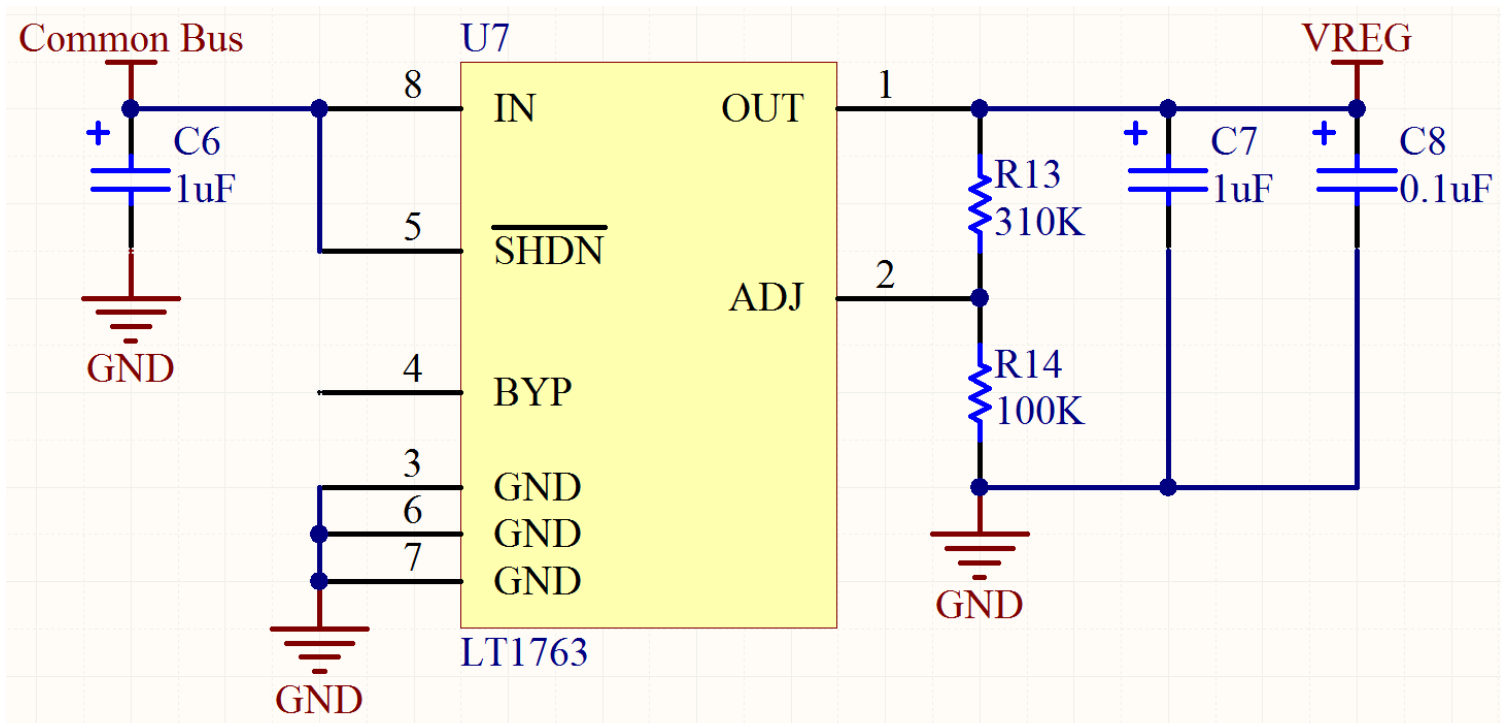

Figure 22: Linear Regulator Circuit

The LT1763 can supply $500 \mathrm{~mA}$ of current and has a dropout voltage of $300 \mathrm{mV}$. Its input voltage range is $1.8 \mathrm{~V}$ to $20 \mathrm{~V}$ [43]. It is an adjustable regulator so the feedback resistors can be changed to manipulate the output voltage. The output voltage will adjust until the voltage seen on the ADJ pin is $1.22 \mathrm{~V}$.

The step-up converter chosen for the reference implementation is the SC4503 from Semtech Corporation. The step-up converter circuit is shown in Figure 23. 


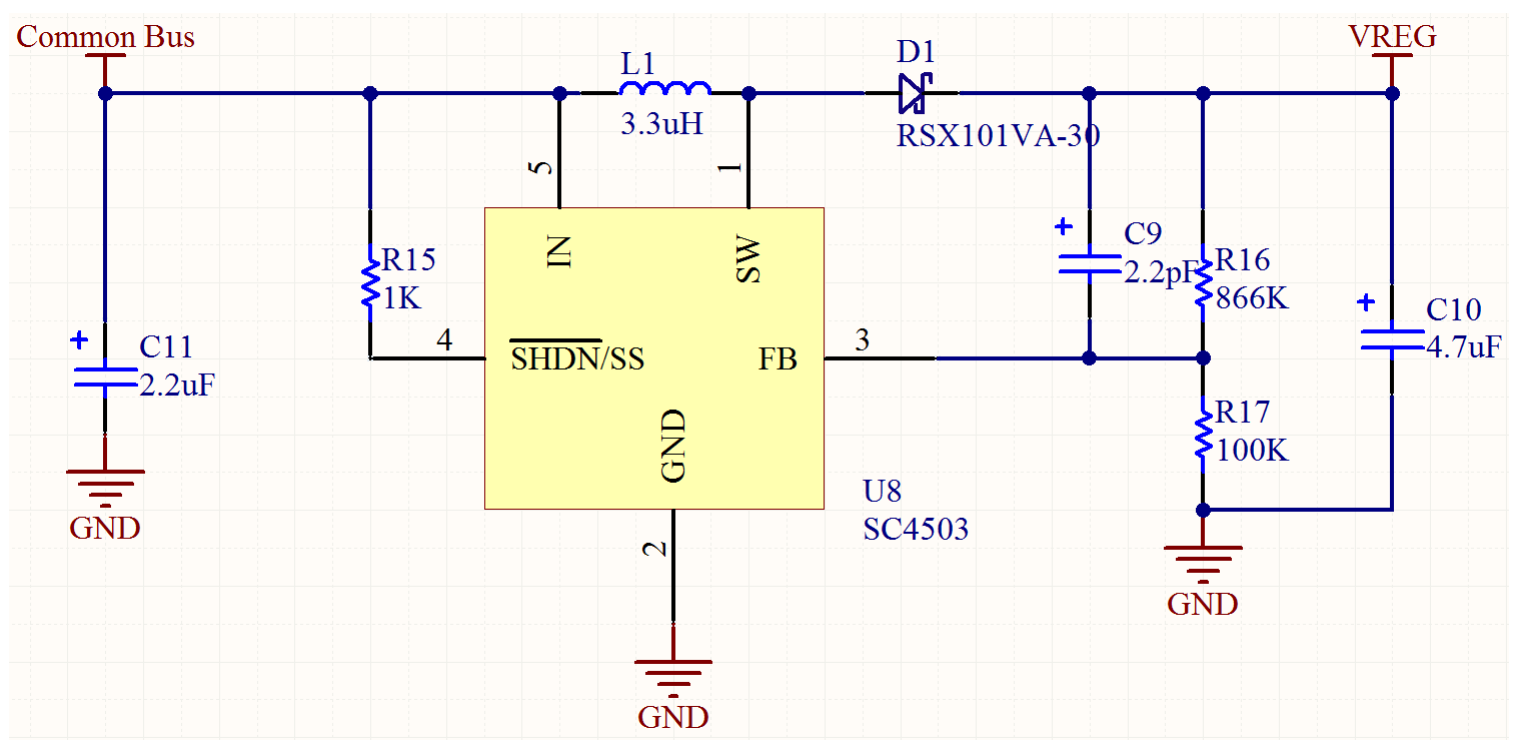

Figure 23: Step-up Converter Circuit

The SC4503 can supply $1.4 \mathrm{~A}$ and has a constant switching frequency of $1.3 \mathrm{MHz}$ [44]. Its input voltage range is $2.5 \mathrm{~V}$ to $20 \mathrm{~V}$. The maximum output voltage is $27 \mathrm{~V}$. The output voltage will be adjusted until $1.25 \mathrm{~V}$ is seen on the FB pin.

The RSX101VA-30 is a Schottky diode used as a rectifying diode. Its forward voltage is $0.43 \mathrm{~V}$ and can handle a reverse voltage of up to $30 \mathrm{~V}$ [45]. The diode has a maximum average rectified forward current of $1 \mathrm{~A}$.

The step-down converter chosen for the reference implementation is the ST1S10 from STMicroelectronics. The step-down converter circuit is shown in Figure 24. 


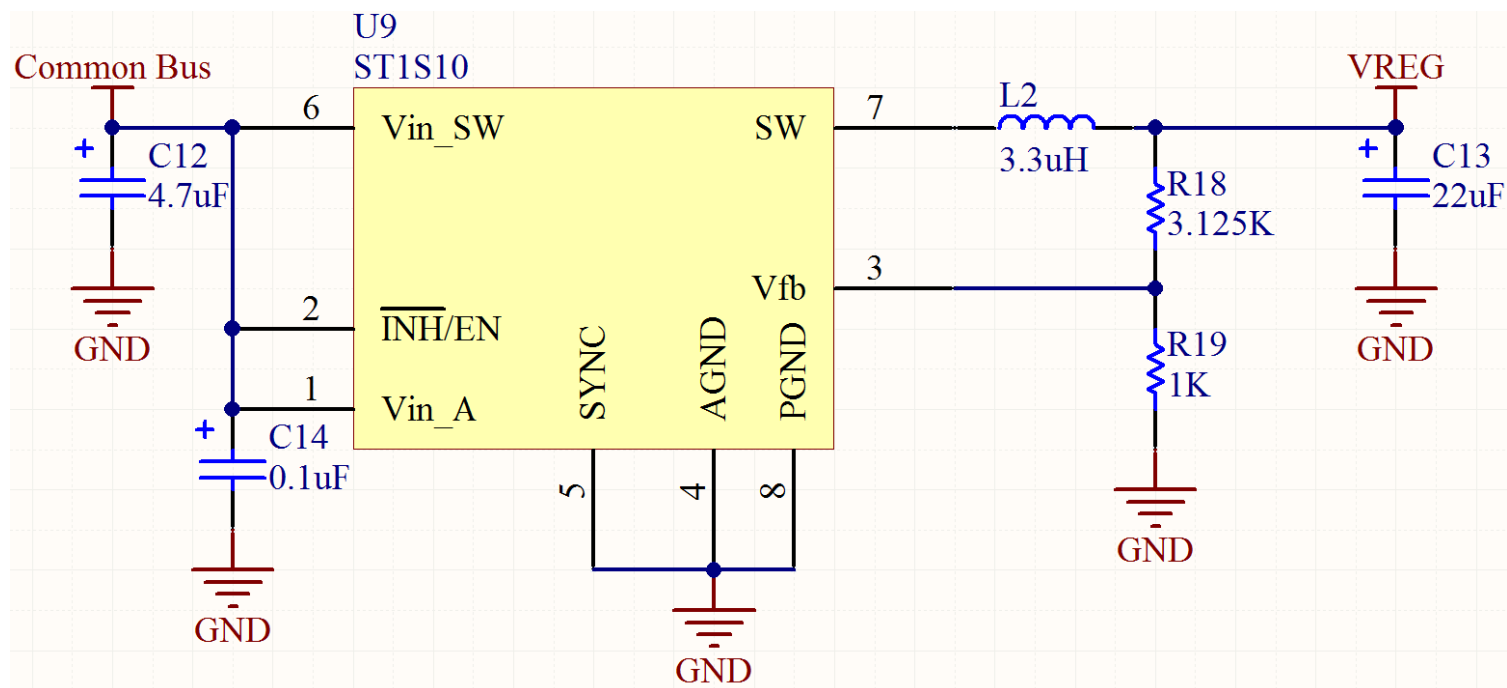

Figure 24: Step-down Converter Circuit

The ST1S10 can supply $3 \mathrm{~A}$ and has a synchronizable switching frequency from $400 \mathrm{kHz}$ up to $1.2 \mathrm{MHz}$ [46]. Its input voltage range is $2.5 \mathrm{~V}$ to $18 \mathrm{~V}$. The output voltage range is 0.8 $\mathrm{V}$ to its input voltage multiplied by 0.85 . The output voltage will be adjusted until $0.8 \mathrm{~V}$ is seen on the $\mathrm{Vfb}$ pin.

\subsubsection{Telemetry}

The payload telemetry circuit gives status information about the payload to the EPS. The features required for the telemetry circuit are the ability to gather voltage and current telemetry, an $\mathrm{I} 2 \mathrm{C}$ interface, and a selectable $\mathrm{I} 2 \mathrm{C}$ address. The telemetry circuit chosen for use on the reference implementation is the PAC1710 from SMSC. The telemetry circuit is shown in Figure 25. 


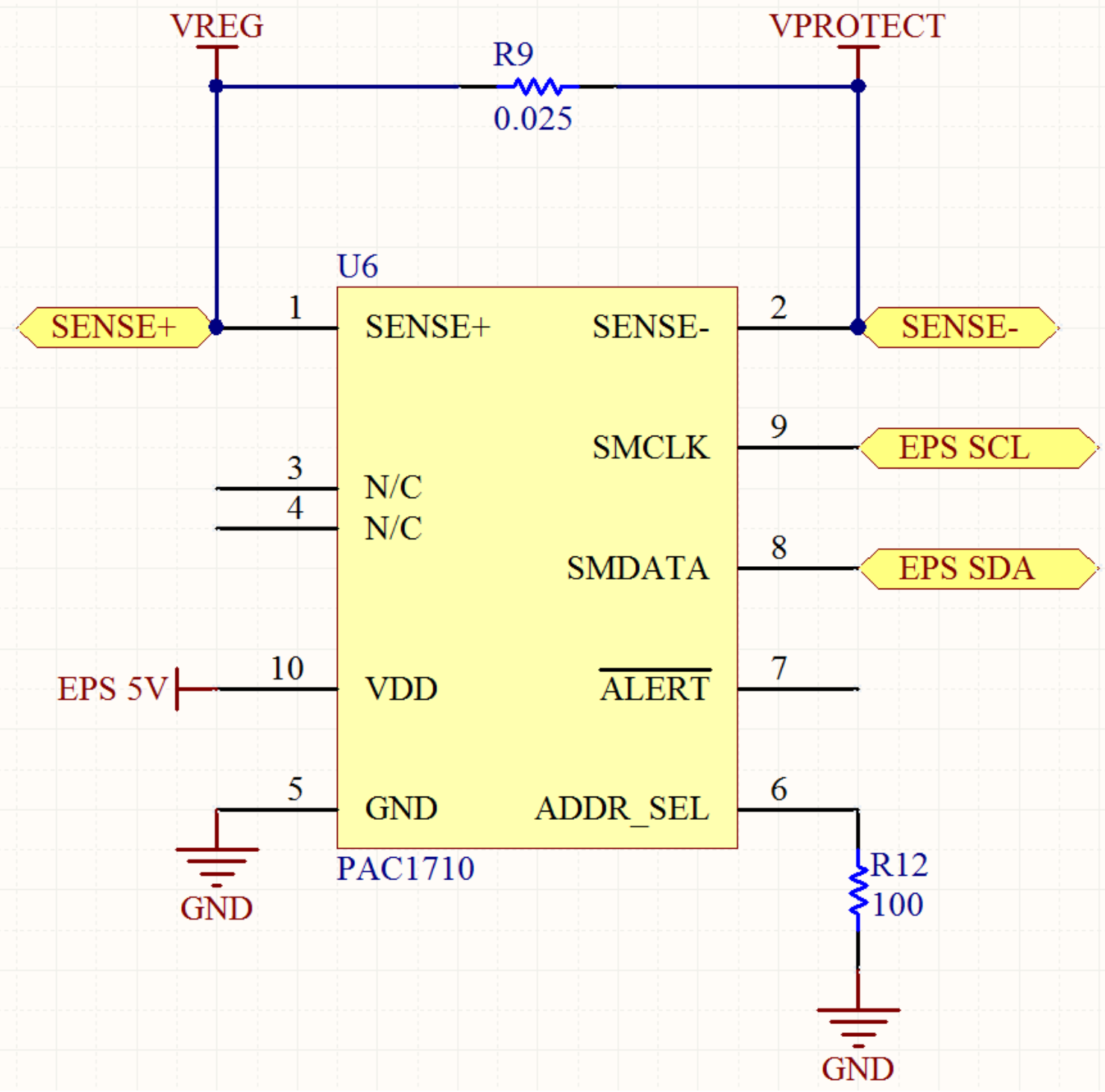

Figure 25: Telemetry Circuit

The PAC1710 is an integrated circuit designed to measure voltage and current. The IC can measure voltage and current up to a resolution of eleven bits [47]. The input power supply range is $3 \mathrm{~V}$ to $5.5 \mathrm{~V}$. The PAC1710 can measure a voltage ranging from $0 \mathrm{~V}$ to 40 V. The differential voltage between the SENSE pins can range from $-80 \mathrm{mV}$ to $80 \mathrm{mV}$, allowing the IC to also report the direction of current flow. 
The $12 \mathrm{C}$ address is user-selectable through the ADDR_SEL pin. The address is determined by the resistor value connected to the pin. The PAC1710 can be set to one of sixteen possible addresses.

The PAC1710 is powered from an external power supply. With a fairly standard input power supply range it is very likely the PAC1710 can piggyback off of a voltage regulator used for a payload. KySat-2 contained a $3.3 \mathrm{~V}$ rail and a $5 \mathrm{~V}$ rail, both of which would be compatible with the PAC1710.

\subsubsection{Load Protection and Control}

Load protection is necessary to turn off the payload when a fault condition occurs. Fault conditions include overvoltage, undervoltage, and overcurrent. The load protection circuit for the reference implementation is based on the LTC4361 from Linear Technology. The load protection circuit is shown in Figure 26. 


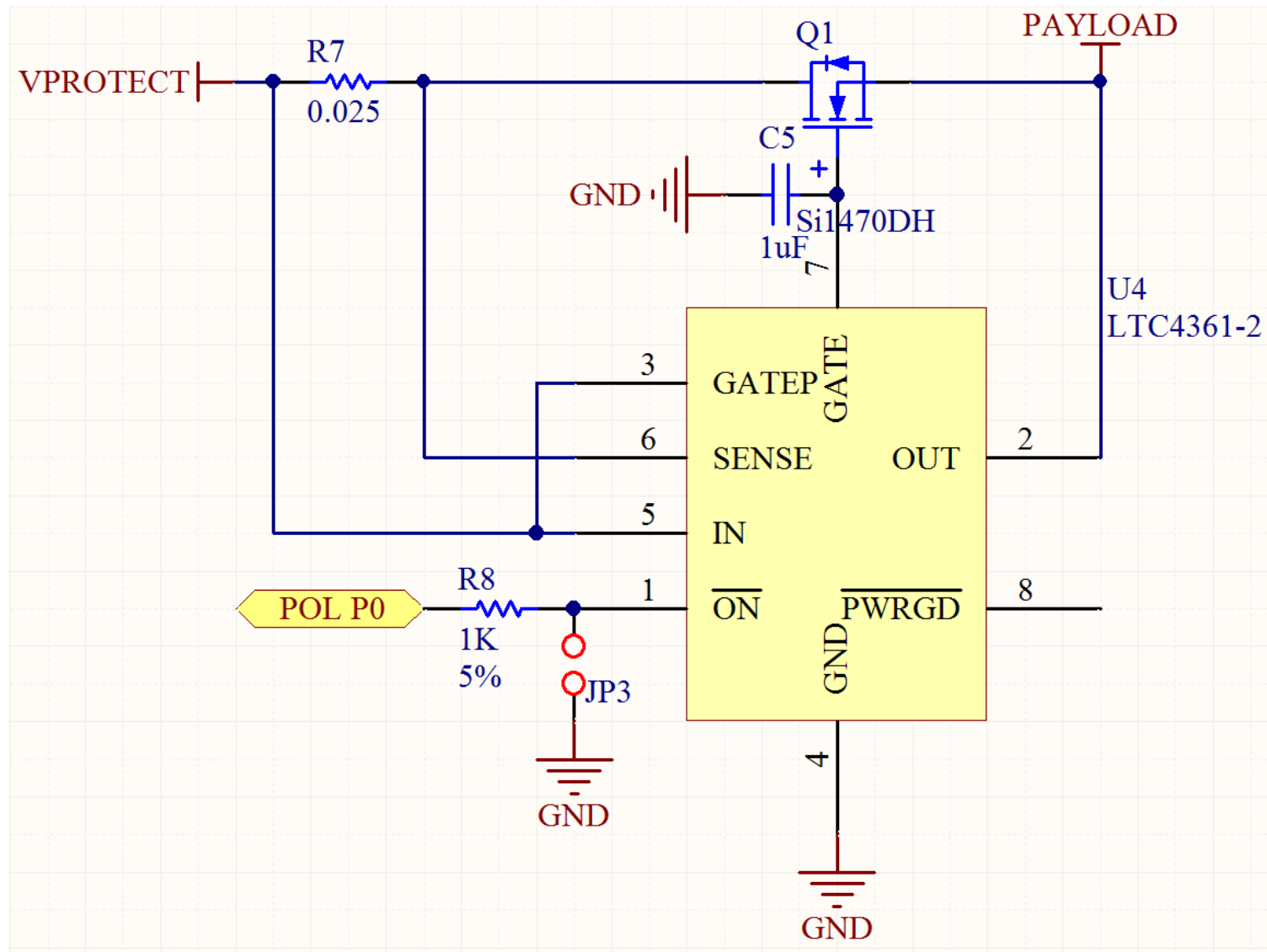

Figure 26: Load Protection and Control Circuit

The LTC4361 provides protection for payloads with a voltage range of $2.5 \mathrm{~V}$ to $5.5 \mathrm{~V}$ [48]. If the IC detects a transient in the input power supply the LTC4361 will remove the payload from the power supply until the transient passes. The LTC4361 protects the payload from a transient up to $80 \mathrm{~V}$. The undervoltage lockout is set to $2.1 \mathrm{~V}$ and the overvoltage lockout is set to $5.8 \mathrm{~V}$.

The limited power supply range is acceptable in the reference implementation because it was designed to protect payloads similar to the ones in KySat-2. The payloads in KySat-2 
used either a $3.3 \mathrm{~V}$ power supply or a $5 \mathrm{~V}$ power supply, both within the protection range of the LTC4361.

A capacitor was added to the GATE pin so that the inrush current to the payload is limited when the payload is turned on.

The current sense resistor is used so that the LTC4361 can detect an overcurrent condition. A $0.025 \Omega$ resistor is used so that the effect of the current sense resistor on the payload's power supply is minimized. Once the LTC4361 detects a voltage difference of $50 \mathrm{mV}$ between the IN and SENSE pins, the MOSFET is turned off and the power supply disconnected from the payload. At the given sense resistor value, the current limit is $2 \mathrm{~A}$.

After a fault condition, the LTC4361 will automatically restart the payload after a $130 \mathrm{~ms}$ delay. There is another version of the LTC4361 that will keep the payload off after a fault condition if that is the desired behavior for the mission.

The LTC4361 also features an enable pin so the payload can be externally controlled. This is useful during EPS bootup because payloads can be individually turned on rather than all at once, allowing critical subsystems to be powered first.

The MOSFET used in the payload protection circuit is the Si1470DH. The Si1470DH is an $\mathrm{N}$-channel MOSFET that connects or disconnects the payload to its power supply. It has 
a maximum drain-source voltage of $30 \mathrm{~V}$ and a current rating of $4 \mathrm{~A}$ [49]. Its threshold voltage is no greater than $1.6 \mathrm{~V}$, with a maximum on-state resistance of $0.095 \Omega$ at a $\mathrm{V}_{\mathrm{gs}}$ of $2.5 \mathrm{~V}$.

For a payload outside of the LTC4361's protection range, an alternative circuit must be used. The alternative payload protection and control circuit is based on the LTC4365 from Linear Technology and the FPF2700 from Fairchild Semiconductor. The alternative payload protection circuit is shown in Figure 27. 


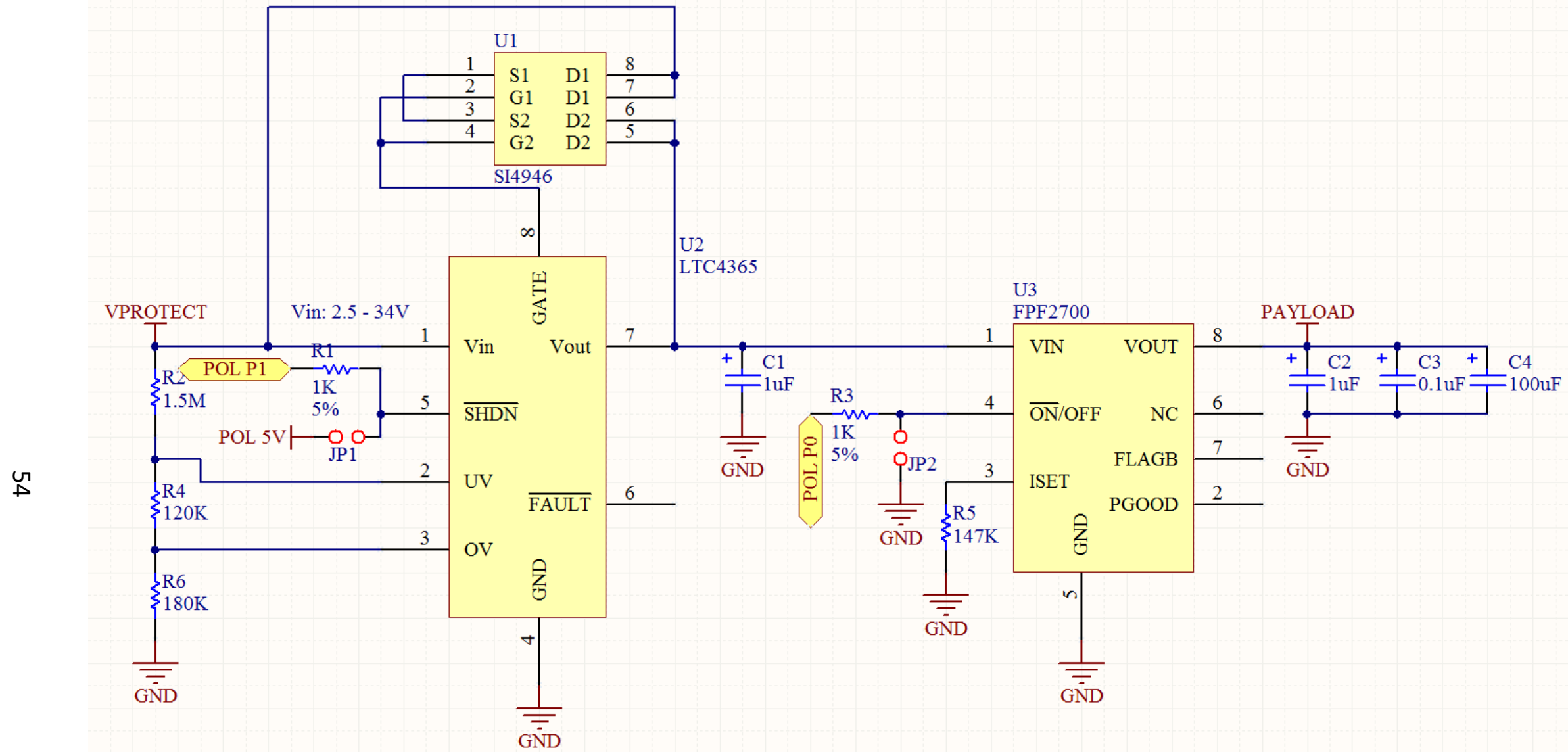

Figure 27: Alternative Payload Protection and Control Circuit 
The alternative circuit functions similarly to the LTC4361 circuit but has an adjustable protection voltage range.

The first half of the protection circuit is the LTC4365. The LTC4365 handles overvoltage and undervoltage protection for the payload. The IC controls a pair of N-channel MOSFETs to connect the payload to its power supply. The LTC4365 has an operating voltage supply range of $2.5 \mathrm{~V}$ to $34 \mathrm{~V}$, with overvoltage protection up to $60 \mathrm{~V}$ [50]. An external resistor divider is used to set the overvoltage and undervoltage limits.

When the UV pin sees a voltage below $0.5 \mathrm{~V}$, the IC will disconnect the payload from its power supply. Once the voltage on UV rises above $0.525 \mathrm{~V}$ and $36 \mathrm{~ms}$ have passed, the payload will be reconnected with the power supply.

When the OV pin sees a voltage above $0.5 \mathrm{~V}$, the IC will disconnect the payload from its power supply. Once the voltage on OV falls below $0.475 \mathrm{~V}$ and $36 \mathrm{~ms}$ have passed, the payload will be reconnected with the power supply.

The LTC4365 contains a SHDN pin that can be used to remove the payload from the power supply by an external controller. 
The Si4946 is the dual N-channel MOSFET IC used with the LTC4365. It has a maximum $\mathrm{V}_{\mathrm{ds}}$ of $60 \mathrm{~V}$ with a continuous current rating of $5.5 \mathrm{~A}$ [51]. Its threshold voltage is typically $2.4 \mathrm{~V}$ and has a maximum on-state resistance of $0.052 \Omega$ at a $\mathrm{V}_{\mathrm{gs}}$ of $4.5 \mathrm{~V}$.

The other half of the protection circuit is the FPF2700. The FPF2700 handles overcurrent protection for the payload. The IC contains an internal N-channel MOSFET to connect the payload to its power supply. The FPF2700 has an input voltage range of $2.8 \mathrm{~V}$ to $36 \mathrm{~V}$ [52], which is very similar to the voltage range of the LTC4365. An external resistor is used to set the current limit. The minimum current limit can range from $0.4 \mathrm{~A}$ to $2 \mathrm{~A}$. The $20 \%$ current limit tolerance sets the maximum current limit to $3 \mathrm{~A}$.

In an overcurrent condition, the FPF2700 clamps the load current so that it cannot rise above the current limit set by the external resistor. If the condition lasts for longer than the FPF2700's blanking period, the payload is disconnected from its power supply. The FPF2700 will wait 127.5 ms before reconnecting the payload to the power source. The FPF2700 also has a thermal shutdown feature if the circuit overheats.

The FPF2700 contains an ON pin that can be used to control the payload from an external device. The FPF2700 combined with the LTC4365 has virtually the same functionality as the LTC4361, but with a larger input voltage range and more components. The majority of CubeSat payloads can be protected with at least one of the two circuits. 


\subsubsection{GPIO Expander}

The GPIO expander is used to control the payload protection circuit. Instead of directly connecting a GPIO pin from the EPS microcontroller to the protection circuit, the microcontroller can just send a command to the GPIO expander to control the payload.

The GPIO expander chosen for use in the reference implementation is the PCA9672 from NXP Semiconductors. The GPIO expander circuit is shown in Figure 28.

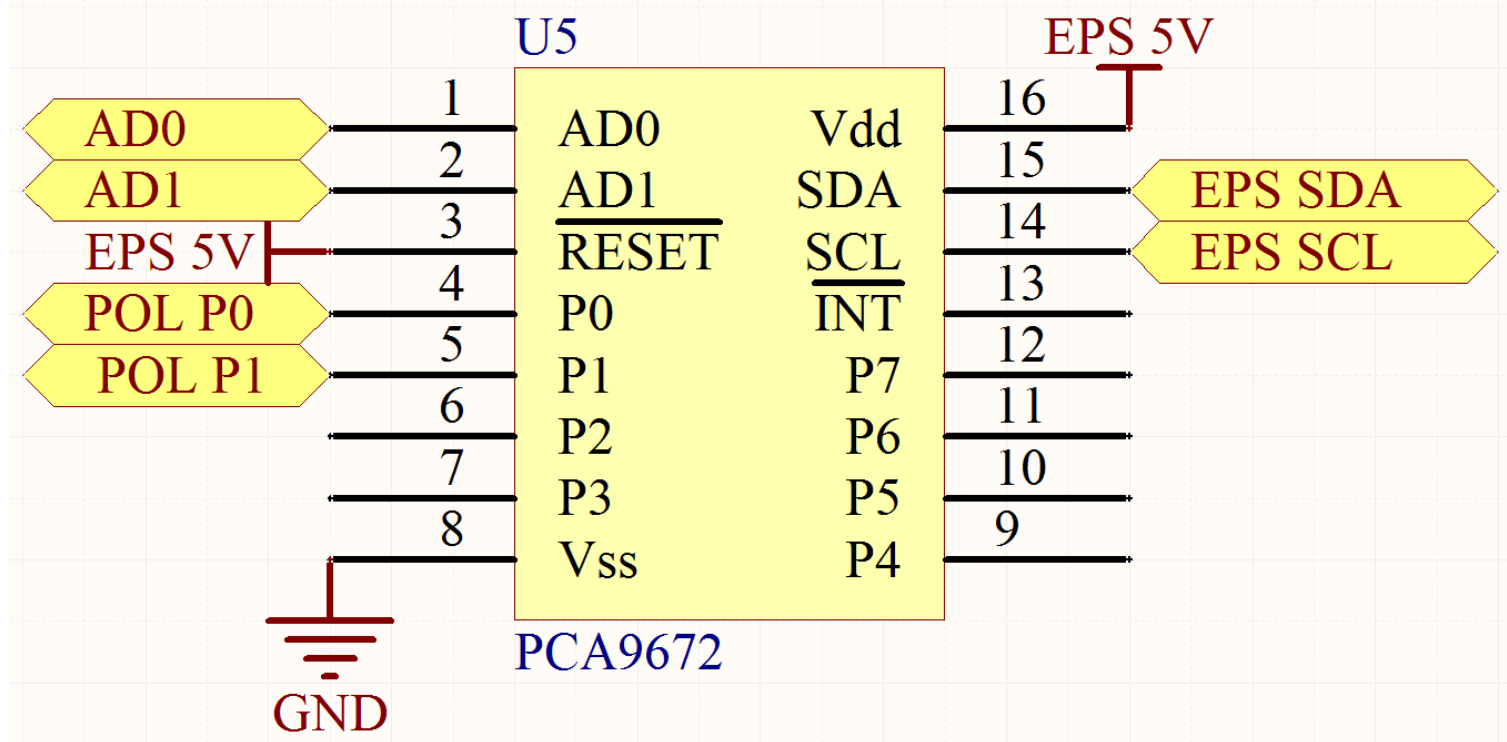

Figure 28: GPIO Expander Circuit

The GPIO expander must be able to communicate through $12 \mathrm{C}$ and have user-selectable addresses. It also needs to have at least four GPIO pins. This requirement was made because the reference implementation is based on KySat-2's EPS, which had four controllable payloads on the satellite. 
The PCA9672 contains eight GPIO pins that can sink up to $25 \mathrm{~mA}$ of current [53]. The IC can be assigned one of sixteen different $12 \mathrm{C}$ addresses. Its operating supply voltage range is $2.3 \mathrm{~V}$ to $5.5 \mathrm{~V}$.

Like the payload telemetry circuit, the GPIO expander is powered by an external power supply. The PCA9672 has a fairly standard input power supply range, so it can probably piggyback off of a payload's voltage regulator. KySat- 2 contained a $3.3 \mathrm{~V}$ rail and a $5 \mathrm{~V}$ rail, both of which would be compatible with the PCA9672. 


\subsection{Experimental Procedures}

The experimental testing results are summarized in Table 2. SM designates a test that used a solar module, BM designates a test that used a battery module, and PM designates a test that used a payload module. A plus sign indicates a module used in series with another module, and a comma indicates a test that used multiple module types connected in parallel. 
Table 2: Prototype Testing Results

\begin{tabular}{|c|c|c|c|c|c|}
\hline $\begin{array}{l}\text { Module } \\
\text { Type }\end{array}$ & Test & Measurement & Expectation & Actual & Notes \\
\hline SM & $\begin{array}{c}\text { Normal } \\
\text { Operation }\end{array}$ & Load Voltage & $3.2 \mathrm{~V}$ & $\begin{array}{c}3.171 \\
\mathrm{~V}\end{array}$ & $\begin{array}{c}3.2 \text { V } 0.06 \mathrm{~A} \\
\text { input, } 51 \Omega \text { load }\end{array}$ \\
\hline SM & $\begin{array}{c}\text { Normal } \\
\text { Operation }\end{array}$ & Load Voltage & $10 \mathrm{~V}$ & $9.95 \mathrm{~V}$ & $\begin{array}{c}10 \mathrm{~V} 0.19 \mathrm{~A} \\
\text { input, } 51 \Omega \text { load }\end{array}$ \\
\hline SM & $\begin{array}{c}\text { Reverse Solar } \\
\text { Cell } \\
\text { Protection }\end{array}$ & Load Voltage & $0 \mathrm{~V}$ & $\begin{array}{c}0.013 \\
\mathrm{mV}\end{array}$ & $\begin{array}{c}3 \mathrm{~V} \text { input, } 51 \Omega \\
\text { load }\end{array}$ \\
\hline SM & $\begin{array}{c}\text { Reverse Solar } \\
\text { Cell } \\
\text { Protection }\end{array}$ & Load Voltage & $0 \mathrm{~V}$ & $\begin{array}{c}0.013 \\
\mathrm{mV}\end{array}$ & $\begin{array}{c}10 \mathrm{~V} \text { input, } 51 \Omega \\
\text { load }\end{array}$ \\
\hline SM & $\begin{array}{c}\text { Reverse Solar } \\
\text { Cell } \\
\text { Protection }\end{array}$ & Load Voltage & $0 \mathrm{~V}$ & $\begin{array}{c}0.013 \\
\mathrm{mV}\end{array}$ & $\begin{array}{c}20 \mathrm{~V} \text { input, } 51 \Omega \\
\text { load }\end{array}$ \\
\hline SM & $\begin{array}{l}\text { Voltage } \\
\text { Telemetry }\end{array}$ & Input Voltage & $4 \mathrm{~V}$ & $\begin{array}{c}3.943 \\
V\end{array}$ & $\begin{array}{c}4 \mathrm{~V} 0.08 \mathrm{~A} \text { input, } \\
51 \Omega \text { load }\end{array}$ \\
\hline SM & $\begin{array}{c}\text { Current } \\
\text { Telemetry } \\
\end{array}$ & Input Current & $0.08 \mathrm{~A}$ & $\begin{array}{c}0.085 \\
\mathrm{~A} \\
\end{array}$ & $\begin{array}{c}4 \mathrm{~V} 0.08 \mathrm{~A} \text { input, } \\
51 \Omega \text { load }\end{array}$ \\
\hline BM & $\begin{array}{l}\text { Voltage } \\
\text { Telemetry }\end{array}$ & $\begin{array}{l}\text { Battery } \\
\text { Voltage }\end{array}$ & $3.95 \mathrm{~V}$ & $\begin{array}{c}3.923 \\
V\end{array}$ & \\
\hline BM & $\begin{array}{c}\text { Current } \\
\text { Telemetry }\end{array}$ & $\begin{array}{c}\text { Battery Charge } \\
\text { Current }\end{array}$ & $0.6 \mathrm{~A}$ & $0.66 \mathrm{~A}$ & $\begin{array}{c}4.3 \mathrm{~V} \text { input, } 0.6 \\
\mathrm{~A} \text { input }\end{array}$ \\
\hline BM & $\begin{array}{l}\text { Undervoltage } \\
\text { Protection }\end{array}$ & Voltage Limit & $2.6 \mathrm{~V}$ & $2.58 \mathrm{~V}$ & $\begin{array}{c}3.9 \mathrm{~V} \text { initial } \\
\text { voltage, } 0.05 \mathrm{~A} \\
\text { discharge } \\
\text { current }\end{array}$ \\
\hline BM & $\begin{array}{l}\text { Overvoltage } \\
\text { Protection }\end{array}$ & Voltage Limit & $4.35 \mathrm{~V}$ & $4.37 \mathrm{~V}$ & $\begin{array}{c}3.5 \mathrm{~V} \text { initial } \\
\text { voltage, } 5 \mathrm{~V} \\
\text { input, } 1 \mathrm{~A} \text { charge } \\
\text { current }\end{array}$ \\
\hline BM & $\begin{array}{l}\text { Discharge } \\
\text { Overcurrent } \\
\text { Protection }\end{array}$ & Current Limit & $1.45 \mathrm{~A}$ & $1.23 \mathrm{~A}$ & $\begin{array}{c}1 \mathrm{~A} \text { initial } \\
\text { discharge } \\
\text { current }\end{array}$ \\
\hline BM & $\begin{array}{l}\text { Charge } \\
\text { Overcurrent } \\
\text { Protection }\end{array}$ & Current Limit & $1.45 \mathrm{~A}$ & $1.34 \mathrm{~A}$ & $\begin{array}{c}1 \text { A initial charge } \\
\text { current }\end{array}$ \\
\hline BM & $\begin{array}{l}\text { Charge } \\
\text { Balancing }\end{array}$ & $\begin{array}{l}\text { Battery } \\
\text { Voltage }\end{array}$ & $4.1 \mathrm{~V}$ & $3.8 \mathrm{~V}$ & $\begin{array}{c}4.15 \mathrm{~V} \text { initial } \\
\text { voltage, } 30 \\
\text { minute runtime }\end{array}$ \\
\hline
\end{tabular}


Table 2: Prototype Testing Results (continued)

\begin{tabular}{|c|c|c|c|c|c|}
\hline PM & $\begin{array}{c}\text { Normal } \\
\text { Operation }\end{array}$ & Load Voltage & $5 \mathrm{~V}$ & $4.95 \mathrm{~V}$ & $\begin{array}{c}7 \vee 0.1 \mathrm{~A} \text { input, } \\
51 \Omega \text { load }\end{array}$ \\
\hline PM & Load Control & Load Voltage & $5 \mathrm{~V}$ & $4.95 \mathrm{~V}$ & $\begin{array}{l}7 \vee 0.1 \mathrm{~A} \text { input, } \\
51 \Omega \text { load }\end{array}$ \\
\hline PM & $\begin{array}{l}\text { Voltage } \\
\text { Telemetry }\end{array}$ & Load Voltage & $5 \mathrm{~V}$ & $\begin{array}{c}4.953 \\
\mathrm{~V}\end{array}$ & $\begin{array}{c}7 \mathrm{~V} 0.1 \mathrm{~A} \text { input, } \\
51 \Omega \text { load }\end{array}$ \\
\hline PM & $\begin{array}{c}\text { Current } \\
\text { Telemetry }\end{array}$ & Load Current & $0.1 \mathrm{~A}$ & $\begin{array}{c}0.0984 \\
\mathrm{~A}\end{array}$ & $\begin{array}{c}7 \mathrm{~V} 0.1 \mathrm{~A} \text { input, } \\
51 \Omega \text { load }\end{array}$ \\
\hline PM & $\begin{array}{l}\text { Normal } \\
\text { Operation }\end{array}$ & Load Voltage & $3.3 \mathrm{~V}$ & $3.13 \mathrm{~V}$ & $\begin{array}{l}12 \mathrm{~V} 0.13 \mathrm{~A} \\
\text { input, } 8.1 \Omega \\
\text { electronic load }\end{array}$ \\
\hline PM & Load Control & Load Voltage & $3.3 \mathrm{~V}$ & $3.13 \mathrm{~V}$ & $\begin{array}{c}12 \mathrm{~V} 0.13 \mathrm{~A} \\
\text { input, } 8.1 \Omega \\
\text { electronic load }\end{array}$ \\
\hline PM & $\begin{array}{l}\text { Voltage } \\
\text { Telemetry }\end{array}$ & Load Voltage & $3.3 \mathrm{~V}$ & $\begin{array}{c}3.315 \\
V\end{array}$ & $\begin{array}{c}12 \mathrm{~V} 0.13 \mathrm{~A} \\
\text { input, } 27.7 \Omega \\
\text { electronic load }\end{array}$ \\
\hline PM & $\begin{array}{l}\text { Current } \\
\text { Telemetry }\end{array}$ & Load Current & $0.119 \mathrm{~A}$ & $\begin{array}{c}0.118 \\
\mathrm{~A}\end{array}$ & $\begin{array}{c}12 \mathrm{~V} 0.13 \mathrm{~A} \\
\text { input, } 27.7 \Omega \\
\text { electronic load }\end{array}$ \\
\hline SM, PM & $\begin{array}{c}\text { Normal } \\
\text { Operation }\end{array}$ & Load Current & $0.4 \mathrm{~A}$ & $\begin{array}{c}0.399 \\
A\end{array}$ & $\begin{array}{l}9 \vee 1 \mathrm{~A} \text { input, } 0.4 \\
\text { A electronic load }\end{array}$ \\
\hline $\begin{array}{c}\text { BM + } \\
\text { BM, PM }\end{array}$ & $\begin{array}{c}\text { Normal } \\
\text { Operation }\end{array}$ & Load Current & $0.4 \mathrm{~A}$ & $\begin{array}{c}0.398 \\
A\end{array}$ & $\begin{array}{c}0.4 \mathrm{~A} \text { electronic } \\
\text { load }\end{array}$ \\
\hline $\begin{array}{c}\mathrm{BM}+ \\
\mathrm{BM}, \mathrm{PM}\end{array}$ & $\begin{array}{l}\text { Undervoltage } \\
\text { Protection }\end{array}$ & Verification & $\mathrm{Y}$ & $Y$ & $\begin{array}{c}0.4 \text { A electronic } \\
\text { load, test ran } \\
\text { until } 0 \text { A load } \\
\text { current }\end{array}$ \\
\hline $\begin{array}{c}\text { SM, BM } \\
+ \text { BM }\end{array}$ & $\begin{array}{c}\text { Normal } \\
\text { Operation }\end{array}$ & $\begin{array}{c}\text { Battery Charge } \\
\text { Current }\end{array}$ & $1.0 \mathrm{~A}$ & $1.0 \mathrm{~A}$ & $9 \mathrm{~V} 1 \mathrm{~A}$ input \\
\hline $\begin{array}{c}\text { SM, BM } \\
+\mathrm{BM}\end{array}$ & $\begin{array}{l}\text { Charge } \\
\text { Balancing }\end{array}$ & $\begin{array}{l}\text { Battery } \\
\text { Voltage }\end{array}$ & $8.2 \mathrm{~V}$ & $8.24 \mathrm{~V}$ & $\begin{array}{c}8.3 \mathrm{~V} \text { initial } \\
\text { voltage, } 5 \\
\text { minute runtime }\end{array}$ \\
\hline $\begin{array}{c}\text { SM, BM } \\
+ \text { BM }\end{array}$ & $\begin{array}{l}\text { Overvoltage } \\
\text { Protection }\end{array}$ & Verification & $\mathrm{Y}$ & $\mathrm{Y}$ & $\begin{array}{l}9 \mathrm{~V} 1 \mathrm{~A} \text { input, } \\
\text { test ran until } 0 \mathrm{~A} \\
\text { input current }\end{array}$ \\
\hline $\begin{array}{c}\text { SM, BM } \\
+ \text { BM, } \\
\text { PM }\end{array}$ & $\begin{array}{l}\text { Normal } \\
\text { Operation }\end{array}$ & $\begin{array}{c}\text { Battery Charge } \\
\text { Current }\end{array}$ & $0.6 \mathrm{~A}$ & $0.6 \mathrm{~A}$ & $\begin{array}{l}9 \vee 1 \mathrm{~A} \text { input, } 0.4 \\
\mathrm{~A} \text { electronic load }\end{array}$ \\
\hline
\end{tabular}


Table 2: Prototype Testing Results (continued)

\begin{tabular}{|c|c|c|c|c|c|}
\hline $\begin{array}{c}\text { SM, BM } \\
\text { + BM, } \\
\text { PM }\end{array}$ & $\begin{array}{c}\text { Normal } \\
\text { Operation }\end{array}$ & $\begin{array}{c}\text { Battery } \\
\text { Discharge } \\
\text { Current }\end{array}$ & $0.2 \mathrm{~A}$ & $0.2 \mathrm{~A}$ & $\begin{array}{c}9 \mathrm{~V} 0.2 \mathrm{~A} \text { input, } \\
0.4 \text { A electronic } \\
\text { load }\end{array}$ \\
\hline $\begin{array}{c}\text { SM, BM } \\
\text { + BM, } \\
\text { PM }\end{array}$ & Telemetry & Verification & Y & Y & $\begin{array}{c}\text { Communication } \\
\text { was possible } \\
\text { with all modules } \\
\text { in the system }\end{array}$ \\
\hline
\end{tabular}

\subsection{Solar Module}

Various tests were performed on the solar modules including normal operation, reverse solar cell protection, and a telemetry test. Two solar modules were placed in parallel and tested for correct operation.

\subsection{Battery Module}

The tests for the battery module focused on the battery protection circuit which includes overvoltage protection, undervoltage protection, overcharge current protection, and overdischarge current protection. Other tests performed include verifying the charge balancing circuit and telemetry. Two sets of battery modules were then placed in series with one another with the two sets in parallel to test for correct operation.

\subsection{Payload Module}

The tests for the payload module include normal operation, load control, and a telemetry test. These tests were performed for a payload module with a $5 \mathrm{~V}$ voltage regulator and a payload module with a $3.3 \mathrm{~V}$ voltage regulator. Two payload modules were connected in parallel to test for correct operation. 


\subsection{Solar Module, Payload Module}

The main test for the solar module and payload module in parallel was for normal operation.

\subsection{Battery Module + Battery Module, Payload Module}

The two tests performed on the two battery modules in series with a payload module in parallel were for normal operation and undervoltage protection.

\subsection{Solar Module, Battery Module + Battery Module}

The tests performed on the solar module in parallel with two battery modules in series were normal operation, charge balancing, and overvoltage protection.

\subsection{Solar Module, Battery Module + Battery Module, Payload Module}

The tests performed on a solar module in parallel with two battery modules in series and a payload module were normal operation while the batteries were charging, normal operation while the batteries were discharging, and a telemetry test. 


\subsection{Discussion}

The following four sections describe the results from the individual prototype testing and the testing of prototype combinations.

\subsection{Solar Module}

The experimental results for the solar module prototype indicate that the solar module correctly transfers energy from the solar cells while minimizing power loss due to the transfer. The voltage drop from the synchronous rectifier was measured to be $0.05 \mathrm{~V}$ for the higher input current. The synchronous rectifier efficiency is critical in small satellite applications, where energy consumption must be minimized.

The tests for reverse solar cell protection and telemetry were successful as well, meaning that the solar module performed as expected.

The solar modules tested in parallel worked as expected with the synchronous rectifier

circuit preventing voltage backfeed from damaging the solar array. Telemetry was received from each module as well.

The efficiency of the solar module prototype is $99.5 \%$, which is slightly less than the expected efficiency, 99.82\%. A potential cause of the efficiency discrepancy is the telemetry circuit, where the sampling frequency is higher than necessary. 


\subsection{Battery Module}

The experimental results for the battery module indicate that the battery module correctly protects its battery from overvoltage, undervoltage, charging overcurrent, and discharging overcurrent. Also, charge balancing and the telemetry circuits were verified to be operational.

The measured current limits for current protection seemed to deviate somewhat from the programmed current limit values. This may be due to the inaccuracy of the current sense resistors. The variances in resistance could be affecting the overcurrent protection limit. Another possibility is the resistance of the traces on the PCB affecting the voltage measured by the protection IC.

The efficiency of the battery module prototype is $83.08 \%$, which is less than the expected efficiency, $88.73 \%$. The difference could be attributed to the non-ideal characteristics of the battery protection circuit because of the losses through the components that connect the battery to the common bus.

The sets of batteries in series then placed in parallel were confirmed to protect each individual cell from overvoltage, undervoltage, overcharge current, and overdischarge current. The charge balancing circuits were operational no matter the cell's position in the pack and telemetry was responsive even when cells were located above other cells in series. 


\subsection{Payload Module}

The experimental results for the payload module indicate that the payload module correctly regulates energy for its load, that it has the ability to control the energy path to the load, and that its telemetry circuits are operational.

The efficiency of the payload module prototype with a linear regulator is $63.94 \%$, which is slightly less than the expected efficiency, $66.76 \%$.

The efficiency of the payload module prototype with a switching regulator is $82.3 \%$, which is slightly less than the expected efficiency, $84.69 \%$.

As expected, there is a correlation between voltage regulator efficiency and payload module efficiency, because the supporting circuits in the payload module draw much less power than the regulator does. Therefore, the efficiency equation for the payload module is dominated by the voltage regulators.

The two payload modules in parallel operated correctly. Voltage was regulated to the proper levels for each payload module without any instability seen. Telemetry was received from each module.

An extra test was performed on the payload module to analyze the payload module's startup. The test setup is shown in Figure 29. 


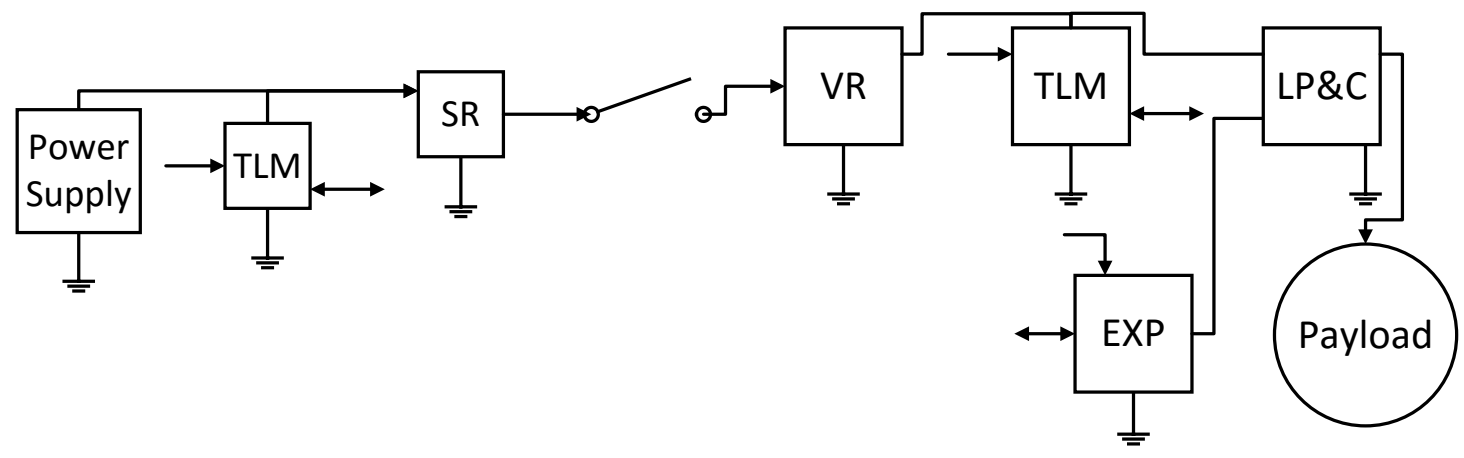

Figure 29: Test Setup for Payload Module

The first test used a linear regulator set at $5 \mathrm{~V}$. The test results are shown in Figure 30. This figure shows the voltage on the common bus and the output of the voltage regulator when the module is starting up. As the payload module is connected to the solar module, there is a small downward spike on the bus voltage. A large voltage transient is seen on the output of the voltage regulator, where the regulator voltage rises to $6.5 \mathrm{~V}$ before settling down to $5 \mathrm{~V}$. Approximately $150 \mathrm{~ms}$ after the payload module is turned on, the payload's voltage begins to increase. This is due to the payload protection circuit, the LTC4361. The LTC4361 has a typical startup delay of $130 \mathrm{~ms}$ before the circuit allows the payload to turn on. The regulator voltage does not start at $0 \mathrm{~V}$, this is attributed to the capacitor on the output side of the regulator not having enough time to fully discharge before the test results were captured. 


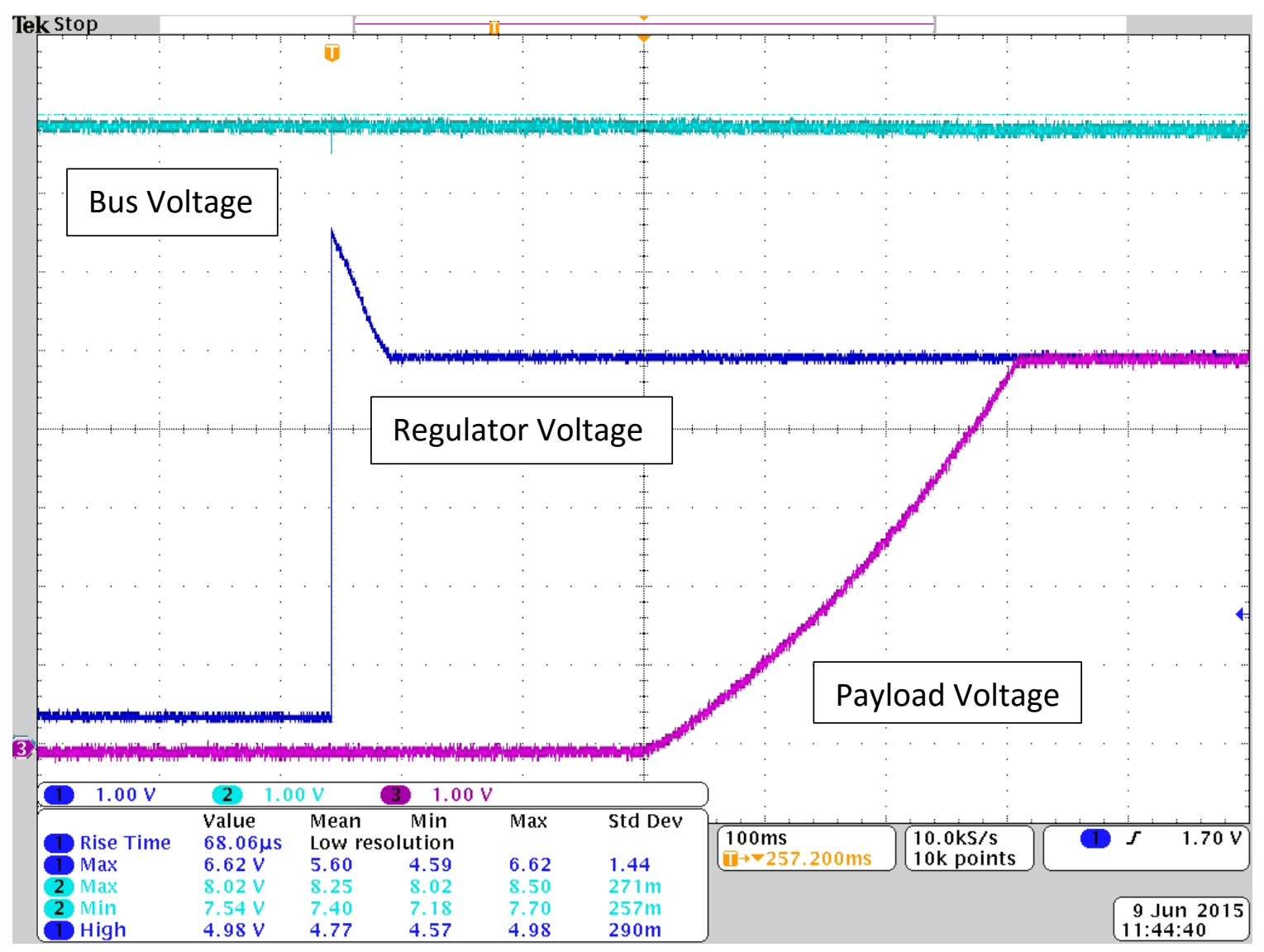

Figure 30: Payload Module 5 V Startup

The circuit has a relatively slow turn on time due to the capacitance on the gate of the control MOSFET. This capacitance was added to decrease the $\mathrm{dV} / \mathrm{dt}$ on the payload. At the end of the waveform, the payload's voltage settles at the same voltage that the regulator supplies. At this point the payload is fully activated and is operating normally.

The second test used a switching regulator set to $3.3 \mathrm{~V}$. The test results are shown in Figure 31. This figure shows the voltage on the common bus and the output of the voltage regulator when the module is starting up. The results from the $3.3 \mathrm{~V}$ payload module test are comparable to the $5 \mathrm{~V}$ payload module. The main differences between the two test 
results are the voltage spike seen on the regulator voltage when the $5 \mathrm{~V}$ payload module started up and the expected switching noise seen on the bus voltage, regulator voltage, and payload voltage on the $3.3 \mathrm{~V}$ payload module.

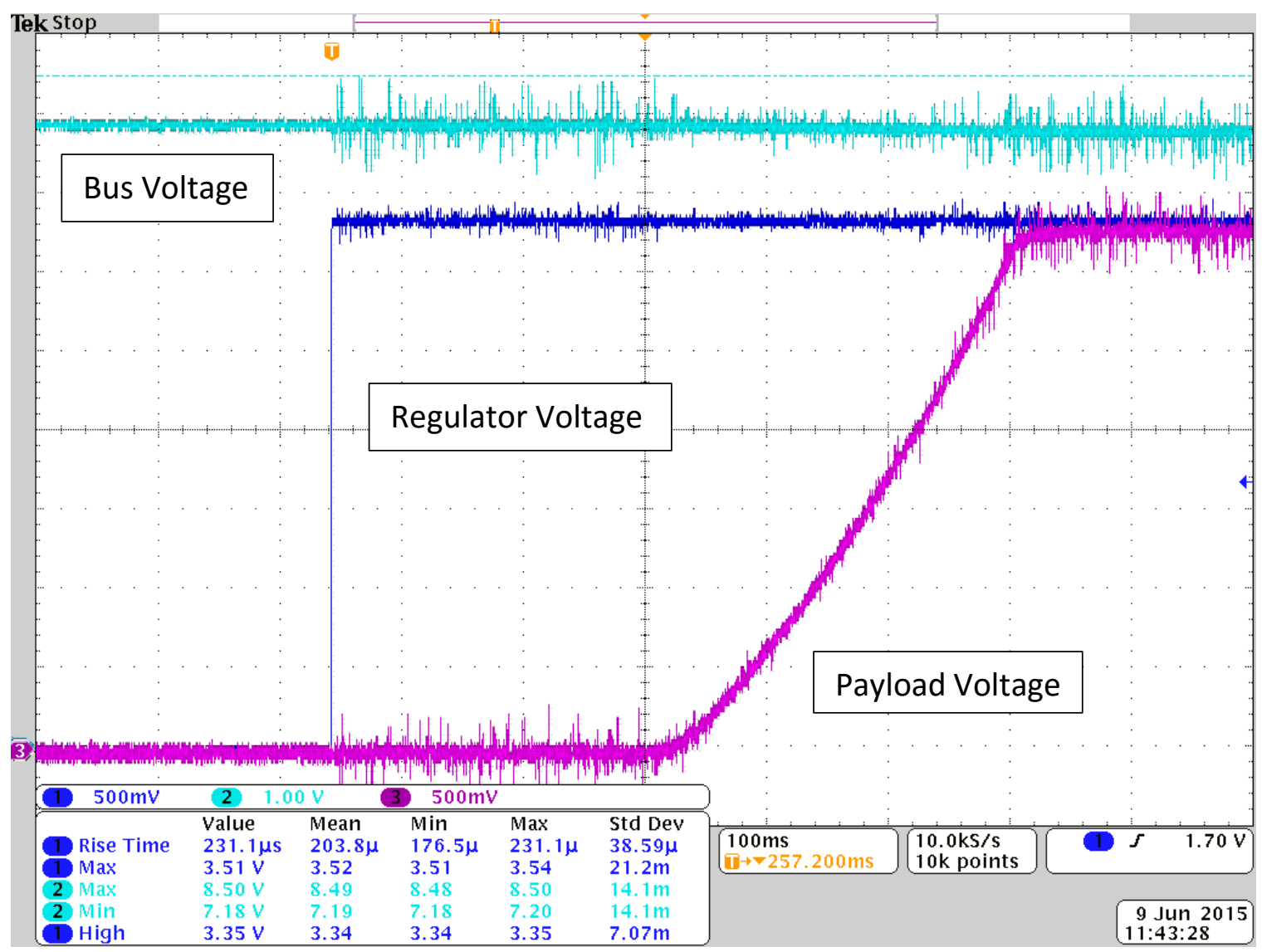

Figure 31: Payload Module 3.3 V Startup

\subsection{System Testing}

The final test involved one solar module, two battery modules in series, and two payload modules connected together on a common bus. The input current, common bus voltage, output voltage of the $5 \mathrm{~V}$ payload module, and the output voltage of the $3.3 \mathrm{~V}$ payload module was logged and graphed in Figure 32. 


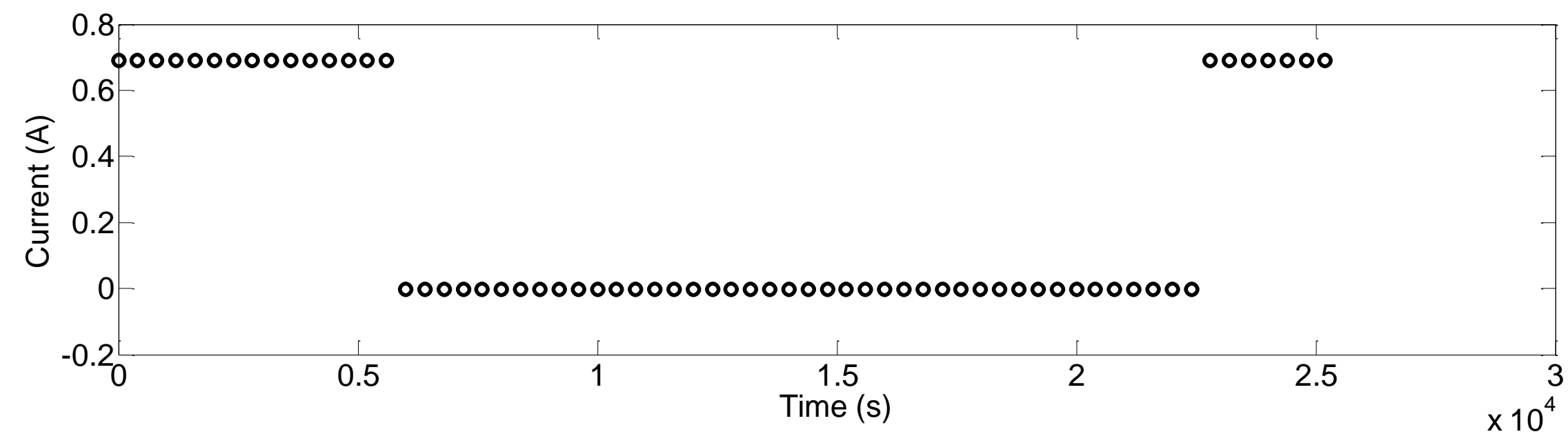

๖ั

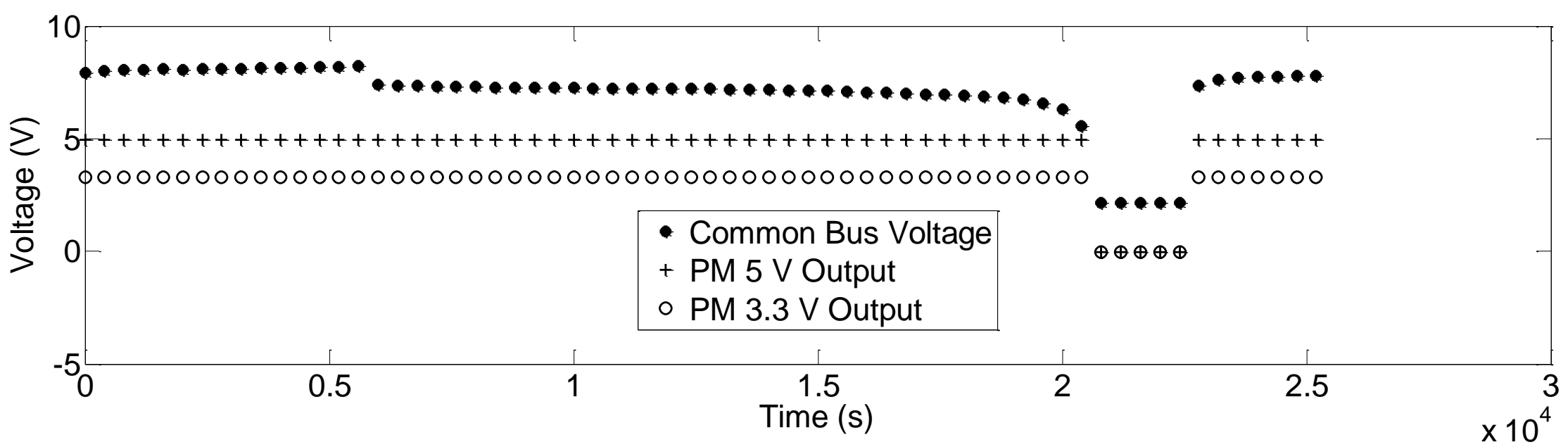

Figure 32: Common Bus Voltage and Payload Module Outputs for System Testing 
For $5000 \mathrm{sec}$, the system was supplied current from the power supply connected to the solar module. At $5000 \mathrm{sec}$, the power supply was turned off. The voltage immediately dropped, due to the difference in charge and discharge curves of the batteries. The batteries discharge until $22000 \mathrm{sec}$. The power supply was turned on at this time and the battery modules immediately started charging.

During the 17000 sec of discharging, the battery modules experienced an undervoltage condition. This was triggered when the common bus voltage reached $5.4 \mathrm{~V}$, which corresponds to approximately $2.7 \mathrm{~V}$ per battery. The expected undervoltage limit is $2.6 \mathrm{~V}$ [38]. However, the maximum undervoltage detection limit is $2.7 \mathrm{~V}$, which agrees with the testing results.

The only time that the payload modules were not supplying energy to their payloads was during the undervoltage condition. At all other times, the payload modules kept their payloads operating correctly. The experimental results for the three module types on a common bus indicate that the three module types are compatible when connected in parallel. Each module performed as expected in the system configurations tested. There do not seem to be any conflicts between modules even when modules are disconnecting and reconnecting to the common bus. The telemetry isolation circuits on the battery module were confirmed to be operating correctly because communication was possible with the battery module on top of the pack. 
Even though the $3.3 \mathrm{~V}$ payload module looks like a negative impedance to the bus due to its switching regulator, no bus instability was observed. 


\subsection{KySat-3}

KySat-3 is a CubeSat mission currently in progress at the Space Systems Laboratory of the University of Kentucky. KySat-3 is a $1 U$ CubeSat with deployable solar panels that will be launched from the International Space Station by use of a Nanoracks launcher in 2016 or 2017. The KySat-3 orbit time is estimated to be a few months, much less than the two years of KySat-2. The mission goal for KySat-3 is to perform the experiments that were unsuccessful in the KySat-2 mission, namely the verification of the Stellar Gyroscope developed by Samir Rawashdeh, a PhD candidate who previously worked in the Space Systems Laboratory. During the KySat-2 project, two flight models of the satellite were constructed and tested. One model was chosen for flight and was launched successfully in 2013. The unused model remained on Earth as a demonstration unit.

In 2015, the Space Systems Laboratory received a grant from NASA to determine the functionality of the backup model and to prepare the satellite for a mission. The backup KySat-2 model, now dubbed KySat-3, underwent initial inspection by the Space Systems Laboratory.

Examination revealed that the solar arrays and the batteries on the back up model were still usable. However, it was found that the EPS unit in the model was inactive and unresponsive. Two options were considered for the EPS replacement. The first was to acquire a working EPS from Morehead State University, the original developers of the EPS 
for KySat-2. Unfortunately, Morehead State University had a very full schedule working on their own CubeSat mission, so this option was not possible.

The second option for the EPS was to develop the EPS at the University of Kentucky. At the time, the distributed EPS prototypes had been fabricated and assembled. Initial tests had been performed on the prototypes of the distributed EPS; because the results were promising, the mission planners decided to have a distributed EPS unit fabricated and assembled for use in KySat-3.

\subsection{Design}

Most of KySat-3's EPS design was based off the prototypes of the distributed EPS reference implementation. The EPS was designed to be a direct drop-in replacement for Morehead State University's EPS used in KySat-2, including form factor and connector layout. The voltage regulators used for KySat-2 [17] were reproduced in KySat-3's EPS to reduce the chance of incompatibility with the existing subsystems. The most major change between the prototypes and the KySat-3 EPS is that each of the modules used in a fully distributed EPS had to be located on the same PCB since KySat-2 used a single board EPS. This forced many components together on a single board, meaning that part placement on the PCB was more difficult. Figure 33 shows the distributed EPS design for KySat-3. 


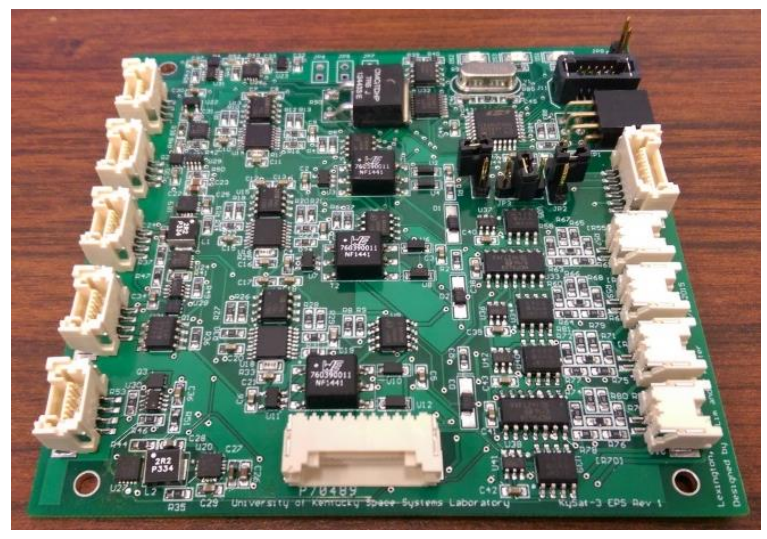

Figure 33: KySat-3 Electrical Power System

The main feature added to KySat-3's EPS that was not present in KySat-2's EPS is an inhibit switch system that utilized the PCB itself. This was achieved by having multiple power and ground planes on the PCB. These planes were isolated from each other, but routed to a single connector on the board. All of the inhibit switches in the satellite are wired to a single connector, and then this connector plugs into the EPS to provide the connection between the planes. This simplifies the satellite construction because the EPS can be easily removed from the satellite stack and replaced when needed. There is also only one connection point for all of the inhibit switches; reducing confusion as to how each inhibit switch connects to the satellite. In KySat-2, the inhibit switches were soldered directly to the power line they were inhibiting, which can be hard to keep track of when assembling the satellite. The method used in KySat-3's EPS should make connecting the inhibit switches much easier during satellite assembly.

A microcontroller was added to KySat-3's EPS so that telemetry could be automatically gathered from the EPS modules. The Command and Data Handling system would then 
ask the EPS microcontroller for that data when needed. A programming header was added to the circuit so the firmware could be updated even when the satellite is assembled.

A watchdog timer was also added to the EPS. If the EPS microcontroller became unresponsive for a specified amount of time, the watchdog timer would toggle the reset pin on the microcontroller and reboot the EPS controller, clearing the fault condition.

\subsection{Testing}

The same tests performed on the EPS prototypes were repeated on the KySat-3 EPS, checking for qualities such as functionality, battery protection, load control, and stability. These tests were successful. Because of the new inhibit switch system, the switches needed to be connected and actuated before the EPS would work. To make testing easier, a dummy connector was created that shorted the connection points where the inhibit switches should be, making the EPS think that the inhibit switches were connected and actuated. The dummy connector was very effective and simplified the testing process.

One new test performed on the KySat-3 EPS is the verification of the inhibit switch system. The inhibit switches isolate different parts of the satellite and are used to make sure certain parts of the satellite do not turn on when they are not supposed to, such as when the satellite is in the satellite stack. The inhibit switches were tested and the subsystem isolation performed as expected. 
Another test involved drawing current from the solar and battery modules. Because all three module types were located on a single PCB, the total current draw of the satellite subsystems would have to run through traces on the circuit board. Testing was performed to make sure these power traces were large enough to handle the current that could be drawn from the EPS. The results indicate that the EPS correctly operates under high current draw.

Nanoracks also provided a list of tests to be performed before the satellite could be integrated. This included visual inspection of the batteries, measurement of battery characteristics such as open circuit and closed circuit voltages, charge cycling data, overcharge limits, overdischarge limits, short circuit protection, vibration testing, and vacuum testing. The KySat-3 EPS also passed these tests.

Figure 34 shows the typical test setup for the KySat-3 EPS. The dummy connector is connected to the EPS near the bottom of the circuit board. Prototype battery modules were used to securely connect batteries to the EPS for testing. 


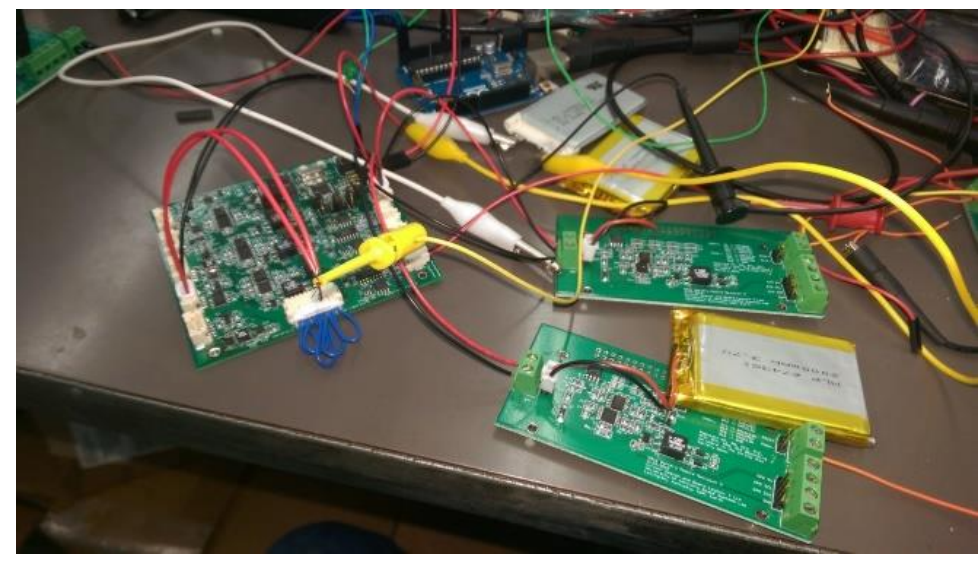

Figure 34: EPS Testing

Telemetry gathering was more difficult when assembling KySat-3's EPS than it would have been for a true distributed EPS. This is because components such as the DS2764 in the battery module would normally be programmed separately, since each battery module is removable. KySat-3's EPS was on a single PCB, so programming the DS2764 would get complicated because the DS2764 has the same default I2C address and are all on the same communication bus when the EPS is populated. For this IC, the population of the DS2764 had to be staggered so that one would be populated then programmed. This process would then repeat for the other two DS2764 ICs.

An Arduino sketch was written to collect the telemetry from the KySat-3 EPS and also to control the payload modules. First, the program would iterate through all the $12 \mathrm{C}$ addresses of the telemetry ICs and verify that the chips were available for communication. Then, the user is presented with a menu. The top option is to show the EPS telemetry. The solar module telemetry is presented, including voltage and current of the solar cells. 
The battery module telemetry is then displayed, including the voltage and current of its local battery and temperature of the IC. The telemetry finishes with the payload module telemetry, including the voltage and current of each payload and the calculated power draw of each payload.

The next menu option allows the user to turn on a payload module. The EPS starts up with all payload modules deactivated. The user enters a number that corresponds to the payload module to be turned on. The program will then display which of the payload modules are on and which are off.

The final menu option allows the user to turn off a payload module. The user enters a number that corresponds to the payload module to be turned off. The program will then display which of the payload modules are on and which are off. 


\subsection{Conclusion}

A modular, scalable, easy to reuse EPS for small satellites has been detailed in this work. The described EPS achieves modularity by dividing the EPS into three distinct units: the solar module, the battery module, and the payload module. The EPS achieves scalability due to the ability of the individual modules to be connected as needed in parallel, in the case of the solar and payload modules, or connected as needed in series and parallel, in the case of the battery module. Many different mission requirements can be met using different combinations of the same three basic modules, reducing development time dedicated to EPS design.

The solar module uses direct energy transfer to simplify the interface between the solar cells and the unregulated bus. A synchronous rectifier is used as the DET interface to reduce losses due to the energy transfer and to prevent voltage backfeed from the unregulated bus. The module is designed so that telemetry can be obtained from the solar cells, providing information about the voltage and current supplied by the solar array.

The battery module includes battery protection in the form of overvoltage protection, undervoltage protection, and overcurrent protection. Charge balancing is also provided, which reduces the chance of battery lockout conditions. Telemetry can be obtained from the module, which can provide information about the voltage and current supplied to or from the battery. 
The payload module includes load protection in the form of overvoltage protection, undervoltage protection, and overcurrent protection. Payload control is also provided to allow for power cycling of the payload. Telemetry can be gathered from the module that would detail the voltage and current drawn by the payload.

Reference implementations of these modules were designed, prototyped, and tested. From the testing performed, it is apparent that the described EPS is stable throughout various module configurations and is efficient under normal operation. The measured efficiency generally agrees with the theoretical efficiency of the three modules. An implementation of the distributed EPS will be used in the CubeSat KySat-3 and is expected to pass all requirements needed for flight. The distributed EPS topology is functional on actual hardware and is shown to be a viable alternative to the traditional centralized EPS units typically found on small spacecraft. 


\section{References}

[1] G. Richardson, K. Schmitt, M. Covert and C. Rogers, "Small Satellite Trends 20092013," in AIAA/USU Conference on Small Satellites, 2015.

[2] R. Robinson and T. Moretto, "Small Satellites for Space Weather Research," Space Weather, vol. 6, no. 5, 2008.

[3] M. Swartwout, "The First One Hundred CubeSats: A Statistical Look," Journal of Small Satellites, vol. 2, no. 2, pp. 213-233, 2013.

[4] K. Woellert, P. Ehrenfreund, A. Ricco and H. Hertzfeld, "Cubesats: Cost-effective science and technology platforms for emerging and developing nations," Advances in Space Research, no. 47, pp. 663-684, 2010.

[5] E. Caday-Eames, "Small Box, Big Potential," Boeing Frontiers, p. 20, October 2006.

[6] F. Ince, "A Role for Cubesats in Responsive Space," in Proceedings of 2nd International Conference on Recent Advances in Space Technologies, 2005.

[7] T. DeBenedictis, "SkyCube: The First Satellite Launched by You!," Kickstarter, 149 2014. [Online]. Available: https://www.kickstarter.com/projects/880837561/skycube-the-first-satellitelaunched-by-you. [Accessed 196 2016].

[8] A. Chin, R. Coelho, L. Brooks, R. Nugent and J. Puig-Suari, "Standardization Promotes Flexibility: A Review of CubeSats' Success," in AIAA Responsive Space Conference, Los Angeles, 2008.

[9] W. Shiroma, L. Martin, J. Akagi, J. Akagi, B. Wolfe, B. Fewell and A. Ohta, "CubeSats: A Bright Future for Nanosatellites," Central European Journal of Engineering, vol. 1, no. 1, pp. 9-15, 2011.

[10] A. Mehrparvar, "CubeSat Design Specification," 202 2014. [Online]. Available: http://www.academia.edu/11525487/CubeSat_Design_Specification_Rev._13_Th e_CubeSat_Program_Cal_Poly_SLO_CubeSat_Design_Specification_CDS_REV_13_ Document_Classification_X_Public_Domain_ITAR_Controlled_Internal_Only. [Accessed 196 2016].

[11] AMSAT, "Chasqui-1," [Online]. AMSAT, Available: http://www.amsat.org/?page_id=3147. [Accessed 196 2016]. 
[12] P. Marks, "CubeSat craze could create space debris catastrophe," New Scientist, 24 9 2014. [Online]. Available: https://www.newscientist.com/article/mg22329882500-cubesat-craze-could-create-space-debris-catastrophe/. [Accessed 196 2016].

[13] H. Kramer, "KySat-1," eoPortal, [Online]. Available: https://directory.eoportal.org/web/eoportal/satellite-missions/k/kysat-1. [Accessed 196 2016].

[14] Space Systems Laboratory, "About KySat-2," Space Systems Laboratory, [Online]. Available: http://ssl.engineering.uky.edu/missions/orbital/kysat-2/about-kysat-2/. [Accessed 196 2016].

[15] M. Patel, Spacecraft Power Systems, Boca Raton: CRC Press, 2005.

[16] K. Hackney, B. K. Malphrus and T. Clements, "AAQ Workshop 2012," 24 April 2012. [Online]. Available: http://aaq.auburn.edu/sites/default/files/presentations/AAQWorkshop2012/Kare nHackney.pdf. [Accessed 9 July 2015].

[17] B. L. Molton, "KySat-2 Electrical Power System Design and Analysis," ProQuest, Ann Arbor, MI, 2013.

[18] R. Burt, "Distributed Electrical Power Systems in Cubesat Applications," Utah State University, Logan, Utah, 2001.

[19] S. Notani, "Development of Distributed, Scalable, and a Flexible Electrical Power System Module for CubeSat and Small Satellites," North Carolina State University, Raleigh, North Carolina, 2011.

[20] "CubeSat Kit Linear EPS," 2012. [Online]. Available: http://www.cubesatkit.com/docs/datasheet/DS_CSK_Linear_EPS_711-00338-

D.pdf. [Accessed 2012].

[21] A. Strain, "User Manual: CubeSat 1 U Electronic Power System and Batteries," 2010. [Online]. Available: http://www.clyde-space.com/documents/1819.

[22] F. Belloni, P. G. Maranesi and M. Riva, "DC/DC Converter for the International Space Station," IEEE Transactions on Aerospace and Electronic Systems, vol. 46, no. 2, pp. 623-634, April 2010. 
[23] Z. Chen, Z. Wang, C. Wang and M. Chen, "Input Ripple Current Characteristics of Aviation Static Inverter," IEEE Transactions on Aerospace and Electronic Systems, vol. 49, no. 3, pp. 1667-1676, 2013.

[24] O. Garcia, P. O. J. Alou, D. Diaz, D. Meneses, J. Cobos, A. Soto, E. Lapena and J. Rancano, "Comparison of Boost-Based MPPT Topologies for Space Applications," IEEE Transactions on Aerospace and Electronic Systems, vol. 49, no. 2, pp. 10911107, April 2013.

[25] S. D. Sudhoff, S. F. Glover, P. T. Lamm, D. H. Schmucker and D. E. Delisle, "Admittance Space Stability Analysis of Power Electronic Systems," IEEE Transactions on Aerospace and Electronic Systems, vol. 36, no. 3, pp. 965-973, July 2000.

[26] A. Griffo and J. Wang, "Large Signal Stability Analysis of 'More Electric' Aircraft Power Systems with Constant Power Loads," IEEE Transactions on Aerospace and Electronic Systems, vol. 48, no. 1, pp. 477-489, January 2012.

[27] A. Ramamurthy, "Flexible Digital Electrical Power System Design and Modeling for Small Satellites," North Carolina State University Master's Theses, 2009.

[28] D. Del Corso, C. Passerone, L. Reyneri, C. Sansoe, S. Speretta and M. Tranchero, "Design of a University Nano-Satellite: the PiCPoT Case," IEEE Transactions on Aerospace and Electronic Systems, vol. 47, no. 3, pp. 1985-2007, July 2011.

[29] D. Erb, "Evaluating the Effectiveness of Peak Power Tracking Technologies for Solar Arrays on Small Spacecraft," University of Kentucky, Lexington, KY, 2011.

[30] M. Uno and K. Tanaka, "Spacecraft Electrical Power System using Lithium-Ion Capacitors," IEEE Transactions on Aerospace and Electronic Systems, vol. 49, no. 1, pp. 175-188, January 2013.

[31] C. Day, "The Design and Testing of an Efficient, Elegant, and Cubic Pico-Satellite Electronics System," California Polytechnic State University, San Luis Obispo, California, 2004.

[32] T. Jeppesen and M. Thomsen, "Power supply for DTU's Cubesat," 2001.

[33] TrisolX, "Solar Wing Data Sheet," [Online]. Available: http://www.trisolx.com/wpcontent/uploads/2015/03/TrisolX-Solar-Wing-Data-Sheet1.pdf. [Accessed 196 2016]. 
[34] Microchip Technology Inc., "MCP3426/7/8," [Online]. Available: http://ww1.microchip.com/downloads/en/DeviceDoc/22226a.pdf. [Accessed 196 2016].

[35] Linear Technology, "LTC4412HV," [Online]. Available: http://cds.linear.com/docs/en/datasheet/4412hvfs.pdf. [Accessed 196 2016].

[36] Vishay Siliconix, "Si4423DY," [Online]. Available: http://www.vishay.com/docs/72085/si4423dy.pdf. [Accessed 196 2016].

[37] "Product Specification: Model PL-703562-2C," 2008. [Online]. Available: http://www.batteryspace.com/prod-specs/4312.pdf.

[38] Maxim Semiconductor, "DS2764 Datasheet," 2006. [Online]. Available: http://datasheets.maximintegrated.com/en/ds/DS2764.pdf. [Accessed 11 2016].

[39] Vishay Siliconix, "Si4933DY," [Online]. Available: http://www.vishay.com/docs/71980/71980.pdf. [Accessed 196 2016].

[40] Silicon Labs, "Si860x," [Online]. Available: https://www.silabs.com/Support\%20Documents/TechnicalDocs/Si860x.pdf. [Accessed 196 2016].

[41] Texas Instruments, "SN6501," [Online]. Available: http://www.ti.com/lit/ds/symlink/sn6501.pdf. [Accessed 196 2016].

[42] Fairchild Semiconductor, "MBR0520L," [Online]. Available: https://www.fairchildsemi.com/datasheets/MB/MBR0520L.pdf. [Accessed 196 2016].

[43] Linear Technology, "LT1763," [Online]. Available: http://cds.linear.com/docs/en/datasheet/1763fh.pdf. [Accessed 196 2016].

[44] Semtech, "SC4503," [Online]. Available: http://www.semtech.com/images/datasheet/sc4503.pdf. [Accessed 196 2016].

[45] Rohm Semiconductor, "RSX101VA-30," [Online]. Available: http://rohmfs.rohm.com/en/products/databook/datasheet/discrete/diode/schot tky_barrier/rsx101va-30.pdf. [Accessed 196 2016].

[46] ST Microelectronics, "ST1S10," [Online]. Available: http://www.st.com/content/ccc/resource/technical/document/datasheet/fb/03/ 
25/5a/eb/45/46/33/CD00169322.pdf/files/CD00169322.pdf/jcr:content/translati ons/en.CD00169322.pdf. [Accessed 196 2016].

[47] Microchip Technology Inc., "PAC1710/20," [Online]. Available: http://ww1.microchip.com/downloads/en/DeviceDoc/20005386B.pdf. [Accessed 196 2016].

[48] Linear Technology, "LTC4361-1/LTC4361-2," [Online]. Available: http://cds.linear.com/docs/en/datasheet/436112fb.pdf. [Accessed 196 2016].

[49] Vishay Siliconix, "Si1470DH," [Online]. Available: http://www.vishay.com/docs/74277/SI1470DH.pdf. [Accessed 196 2016].

[50] Linear Technology, "LTC4365," [Online]. Available: http://cds.linear.com/docs/en/datasheet/4365fa.pdf. [Accessed 196 2016].

[51] Vishay Siliconix, "Si4946BEY," [Online]. Available: http://www.vishay.com/docs/73411/si4946be.pdf. [Accessed 196 2016].

[52] Fairchild Semiconductor, "FPF2700/FPF2701/FPF2702," [Online]. Available: https://www.fairchildsemi.com/datasheets/FP/FPF2702.pdf. [Accessed 196 2016].

[53] NXP Semiconductors, "PCA9672," [Online]. Available: http://www.nxp.com/documents/data_sheet/PCA9672.pdf. [Accessed 196 2016]. 
Vita

Timothy Meng Lim

\section{Education}

Bachelor of Science in Electrical Engineering, Graduated in May 2013

Minors in Computer Science and Mathematics

\section{Awards and Activities}

NASA Space Grant Fellowship, 2014-2015

Graduate Research Assistantship, 2013-2015

University Scholar, 2013-2015

Presidential Scholarship, 2009-2013

\section{Experience}

Space Systems Laboratory, Lexington, Kentucky

Graduate Research Assistant, August 2012 - August 2015

Undergraduate Researcher, May 2012 - August 2012

Sandia National Laboratories, Albuquerque, New Mexico

Graduate Intern, May 2014 - August 2014

\section{Presentations}

- "A Scalable, Modular, and Reusable Electrical Power System for Small Satellites" at the 2015 Kentucky EPSCoR Conference, Lexington, Kentucky

- "A Scalable, Modular, and Reusable Electrical Power System for Small Satellites" at the 2013 Kentucky EPSCoR Conference, Louisville, Kentucky 